\title{
The 2020 edition of the GEISA spectroscopic database
}

\section{Highlights}

- $\quad$ GEISA-2020 database release: 6,746,987 entries in the line parameters database

- 23 molecules updated and 6 new molecules added ( $\mathrm{HONO}, \mathrm{COFCl}, \mathrm{CH}_{3} \mathrm{~F}, \mathrm{CH}_{3} \mathrm{I}, \mathrm{RuO}_{4}$, $\mathrm{H}_{2} \mathrm{C}_{3} \mathrm{H}_{2}$ (isomer of $\mathrm{C}_{3} \mathrm{H}_{4}$ )

- $\quad$ Evaluation of the spectroscopic parameters through radiative transfer simulations compared to atmospheric spectra (SPARTE chain) 


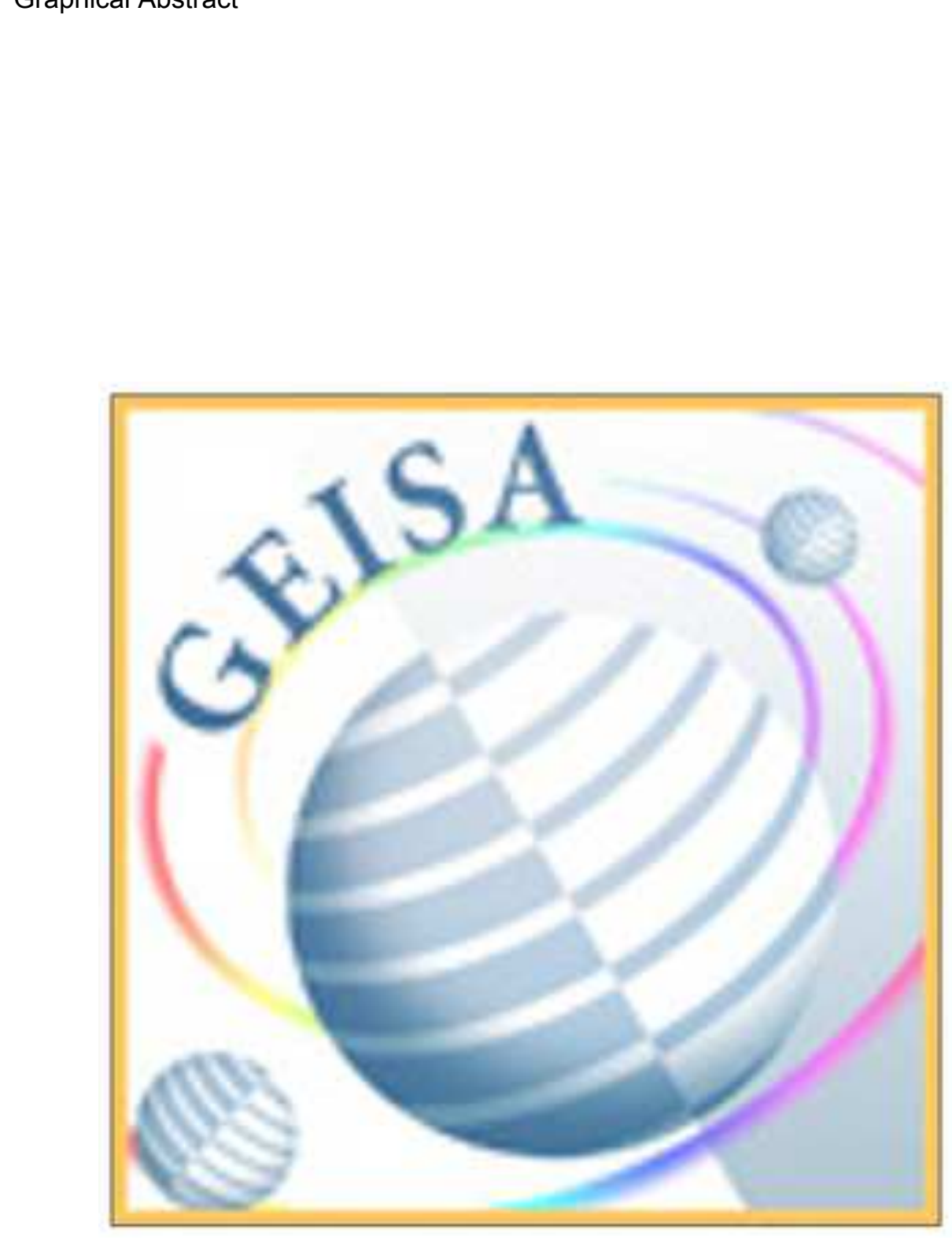

\section{0 release and validations \\ 2020 rele}
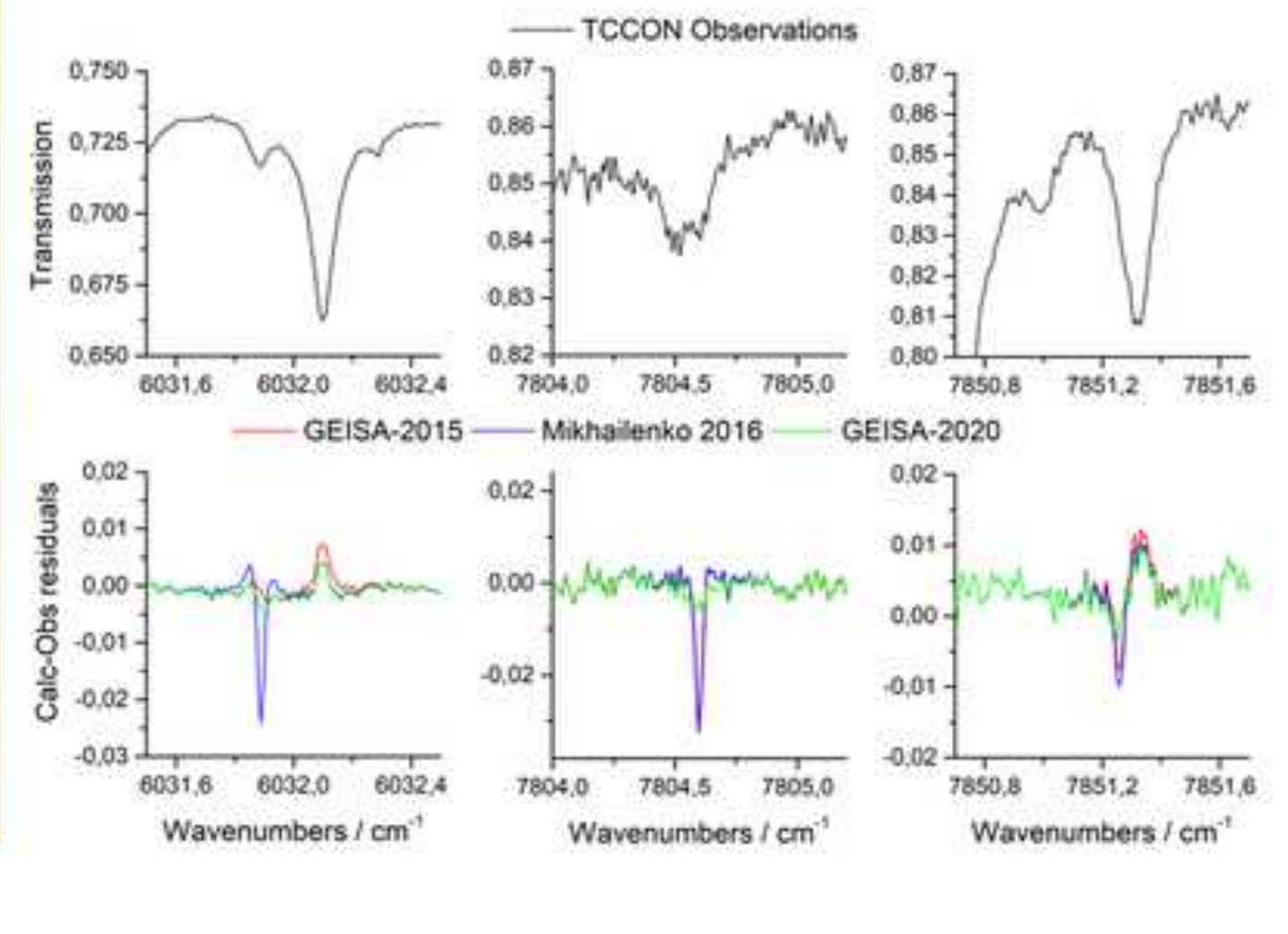

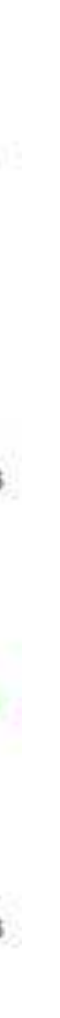




\section{The 2020 edition of the GEISA spectroscopic database}

T. Delahaye ${ }^{1}$, R. Armante ${ }^{1}$, N.A. Scott ${ }^{1}$, N. Jacquinet-Husson ${ }^{1}$, A. Chédin ${ }^{1}$, L. Crépeau ${ }^{1}$, C. Crevoisier ${ }^{1}$, V. Douet ${ }^{2}$, A. Perrin ${ }^{1}$, A. Barbe ${ }^{3}$, V. Boudon ${ }^{4}$, A. Campargue ${ }^{5}$, L.H. Coudert ${ }^{6}$,V. Ebert ${ }^{14,15}$, J.-M. Flaud ${ }^{7}$, R.R. Gamache ${ }^{9}$, D. Jacquemart ${ }^{10}$, A. Jolly ${ }^{7}$, F. Kwabia Tchana ${ }^{7}$, A. Kyuberis ${ }^{22}$, G. Li ${ }^{14}$, O.M. Lyulin ${ }^{11}$, L. Manceron ${ }^{10,16}$, S. Mikhailenko ${ }^{11}$, N. MoazzenAhmadi ${ }^{23}$, H.S.P. Müller ${ }^{12}$, O.V. Naumenko ${ }^{11}$, A. Nikitin ${ }^{11}$, V.I Perevalov ${ }^{11}$, C. Richard ${ }^{4}$, E. Starikova ${ }^{11}$, S.A. Tashkun ${ }^{11}$, Vl.G. Tyuterev ${ }^{3,17}$, J. Vander Auwera ${ }^{13}$, B.Vispoel ${ }^{9,18,19}$, A. Yachmenev ${ }^{20,21}$, S. Yurchenko ${ }^{8}$.

${ }^{1}$ Laboratoire de Météorologie Dynamique/IPSL, CNRS, Ecole Polytechnique, Université Paris-Saclay, 91128, Palaiseau, France

${ }^{2}$ Institut Pierre Simon Laplace, Université Pierre et Marie Curie, 75252 Paris, France

${ }^{3}$ Université de Reims-Champagne-Ardenne, Groupe de Spectrométrie Moléculaire et Atmosphérique, 51062 Reims, France

${ }^{4}$ Laboratoire Interdisciplinaire Carnot de Bourgogne, UMR 6303 CNRS-Univ. Bourgogne Franche-Comté, 9 Avenue Alain Savary, BP 47 870, F-21078 DIJON Cedex, France

${ }^{5}$ Univ. Grenoble Alpes, CNRS, LIPhy, 38000 Grenoble, France

${ }^{6}$ Université Paris-Saclay, CNRS, Institut des Sciences Moléculaires d’Orsay, 91405 Orsay, France

${ }^{7}$ Laboratoire Interuniversitaire des Systèmes Atmosphériques (LISA), UMR CNRS 7583, Université de Paris, Université Paris-Est Créteil, Institut Pierre-Simon Laplace, 61 avenue du Général de Gaulle, 94010 Créteil Cedex, France

${ }^{8}$ Department of Physics and Astronomy, University College London, London WC1E 6BT, United Kingdom

${ }^{9}$ University of Massachusetts Lowell, Department of Environmental Earth and Atmospheric Sciences, Lowell, MA 01854, USA

${ }^{10}$ Sorbonne Université, CNRS, De la MOlécule aux NAno-objets : Réactivité, Interactions et Spectroscopies, MONARIS, 75005 Paris, France

${ }^{11}$ V.E. Zuev Institute of Atmospheric Optics, SB, Russian Academy of Sciences, 1, Academician Zuev square, 634055, Tomsk, Russia

${ }^{12}$ I. Physikalisches Institut, Universität zu Köln, 50937 Köln, Germany

${ }^{13}$ Spectroscopy, Quantum Chemistry and Atmospheric Remote Sensing (SQUARES), C.P. 160/09, Université Libre de Bruxelles, 50 avenue F.D. Roosevelt, B-1050 Brussels, Belgium.

${ }^{14}$ Physikalisch-Technische Bundesanstalt, Bundesallee 100, 38116 Braunschweig, Germany

${ }^{15}$ Reactive Flows and Diagnostics, Technische Universität Darmstadt, Otto-Berndt-Str. 3 64287 Darmstadt, Germany

${ }^{16}$ Synchrotron Soleil Ligne AILES, BP 48, 91192 Cedex Gif-sur-Yvette, France

${ }^{17}$ QUAMER laboratory, Tomsk State University, 36 Lenin Ave., Tomsk, Russia 634050

${ }^{18}$ Research Unit Lasers and Spectroscopies (LLS), Institute of Life, Earth and Environment (ILEE), University of Namur (UNamur), 61 rue de Bruxelles, B-5000, Namur, Belgium

${ }^{19}$ Royal Belgian Institute for Space Aeronomy (BIRA-IASB), 3 Avenue Circulaire, 1180, Brussels, Belgium

${ }^{20}$ Center for Free-Electron Laser Science, Deutsches Elektronen-Synchrotron DESY, Notkestraße 85, 22607 Hamburg, Germany 
${ }^{21}$ Center for Ultrafast Imaging, Universität Hamburg, Luruper Chaussee 149, 22761 Hamburg, Germany

${ }^{22}$ Van Swinderen Institute for Particle Physics and Gravity, University of Groningen, Nijenborgh 4, 9747 Groningen, The Netherlands

${ }^{23}$ Department of Physics and Astronomy, University of Calgary, 2500 University Drive North West, Calgary, Alberta T2N 1N4, Canada

\section{Highlights}

- $\quad$ GEISA-2020 database release: 6,746,987 entries in the line parameters database

- 23 molecules updated and 6 new molecules added (HONO, $\mathrm{COFCl}, \mathrm{CH}_{3} \mathrm{~F}, \mathrm{CH}_{3} \mathrm{I}, \mathrm{RuO}_{4}$, $\mathrm{H}_{2} \mathrm{C}_{3} \mathrm{H}_{2}$ (isomer of $\mathrm{C}_{3} \mathrm{H}_{4}$ )

- $\quad$ Evaluation of the spectroscopic parameters through radiative transfer simulations compared to atmospheric spectra (SPARTE chain)

\section{Corresponding author}

Dr. Raymond Armante

Phone: +33169335111

E-mail: raymond.armante@lmd.ipsl.fr 


\section{ABSTRACT}

This paper describes the 2020 release of the GEISA database (Gestion et Etude des Informations Spectroscopiques Atmosphériques: Management and Study of Atmospheric Spectroscopic Information), developed and maintained at LMD since 1974. GEISA is the reference database for several current or planned Thermal and Short-Wave InfraRed (TIR and SWIR) space missions IASI (Infrared Atmospheric Sounding Interferometer), IASI-NG (IASI New Generation), MicroCarb (Carbon Dioxide Monitoring Mission), Merlin (MEthane Remote sensing LIdar missioN). It is actually a compilation of three databases: the "line parameters database", the "cross-section sub-database" and the "microphysical and optical properties of atmospheric aerosols sub-database". The new edition concerns only the line parameters dataset, with significant updates and additions implemented using the best available spectroscopic data.

The GEISA-2020 line parameters database involves 58 molecules (145 isotopic species) and contains $6,746,987$ entries, in the spectral range from $10^{-6}$ to $35877 \mathrm{~cm}^{-1}$. In this version, 23 molecules have been updated (with 10 new isotopic species) and 6 new molecules have been added ( $\mathrm{HONO}, \mathrm{COFCl}, \mathrm{CH}_{3} \mathrm{~F}, \mathrm{CH}_{3} \mathrm{I}, \mathrm{RuO}_{4}, \mathrm{H}_{2} \mathrm{C}_{3} \mathrm{H}_{2}$ (isomer of $\mathrm{C}_{3} \mathrm{H}_{4}$ )) corresponding to 15 isotopic species. The compilation can be accessed through the AERIS data and services center for the atmosphere website (https://geisa.aeris-data.fr/), with the development of a powerful graphical tool and convenient searching, filtering, and plotting of data using modern technologies (PostgreSQL database, REST API, VueJS, Plotly).

Based on four examples $\left(\mathrm{H}_{2} \mathrm{O}, \mathrm{O}_{3}, \mathrm{O}_{2}\right.$ and $\left.\mathrm{SF}_{6}\right)$, this paper also shows how the LMD in house validation algorithm SPARTE (Spectroscopic Parameters And Radiative Transfer Evaluation) helps to evaluate, correct, reject or defer the input of new spectroscopic data into GEISA and this, thanks to iterations with researchers from different communities (spectroscopy, radiative transfer).

Key words: molecular spectroscopic database ; line parameters ; earth and planetary radiative transfer ; atmospheric absorption ; spectroscopic parameters evaluation 


\section{Introduction":}

From the mid 1960's, various scientific communities (Remote Sensing, Astrophysics, Atmospheric Physics, Metrology, Climate and Chemistry) have required access to databases detailing the spectral characteristics of atmospheric molecular absorption and atmospheric particle scattering. The purpose of spectroscopic databases like GEISA [1] and HITRAN [2] is to give, to each community, access to the best information at a given time.

In France, archiving spectroscopic data in conjunction with remote sensing applications was first initiated in the 70's. The first release of the GEISA database [3] included major absorbers $\left(\mathrm{N}_{2}, \mathrm{O}_{2}, \mathrm{H}_{2} \mathrm{O}, \mathrm{CO}_{2}, \mathrm{O}_{3}, \mathrm{~N}_{2} \mathrm{O}, \mathrm{CO}, \mathrm{CH}_{4}\right)$ of the earth atmosphere as well as complementary species (e.g. $\mathrm{NH}_{3}, \mathrm{HNO}_{3}, \mathrm{PH}_{3}, \mathrm{C}_{2} \mathrm{H}_{4}, \mathrm{C}_{2} \mathrm{H}_{2}, \mathrm{HC}_{3} \mathrm{~N}, \mathrm{HCOOH}, \mathrm{NO}, \mathrm{SO}_{2}, \mathrm{NO}_{2}$ ). Some molecules, mainly related to planetary atmospheres (e.g. within the frame of the Voyager experiment and observations of the giant planets) like $\mathrm{GeH}_{4}, \mathrm{C}_{3} \mathrm{H}_{8}, \mathrm{C}_{2} \mathrm{~N}_{2}, \mathrm{C}_{3} \mathrm{H}_{4}, \mathrm{HNC}, \mathrm{C}_{6} \mathrm{H}_{6}$, and $\mathrm{C}_{2} \mathrm{HD}$ were also included. Since its first publication, (Chédin et al. (1982) [3]), including spectroscopic data and management softwares, GEISA has undergone numerous updates (Husson et al. (1992) [4], Jacquinet-Husson et al. (1999, 2008, 2009, 2016) [1,5-7]).

One of the differences of GEISA, in comparison with other databases such as HITRAN, is that we treat isotopologues with a symmetry property as separate molecules, when necessary. For example, the molecule index for $\mathrm{CH}_{4}$ is 6 , while that of $\mathrm{CH}_{3} \mathrm{D}$ is 23 . See Table 2 for further examples. This was initiated in the mid 70's with $\mathrm{CH}_{3} \mathrm{D}$ and $\mathrm{CH}_{4}$ within the frame of the Voyager experiment and later on with $\mathrm{HDO}$ and $\mathrm{H}_{2} \mathrm{O}, \mathrm{C}_{2} \mathrm{HD}$ and $\mathrm{C}_{2} \mathrm{H}_{2}$. Another difference is that some species are specifically considered by only one database (for example $\mathrm{O}$ and $\mathrm{H}_{2}$ for HITRAN, $\mathrm{C}_{3} \mathrm{H}_{8}$ and $\mathrm{C}_{3} \mathrm{H}_{4}$ for GEISA).

Among the important number of information updated, a large part has been done with the valuable and sustained support of the international spatial agencies. Especially, since the launch of Metop-A (24 October 2006), GEISA became the official reference spectroscopic database used by the international working group (ISSWG) in charge of the IASI instrument. GEISA is also now involved in the definition of three future space missions: IASI-NG, Merlin and $\underline{\text { MicroCarb. }}$.

1 Acronyms used in the text are documented in Appendix A 
GEISA and its associated management software facilities are implemented and distributed (in the same way as GEISA-2011) via the atmospheric pole AERIS. It is used online by more than 350 laboratories working in various fields including atmospheric physics, planetary science, astronomy, astrophysics.

As in previous editions of GEISA, new data have been provided by different groups. They are listed in Column 3 of Table 1 together with their contribution.

Since the beginning of the 2000's, a specific effort has been made in GEISA and HITRAN to undertake a more systematic evaluation of spectroscopic parameters when selecting, introducing or replacing data. This has been enabled by the evolving capacity of several space-borne, ground-based or laboratory observations that have reached a level of precision sufficient to evaluate a large range of spectroscopic parameters produced by laboratory measurements or theory. Concerning GEISA, use is made of the now wellestablished evaluation method (called SPARTE, Spectroscopic Parameters And Radiative Transfer Evaluation) [8] that was developed and first used during the former GEISA release (called GEISA-2015 in the following). Using high resolution and high signal-to-noise ratio space-borne or ground-based measurements (like the one provided in the Near and Short-Wave Infrared by ground-based spectrometers of the Total Carbon Column Observing Network (TCCON) [9] and in the Thermal Infrared by the Infrared Atmospheric Sounding Interferometer (IASI) SPARTE enables to identify spectroscopic issues by investigating the differences between observations and simulations performed using the 4A/OP radiative transfer code [10].

This paper provides, in section 2, a detailed description of the data newly implemented or corrected in the latest 2020 GEISA release, for the line parameters sub-database only (the corresponding cross-section and aerosol will be updated and documented in a forthcoming paper). In this GEISA-2020 edition, the format is unchanged from the previous one. The inclusion of additional spectroscopic parameters describing refined collisional effects such as the speed dependence and Dicke narrowing effects is planned for a forthcoming version.

Examples of spectroscopic evaluations performed using, among others, the SPARTE algorithm are presented in Section 3. Focusing on $\mathrm{H}_{2} \mathrm{O}, \mathrm{O}_{2}, \mathrm{O}_{3}$ and $\mathrm{SF}_{6}$ molecules, we illustrate how the evaluation guided our selection of sources of line parameters.

\section{GEISA-2020 Line parameters database description}

\section{General Overview}

The GEISA-2020 edition is based on the release of spectroscopic data for 23 molecules in the range of $10^{-6}$ to $35,877 \mathrm{~cm}^{-1}$, and on the addition of 6 molecules in the range 296 to $1913 \mathrm{~cm}^{-1}$ (i.e. ' $\mathrm{HONO}, \mathrm{COFCl}, \mathrm{CH}_{3} \mathrm{I}, \mathrm{CH}_{3} \mathrm{~F}, \mathrm{RuO}_{4}$ and $\mathrm{H}_{2} \mathrm{C}_{3} \mathrm{H}_{2}$ (allene, isomer of $\mathrm{C}_{3} \mathrm{H}_{4}$ )), whose 
molecule code number (parameter I) has been fixed to 53 to 58 , respectively. The molecules which were updated are listed in Table 1, together with their molecule code in the GEISA notation and indication about the involved research groups. Note that the choice has been made in GEISA not to provide partition sums calculations. We have always relied on the use of TIPS code by Gamache et al. [11]. As TIPS is based on HITRAN molecule list, and as differences subsist with the two databases in the molecular content, we suggested several times in the past that TIPS add extra molecules as for $\mathrm{GeH}_{4}, \mathrm{C}_{3} \mathrm{H}_{8}, \mathrm{HNC}$ or $\mathrm{C}_{2} \mathrm{H}_{6}$. The new version of TIPS is based on HITRAN2020 and doesn't include HONO for example, as in GEISA-2020. We plan to suggest to R. Gamache to include data for missing molecules in TIPS, if possible.

\begin{tabular}{|c|c|c|c|}
\hline Molecule ID. & Code & Contributors & GEISA code \\
\hline $\mathrm{H}_{2} \mathrm{O}$ & 1 & A. Campargue, S. Mikhailenko, Y. Yurchenko, B. Gamache & CA6, CA9, K19, Y20 \\
\hline $\mathrm{CO}_{2}$ & 2 & V. Perevalov, S. Tashkun & P19 \\
\hline $\mathrm{O}_{3}$ & 3 & A.Barbe, S.Mikhailenko, E.Starikova, V. Tyuterev & T19, M19 \\
\hline $\mathbf{N}_{2} \mathrm{O}$ & 4 & V. Ebert, G. Li & L19 \\
\hline CO & 5 & G. Li, I. Gordon & L19 \\
\hline $\mathrm{CH}_{4}$ & 6 & A. Nikitin, V.Tyuterev, E.Starikova & N19, S19 \\
\hline $\mathrm{SO}_{2}$ & 9 & O. Naumenko & $1 \mathrm{~N} 9,2 \mathrm{~N} 9,3 \mathrm{~N} 9,4 \mathrm{~N} 9,5 \mathrm{~N} 9$ \\
\hline $\mathrm{NO}_{2}$ & 10 & A. Perrin, L. Manceron & P19 \\
\hline $\mathrm{NH}_{3}$ & 11 & N. Maaroufi, F. Kawbia & M19 \\
\hline PH3 & 12 & A. Nikitin & N19 \\
\hline $\mathrm{HNO}_{3}$ & 13 & A. Perrin & P19 \\
\hline HF, HBr, HI & $15,17,18$ & G. Li, I. Gordon & L19 \\
\hline $\mathrm{HCl}$ & 16 & G. Li, V. Ebert & L19 \\
\hline OCS & 20 & S. Galalou, F. Kwabia & A16, G19 \\
\hline $\mathrm{C}_{2} \mathrm{H}_{6}$ & 22 & N. Moazzen-Ahmadi & M19 \\
\hline $\mathrm{C}_{2} \mathrm{H}_{2}$ & 24 & D. Jacquemart, A. Campargue, V. Perevalov, O. Lyulin & J19, J20, L19, C19 \\
\hline $\mathrm{C}_{2} \mathrm{H}_{4}$ & 25 & J. Vander Auwera & A19 \\
\hline $\mathrm{GeH}_{4}$ & 26 & V. Boudon & B19 \\
\hline NO+ & 45 & H.S.P. Müller & M18 \\
\hline $\mathbf{C F}_{4}$ & 49 & V. Boudon & B19 \\
\hline HDO & 51 & L. Coudert, A. Kyuberis & $\mathrm{CO} 9, \mathrm{~K} 19$ \\
\hline \multicolumn{4}{|c|}{ New molecules } \\
\hline HONO & 53 & A. Perrin & $\mathrm{P} 18$ \\
\hline COFCI & 54 & A. Perrin & P19 \\
\hline $\mathrm{CH}_{3} \mathrm{I}$ & 55 & F. Kwabia, A. Perrin & P19 \\
\hline $\mathrm{CH}_{3} \mathrm{~F}$ & 56 & D. Jacquemart & J19 \\
\hline $\mathrm{RuO}_{4}$ & 57 & V. Boudon & B19 \\
\hline $\begin{array}{c}\mathrm{H}_{2} \mathrm{C}_{3} \mathrm{H}_{2}, \text { Allene } \\
\left(\mathrm{C}_{3} \mathrm{H}_{4} \text { isomer }\right)\end{array}$ & 58 & A. Jolly & J19 \\
\hline
\end{tabular}


Table 1: Updated molecular species in the GEISA-2020 edition. The internal GEISA code for the identification of the source of the data is indicated within parentheses (parameter $G$ ).

To have a more precise idea of the update, Table 2 gives the main differences between GEISA2015 and GEISA-2020 (in term of spectral range, number of lines and integrated intensity range).

\begin{tabular}{|c|c|c|c|c|c|c|c|c|c|}
\hline \multirow{3}{*}{ Mol. } & \multirow{3}{*}{ ID } & \multicolumn{4}{|c|}{ GEISA-2015 } & \multicolumn{4}{|c|}{ GEISA-2020 } \\
\hline & & \multirow[t]{2}{*}{$\begin{array}{l}\text { Spectral range } \\
\left(\mathrm{cm}^{-1}\right)\end{array}$} & \multirow[t]{2}{*}{ \# lines } & \multicolumn{2}{|c|}{$\begin{array}{c}\begin{array}{c}\text { Exponent of the } \\
\text { intensity } \\
\left(\mathrm{cm} \text { molecule }^{-1}\right) \\
\text { at } 296 \mathrm{~K} .\end{array} \\
\end{array}$} & \multirow[t]{2}{*}{$\begin{array}{l}\text { Spectral range } \\
\left(\mathrm{cm}^{-1}\right)\end{array}$} & \multirow[t]{2}{*}{ \# lines } & \multicolumn{2}{|c|}{$\begin{array}{c}\text { Exponent of } \\
\text { the intensity } \\
\left(\mathrm{cm} \text { molecule }^{-1}\right) \\
\text { at } 296 \mathrm{~K} .\end{array}$} \\
\hline & & & & Max. & Min. & & & \begin{tabular}{|l} 
Max. \\
\end{tabular} & Min. \\
\hline $\mathrm{H}_{2} \mathrm{O}$ & 1 & $0.052-25336.949$ & 191846 & -18 & -36 & $0.053-25336.949$ & 362222 & -18 & -36 \\
\hline $\mathrm{CO}_{2}$ & 2 & $5.890-14075.298$ & 534227 & -18 & -30 & $345.936-14075.301$ & 532533 & -18 & -30 \\
\hline $\mathrm{O}_{3}$ & 3 & $0.026-6996.681$ & 405919 & -20 & -31 & $0.026-6996.681$ & 464288 & -20 & -31 \\
\hline $\mathrm{N}_{2} \mathrm{O}$ & 4 & $0.838-7796.633$ & 50633 & -17 & -25 & $0.838-7796.633$ & 50633 & -18 & -26 \\
\hline $\mathrm{CO}$ & 5 & $3.414-8464.882$ & 13515 & -18 & -77 & $3.402-14477.377$ & 14985 & -19 & -78 \\
\hline $\mathrm{CH}_{4}$ & 6 & $0.001-11501.877$ & 421811 & -19 & -39 & $0.001-11501.877$ & 447004 & -19 & -39 \\
\hline $\mathrm{O}_{2}$ & 7 & $10-6-15927.804$ & 16197 & -24 & -54 & $0.000-15927.804$ & 16197 & -24 & -54 \\
\hline $\mathrm{NO} *$ & 8 & $10-6-9273.214$ & 105079 & -19 & -94 & $0.000-9273.214$ & 105079 & -20 & -95 \\
\hline $\mathrm{SO}_{2}$ & 9 & $0.017-4092.948$ & 83668 & -20 & -30 & $0.017-4159.945$ & 561008 & -20 & -30 \\
\hline $\mathrm{NO}_{2}$ & 10 & $0.498-3074.152$ & 104223 & -18 & -27 & $0.498-4775.314$ & 185965 & -19 & -28 \\
\hline $\mathrm{NH}_{3}$ & 11 & $0.058-6999.429$ & 46414 & -19 & -39 & $0.058-6999.429$ & 46414 & -19 & -39 \\
\hline $\mathrm{PH}_{3}$ & 12 & $17.805-3601.652$ & 20364 & -18 & -27 & $8.904-3659.266$ & 34542 & -19 & -28 \\
\hline $\mathrm{HNO}_{3}$ & 13 & $0.012-1769.982$ & 691161 & -20 & -28 & $0.012-1769.982$ & 738171 & -20 & -28 \\
\hline $\mathrm{OH} *$ & 14 & $0.005-35877.031$ & 42866 & -16 & -84 & $0.005-35877.031$ & 42866 & -17 & -85 \\
\hline $\mathrm{HF}$ & 15 & $41.111-11535.570$ & 107 & -16 & -25 & $13.620-32351.592$ & 20010 & -17 & -99 \\
\hline $\mathrm{HCl}$ & 16 & $20.240-13457.841$ & 533 & -18 & -25 & $5.342-20231.245$ & 53436 & -19 & -99 \\
\hline $\mathrm{HBr}$ & 17 & $16.231-9758.564$ & 1293 & -18 & -32 & $7.656-16033.492$ & 8980 & -19 & -71 \\
\hline $\mathrm{HI}$ & 18 & $12.509-8487.305$ & 806 & -19 & -29 & $5.888-13907.689$ & 4751 & -20 & -64 \\
\hline $\mathrm{ClO} *$ & 19 & $0.015-1207.639$ & 7230 & -20 & -29 & $0.015-1207.639$ & 7230 & -21 & -30 \\
\hline OCS & 20 & $0.381-4199.671$ & 33809 & -17 & -27 & $0.381-7821.109$ & 37479 & -18 & -28 \\
\hline $\mathrm{H}_{2} \mathrm{CO} *$ & 21 & $0.000-3099.958$ & 44611 & -20 & -39 & $0.000-3099.958$ & 44611 & -20 & -39 \\
\hline $\mathrm{C}_{2} \mathrm{H}_{6}$ & 22 & $706.601-3070.971$ & 53803 & -20 & -29 & $225.045-3070.971$ & 65741 & -20 & -38 \\
\hline $\mathrm{CH}_{3} \mathrm{D}$ * & 23 & $7.760-6510.324$ & 58763 & -23 & -30 & $7.760-6510.324$ & 58763 & -23 & -30 \\
\hline $\mathrm{C}_{2} \mathrm{H}_{2}$ & 24 & $604.774-9889.038$ & 12969 & -18 & -28 & $13.624-9889.038$ & 70107 & -18 & -31 \\
\hline $\mathrm{C}_{2} \mathrm{H}_{4}$ & 25 & $614.740-3242.172$ & 53227 & -20 & -37 & $614.740-3242.172$ & 100100 & -20 & -37 \\
\hline $\mathrm{GeH}_{4}$ & 26 & $1937.371-224.570$ & 824 & -18 & -21 & $1928.902-2265.678$ & 32372 & -19 & -23 \\
\hline $\mathrm{HCN} *$ & 27 & $0.018-17581.009$ & 138103 & -19 & -32 & $0.019-17581.009$ & 138103 & -19 & -32 \\
\hline $\mathrm{C}_{3} \mathrm{H}_{8} *$ & 28 & $700.015-799.930$ & 8983 & -21 & -23 & $700.015-799.930$ & 8983 & -22 & -24 \\
\hline $\mathrm{C}_{2} \mathrm{~N}_{2} *$ & 29 & $200.817-2181.690$ & 71954 & -20 & -24 & $200.818-2181.690$ & 71954 & -20 & -24 \\
\hline $\mathrm{C}_{4} \mathrm{H}_{2} *$ & 30 & $189.422-1302.217$ & 417540 & -19 & -24 & $189.423-1302.217$ & 417540 & -19 & -24 \\
\hline $\mathrm{HC}_{3} \mathrm{~N} *$ & 31 & $463.604-759.989$ & 179347 & -19 & -23 & $463.604-759.989$ & 179347 & -20 & -24 \\
\hline $\mathrm{HOCl} *$ & 32 & $0.0236-3799.682$ & 17862 & -19 & -27 & $0.024-3799.682$ & 17862 & -20 & -28 \\
\hline $\mathrm{N}_{2} *$ & 33 & $1992.63-2625.497$ & 120 & -27 & -33 & $1992.628-2625.497$ & 120 & -28 & -34 \\
\hline $\mathrm{CH}_{3} \mathrm{Cl} *$ & 34 & $0.872-3197.961$ & 83043 & -21 & -32 & $0.873-3197.961$ & 83043 & -21 & -32 \\
\hline $\mathrm{H}_{2} \mathrm{O}_{2} *$ & 35 & $0.043-1730.371$ & 126983 & -19 & -28 & $0.043-1730.371$ & 126983 & -20 & -29 \\
\hline $\mathrm{H}_{2} \mathrm{~S} *$ & 36 & $1.030-1329.780$ & 58650 & -19 & -30 & $1.031-11329.780$ & 58650 & -19 & -30 \\
\hline $\mathrm{HCOOH} *$ & 37 & $10.018-1889.334$ & 62684 & -19 & -25 & $10.018-1889.334$ & 62684 & -20 & -26 \\
\hline $\mathrm{COF}_{2} *$ & 38 & $725.005-2001.348$ & 70904 & -19 & -23 & $725.005-2001.348$ & 70904 & -20 & -24 \\
\hline $\mathrm{SF}_{6} *$ & 39 & $588.488-975.787$ & 92398 & -19 & -23 & $588.488-975.787$ & 92398 & -20 & -24 \\
\hline $\mathrm{C}_{3} \mathrm{H}_{4} *$ & 40 & $288.913-673.479$ & 19001 & -19 & -23 & $288.913-673.479$ & 19001 & -20 & -24 \\
\hline $\mathrm{HO}_{2} *$ & 41 & $0.173-3675.819$ & 38804 & -19 & -25 & $0.173-3675.819$ & 38804 & -20 & -26 \\
\hline
\end{tabular}




\begin{tabular}{|c|c|c|c|c|c|c|c|c|c|}
\hline \multirow{3}{*}{ Mol. } & \multirow{3}{*}{ ID } & \multicolumn{4}{|c|}{ GEISA-2015 } & \multicolumn{4}{|c|}{ GEISA-2020 } \\
\hline & & \multirow[t]{2}{*}{$\begin{array}{l}\text { Spectral range } \\
\left(\mathrm{cm}^{-1}\right)\end{array}$} & \multirow[t]{2}{*}{ \# lines } & \multicolumn{2}{|c|}{$\begin{array}{c}\text { Exponent of the } \\
\text { intensity } \\
\left(\mathrm{cm} \text { molecule }^{-1}\right) \\
\text { at } 296 \mathrm{~K} \text {. }\end{array}$} & \multirow[t]{2}{*}{$\begin{array}{c}\text { Spectral range } \\
\left(\mathrm{cm}^{-1}\right)\end{array}$} & \multirow[t]{2}{*}{ \# lines } & \multicolumn{2}{|c|}{$\begin{array}{c}\text { Exponent of } \\
\text { the intensity } \\
\left(\mathrm{cm} \text { molecule }^{-1}\right) \\
\text { at } 296 \mathrm{~K} .\end{array}$} \\
\hline & & & & Max. & Min. & & & Max. & Min. \\
\hline $\mathrm{ClONO}_{2} *$ & 42 & $0.636-797.741$ & 356899 & -21 & -27 & $0.636-797.741$ & 356899 & -22 & -28 \\
\hline $\mathrm{CH}_{3} \mathrm{Br} *$ & 43 & $794.403-1705.612$ & 36911 & -21 & -27 & $794.403-1705.612$ & 36911 & -21 & -27 \\
\hline $\mathrm{CH}_{3} \mathrm{OH} *$ & 44 & $0.019-1407.206$ & 19897 & -19 & -34 & $0.019-1407.206$ & 19897 & -20 & -35 \\
\hline $\mathrm{NO}^{+}$ & 45 & $1634.83-2530.462$ & 1206 & -18 & -80 & $3.938-4742.008$ & 1333 & -19 & -81 \\
\hline $\mathrm{HNC} *$ & 46 & $0.145-4692.098$ & 75554 & -18 & -30 & $0.146-4692.098$ & 75554 & -18 & -30 \\
\hline $\mathrm{C}_{6} \mathrm{H}_{6} *$ & 47 & $642.427-705.262$ & 9797 & -20 & -23 & $642.427-705.262$ & 9797 & -21 & -24 \\
\hline $\mathrm{C}_{2} \mathrm{HD} *$ & 48 & $416.785-3421.864$ & 15512 & -22 & -28 & $416.785-3421.864$ & 15512 & -23 & -29 \\
\hline $\mathrm{CF}_{4}$ & 49 & $594.581-1312.647$ & 60033 & -19 & -23 & $1.173-1329.697$ & 258208 & -20 & -30 \\
\hline $\mathrm{CH}_{3} \mathrm{CN} *$ & 50 & $890.052-1650.000$ & 17172 & -19 & -37 & $890.052-1650.000$ & 17172 & -20 & -38 \\
\hline HDO & 51 & $0.007-17080.098$ & 63641 & -22 & -33 & $0.000-19935.167$ & 77599 & -22 & -39 \\
\hline $\mathrm{SO}_{3} *$ & 52 & $0.477-2824.347$ & 10881 & -19 & -31 & $0.478-2824.347$ & 10881 & -19 & -31 \\
\hline $\mathrm{HONO}$ & 53 & & & & & $722.534-996.281$ & 26041 & -20 & -25 \\
\hline COFCL & 54 & & & & & $734.997-1912.632$ & 215639 & -20 & -24 \\
\hline $\mathrm{CH}_{3} \mathrm{I}$ & 55 & & & & & $693.022-1125.255$ & 70291 & -21 & -31 \\
\hline $\mathrm{CH}_{3} \mathrm{~F}$ & 56 & & & & & $1067.375-1290.255$ & 1499 & -21 & -24 \\
\hline $\mathrm{RUO}_{4}$ & 57 & & & & & $889.987-948.138$ & 30205 & -20 & -23 \\
\hline $\mathrm{H}_{2} \mathrm{C}_{3} \mathrm{H}_{2}$ & 58 & & & & & $296.316-1192.446$ & 31686 & -20 & -27 \\
\hline Total \# line & & & $5,067,351$ & & & & $6,746,987$ & & \\
\hline
\end{tabular}

*: Molecule which has not been updated in the GEISA-2020

Table 2. Contents of the GEISA-2020 line parameters database. Details per molecule of the evolution of GEISA contents since its 2015 edition. Reference temperature is $296 \mathrm{~K}$.

\section{Description of updates per individual molecular species}

This description is given in sub-sections 2.2.1 to 2.2.25, for each molecular species identified by its formula associated with its GEISA identification code.

\subsection{1 $\mathrm{H}_{2} \mathrm{O}$ and $\mathrm{HDO}$}

\subsubsection{1 $\mathrm{H}_{2} \mathrm{O}$ (molecule 1)}

New $\mathrm{H}_{2} \mathrm{O}$ data implemented in GEISA-2020 consist in three main parts which are: $(i)$ an updated line list for the main $\mathrm{H}_{2}{ }^{16} \mathrm{O}$ isotopologue between 5850 and $8340 \mathrm{~cm}^{-1}$, (ii) the addition of electric-quadrupole transitions up to $10000 \mathrm{~cm}^{-1}$, and (iii) a major update of doubly deuterated $\mathrm{D}_{2} \mathrm{O}$ isotopologues up to $18,000 \mathrm{~cm}^{-1}$.

GEISA-2020 was updated using line intensities, air-broadening and -shifting coefficients provided from Mikhailenko et al. [12], whereas the line positions were refined using the most recent version of their line list [13]. Note that local discrepancies due to erroneous broadening values of some $\mathrm{H}_{2} \mathrm{O}$ lines were found in these line lists and in GEISA-2015 (see for example residuals of the $\mathrm{H}_{2} \mathrm{O}$ line at $7804.6092 \mathrm{~cm}^{-1}$ in section 3.1.1), these lines were corrected in GEISA-2020 with calculated air-broadening parameters from Vispoel et al. [14,15] were used 
to correct the incriminated lines (see details below). As a result, 40,980 lines were updated in GEISA-2020 (from which 7572 are new lines not referenced in GEISA-2015). Note that we present in section 3.1.1 a quantitative evaluation of these $\mathrm{H}_{2} \mathrm{O}$ data.

The internal GEISA code presented in Table 1 for the data identification has been set to $\boldsymbol{C A 6}$ and $\boldsymbol{C A 9}$.

Up to now, similarly to all other databases, the GEISA $\mathrm{H}_{2} \mathrm{O}$ database was limited to rovibrational electric-dipole transitions. Electric-quadrupole transitions do also exist, but they are typically a million times weaker than electric-dipole transitions, making their observation extremely challenging. The recent detection of weak quadrupole transitions in the spectrum of water vapor $[16,17]$ has shown that in their present status the spectroscopic databases are not complete for polyatomic molecules. Actually, databases provide lists of electric-dipole transitions above an intensity cut-off (e.g. $10^{-36} \mathrm{~cm} /$ molecule for water in the GEISA database) largely below intensity values of the strongest electric-quadrupole lines (e.g. up to $10^{-26}$ $\mathrm{cm} /$ molecule for water vapor [17]). The laboratory measurements of Refs [16,17] (in total, about twenty quadrupole lines near 5.4, 2.5 and $1.3 \mu \mathrm{m}$ ) have validated the $a b$ initio intensities computed in Ref. [16] within the experimental error bars. Consequently, in the present release, the $a b$ initio quadrupole line list of Ref. [16] up to $10,000 \mathrm{~cm}^{-1}$ (6429 lines in total above a 10${ }^{30} \mathrm{~cm} /$ molecule intensity cut-off) has been incorporated in the water vapor line list for the main isotopologue $\mathrm{H}_{2}{ }^{16} \mathrm{O}$. Figure 1 shows an overview of the electric-dipole and electric-quadrupole transitions listed in GEISA 2020, up to $9500 \mathrm{~cm}^{-1}$. In the calculations of Ref. [16], the variational values of the lower and upper energy levels of $\mathrm{H}_{2}{ }^{16} \mathrm{O}$ were replaced by the corresponding empirical values from IUPAC [18]. The resulting line position accuracy is thus expected to be of the order of $10^{-3} \mathrm{~cm}^{-1}$ for most of the quadrupole lines. 


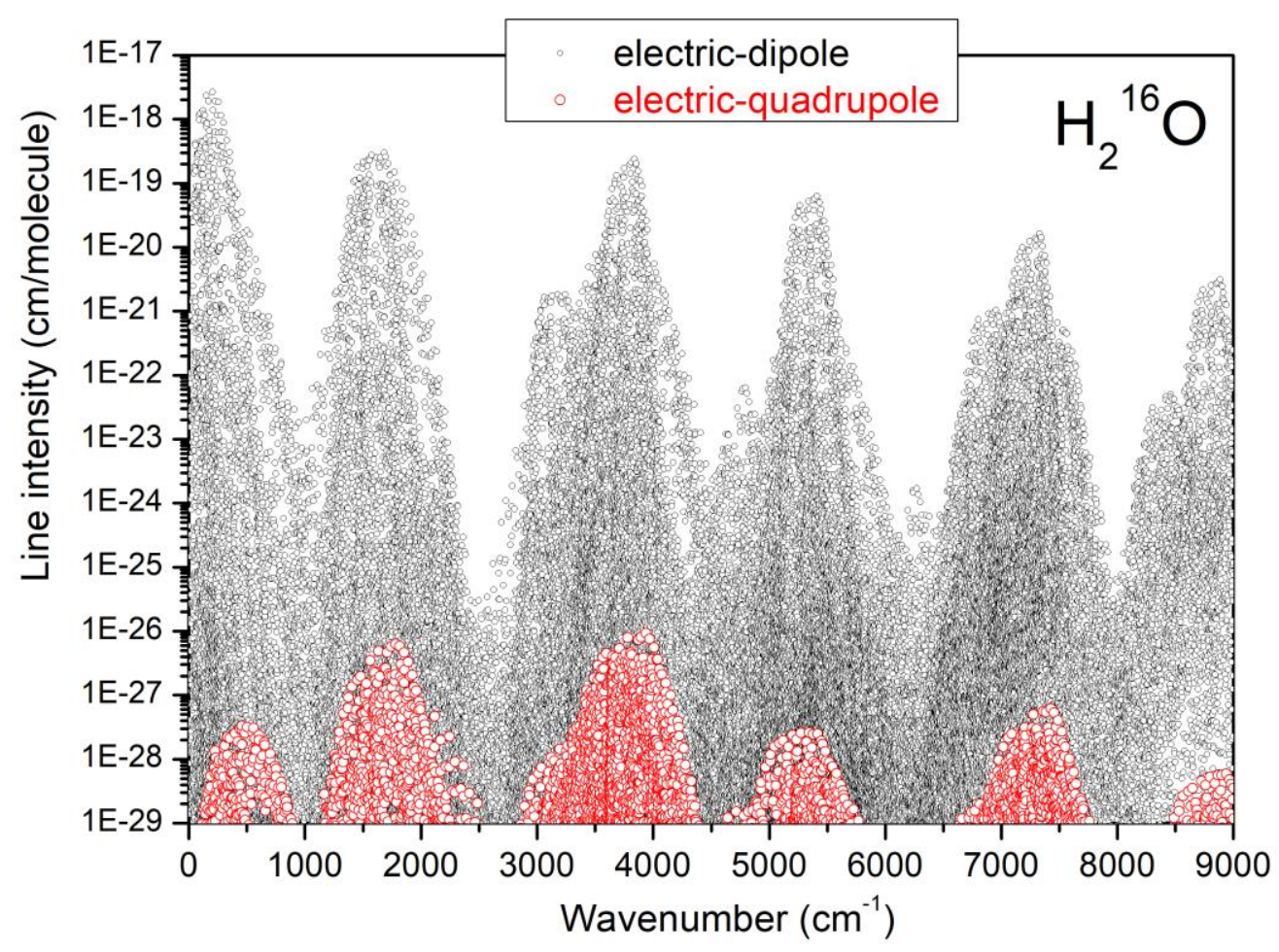

Figure 1: Overview of the $\mathrm{H}_{2}{ }^{16} \mathrm{O}$ absorption line list in GEISA-2020 up to $9000 \mathrm{~cm}^{-1}$. The electric-quadrupole transitions (red dots) are superimposed to the electric-dipole transitions (black dots).

The internal GEISA code for the data identification has been set to $Y 20$.

As line shape parameters are critical for atmospheric applications, an updated calculation for $\mathrm{H}_{2} \mathrm{O}-\mathrm{H}_{2} \mathrm{O}, \mathrm{H}_{2} \mathrm{O}-\mathrm{N}_{2}$ and $\mathrm{H}_{2} \mathrm{O}-\mathrm{O}_{2}$ broadenings and shifts, along with the temperature dependence of these parameters was provided by Gamache and Vispoel (unpublished data, 2020). These parameters were calculated for $\mathrm{H}_{2}{ }^{16} \mathrm{O}, \mathrm{H}_{2}{ }^{18} \mathrm{O}, \mathrm{H}_{2}{ }^{17} \mathrm{O}$ (but also $\mathrm{HD}^{17} \mathrm{O}, \mathrm{HD}^{18} \mathrm{O}, \mathrm{D}_{2}{ }^{16} \mathrm{O}, \mathrm{D}_{2}{ }^{18} \mathrm{O}$, and $\mathrm{D}_{2}{ }^{17} \mathrm{O}$ species), and include the $\mathrm{H}_{2}{ }^{16} \mathrm{O}$ quadrupole transitions. From values calculated using the Modified Complex Robert Bonamy (MCRB) model by Vispoel et al. [14] for $\mathrm{H}_{2} \mathrm{O}-\mathrm{N}_{2}$ and $\mathrm{H}_{2} \mathrm{O}-\mathrm{O}_{2}$ (Vispoel and Gamache, unpublished data, 2020), the pressure broadening information for $\mathrm{H}_{2} \mathrm{O}$-air was produced considering $\gamma($ air $)=0.79 \gamma\left(\mathrm{N}_{2}\right)+0.21 \gamma\left(\mathrm{O}_{2}\right)$, with a similar formula for the line shift. Note that the calculations were performed for 13 temperatures from $200 \mathrm{~K}$ to $3000 \mathrm{~K}$, considering 10,782 rotational transitions in the rotational band and for 1 to 4 vibrational quanta changes in the $v_{1}, v_{2}$, and $v_{3}$ bands, giving updated profile parameters for about 140,000 transitions.

Pressure-broadening and -shifting parameters of more than 300,000 dipole transitions needed to be carefully selected, evaluated and systematically compared to previous data of the database. 
This specific process being a task of major importance, it will be part of a future dedicated publication on $\mathrm{H}_{2} \mathrm{O}$. As a result, only line-shape parameters for quadrupole transitions were considered for this update of GEISA, except for some problematic electric-dipole isolated lines known to be problematic in GEISA-2015 (cf. section 3.1.1 for a detailed example of $\mathrm{H}_{2} \mathrm{O}$ data validation). For GEISA-2020, line-shape parameters of 6475 lines were updated in this way.

Besides the main isotopologue $\mathrm{H}_{2}{ }^{16} \mathrm{O}$, another update was made in GEISA-2020 for the doubly deuterated $\mathrm{D}_{2} \mathrm{O}$ isotopologues of water vapor, based on the recent work of Kyuberis et al. [19]. A total of 156,375 new lines were added and 5860 lines updated with respect to the previous version of the database. In particular, data for the isotopologue $\mathrm{D}_{2}{ }^{17} \mathrm{O}$, which were missing in all previous versions of GEISA, were implemented. These $a b$ initio calculations were obtained using the base PES (Potential Energy Surface) of Shirin et al. [20] which was explicitly developed for $\mathrm{D}_{2} \mathrm{O}$. More details can be found in Ref. [19]. Half-width and pressure-shift data were taken from the measurement database of Gamache and Hartmann [21] for 228, 227, 133 $\left(119,119,88\right.$ for line shifts) transitions of $\mathrm{D}_{2}{ }^{16} \mathrm{O}, \mathrm{D}_{2}{ }^{18} \mathrm{O}$, and $\mathrm{D}_{2}{ }^{17} \mathrm{O}$, respectively. For the remaining transitions, data from Ref. [19] were retained.

The internal GEISA code for the data identification has been set to $\mathbf{K 1 9}$.

\subsubsection{HDO (molecule 51)}

Following the data update made for $\mathrm{H}_{2} \mathrm{O}$ (cf. previous section), the HDO linelist was also updated using line intensities and air-broadening and -shifting coefficients provided by Mikhailenko et al. [12], and line positions which were refined using the most recent version of their line list [13]. As a result, 17,015 lines were updated in GEISA-2020 (from which 4468 are new lines not referenced in GEISA-2015).

The internal GEISA code for the data identification has been set to $\boldsymbol{C A 6}$ and $\boldsymbol{C A 9}$.

Moreover, recent data from Coudert [22], based on the line positions and line strengths analyses spanning the 0 to $2000 \mathrm{~cm}^{-1}$ spectral range, were added in the new version of GEISA. The line list contains rovibrational transitions between the ground and (010) states as well as transitions belonging to the $v_{2}$ band. The maximum value of the rotational quantum number $J$ was set to 22 and an intensity cut-off of $10^{-28} \mathrm{~cm}^{-1} /\left(\right.$ molecule $\mathrm{cm}^{-2}$ ) was used for a temperature of $296 \mathrm{~K}$ and an isotopic abundance [23] of $3.107 \times 10^{-4}$. In total 5813 lines were updated, including 260 lines for the first time in GEISA-2020.

The internal GEISA code for the data identification has been set to $\mathbf{C O 9}$. 
Finally, ab initio predictions from Kyuberis et al. [19] were also considered. The most abundant deuterated water species $\mathrm{HD}^{16} \mathrm{O}$ required the most extensive variational calculations. The base potential was the fitted HDO07 PES due to Yurchenko et al. [24]. Calculations were performed for $J$ up to 23 but intensities were limited to transitions below $20000 \mathrm{~cm}^{-1}$. Concerning $\mathrm{HD}^{17} \mathrm{O}$ and $\mathrm{HD}^{18} \mathrm{O}$, isotopic abundance factors imply that only strong lines are important for atmospheric studies, which raises fewer issues with unstable intensities. For these species line lists generated by Down [25] were used (see Ref. [19] for more information). In total 67,928 lines were updated, from which 9230 lines were not referenced in GEISA-2015.

The internal GEISA code for the data identification has been set to $\mathbf{K 1 9}$.

\subsection{2 $\mathrm{CO}_{2}$ (molecule 2)}

The GEISA-2020 carbon dioxide line list has been updated between 345.935625 and $14075.301276 \mathrm{~cm}^{-1}$ based on the updated version of the CDSD-296 databank [26]. Compared to the previous version of the CDSD-296 [27] on which GEISA-2015 was based [1], in the new version, the $\Delta \mathrm{P}=9$ region for all isotopologues was updated $\left[P=2 V_{1}+V_{2}+3 V_{3}\right.$ is the polyad number ( $V i$ being the vibrational quantum numbers)]. Moreover, in the previous version of the CDSD-296, the line intensities of some asymmetric isotopologues were incorrectly recalculated from the effective dipole moment parameters of more abundant ones, and were corrected in this new version GEISA-2020. After the publication of the updated version of the CDSD-296 [26], some updates were made [28] and also included in GEISA-2020. First, the line intensities for the $\Delta \mathrm{P}=6$ series of transitions in the ${ }^{16} \mathrm{O}^{12} \mathrm{C}^{18} \mathrm{O}$ isotopologue were recalculated using the new set of the effective dipole moment parameters. Secondly, 226 lines with $\Delta \ell_{2}=4$ for the ${ }^{12} \mathrm{C}^{16} \mathrm{O}_{2}$, ${ }^{13} \mathrm{C}^{16} \mathrm{O}_{2}$ and ${ }^{16} \mathrm{O}^{12} \mathrm{C}^{18} \mathrm{O}$ isotopologues were newly added, which were not available in the CDSD-296 because of the used $\Delta \ell_{2}<4$ cut-off.

The 01111-00001 band and the respective hot bands of the ${ }^{16} \mathrm{O}^{12} \mathrm{C}^{18} \mathrm{O}$ isotopologue were excluded from the last version of the CDSD-296 because their effective dipole moment parameters responsible for the line intensities of these bands were fitted to the line intensities deduced from the Venus spectra obtained by the Venus Express satellite [29]. These line intensities have been considered as not sufficiently precise. Considering its importance for the astronomer's community [30], only this specific 01111-00001 band has been added to the GEISA-2020 release: the corresponding values are from the GEISA-2011 version.

All these updates are now included in GEISA-2020 and have been referenced with the identifier P19 (J internal code parameter). 


\subsection{3 $\mathrm{O}_{3}$ (molecule 3)}

Due to the importance of the ozone molecule for atmospheric applications, measurements and calculations of ozone spectra undergo continuous extension and improvement [31-34] (and references therein). The current GEISA-2020 update corresponds essentially to the S\&MPO2020 version of the "Spectroscopy and Molecular Properties of Ozone" information system [35] jointly developed by Reims and Tomsk groups. The linelists were produced using effective Hamiltonian and effective transition dipole moment models derived from analyses of experimental Fourier Transform spectra in the infrared as described in $[35,36]$.

(i) Main ozone isotopologue ${ }^{16} \mathrm{O}_{3}$

Eighteen bands of the main ozone isotopologue ${ }^{16} \mathrm{O}_{3}$ were newly included in GEISA2020. In the range between 4384 and $4826 \mathrm{~cm}^{-1}$ the hot bands corresponding to the upper tetrad of strongly coupled vibrational states $(213) /(080) /(114) /(321)$ were included. Cold bands of the $(023) /(122) /(400)$ triad of interacting states $\left(4268-4455 \mathrm{~cm}^{-1}\right)$ were calculated using unpublished $^{2}$ parameters of Barbe and Mikhailenko [37,38] available at the S\&MPO web site (https://smpo.iao.ru/transitions/params). The resonance coupling parameters were given in the representation of ladder angular momentum components as defined in [35]. The transition moment parameters for the line intensities of the hot bands between 3564 and $3752 \mathrm{~cm}^{-1}$ are those of Ref. [32]. The hot bands $5 v_{3}-v_{2}, 3 v_{1}+v_{2}+v_{3}-v_{2}$ and $v_{1}+4 v_{3}-v_{2}$ (in the region $4128-$ $4229 \mathrm{~cm}^{-1}$ ) were calculated using Effective Hamiltonian (EH) parameters [39] and unpublished transition moment parameters obtained by Barbe [37,38]. In addition, five previously missing hot bands between 598 and $1542 \mathrm{~cm}^{-1}$ belonging to the tetrad of interacting $(002) /(101) /(030) /(200)$ vibrational states were added. Unpublished EH parameters of the upper states [37,38] as well as published parameters of the lower states [40-42] were used for line position calculations. Line intensity calculations used unpublished parameters for the $2 v_{1}$ $v_{2}$ band $[37,38]$ and parameters of Refs. $[43,44]$ for the $3 v_{2}-2 v_{2}, v_{1}+v_{3}-2 v_{2}, 3 v_{2}-v_{1}$, and $3 v_{2}-v_{3}$ bands.

Twenty-four bands previously included in the GEISA line list between 281 and $4122 \mathrm{~cm}^{-}$ ${ }^{1}$ were updated:

- The $v_{3}-v_{2}$ and $v_{1}-v_{2}$ hot bands $\left(281-446 \mathrm{~cm}^{-1}\right)$ were calculated using EH parameters of Flaud et al. [40] and dipole moment transition parameters of Birk et al. [45].

\footnotetext{
${ }^{2}$ Note: described data are mostly coming from currently unpublished work, planned to be presented in Ref. [37]. These data are also available at the S\&MPO web site (https://smpo.iao.ru).
} 
- Three hot bands $(002) /(101) /(030)$ - (010) in the $1302-1476 \mathrm{~cm}^{-1}$ range were calculated using unpublished upper state EH parameters by Barbe and Tyuterev [37,38] and the dipole moment transition parameters of S\&MPO-2015. The lower state parameters were taken from [41].

- The same upper state EH parameters were used for six hot bands $(002) /(101) /(200)-$ $(001) /(100)\left(899-1235 \mathrm{~cm}^{-1}\right)$ with the dipole moment transition parameters of [44]. The lower state parameters were taken from [40].

- Two cold bands $2 v_{2}+v_{3}$ and $v_{1}+2 v_{2}\left(2336-2617 \mathrm{~cm}^{-1}\right)$ were calculated using parameters by Barbe, Sulakshina et al. [46].

- The line positions of the hot $\left(v_{2}+3 v_{3}-v_{2}\right.$ and $\left.v_{1}+v_{2}+2 v_{3}-v_{2}\left(2899-3122 \mathrm{~cm}^{-1}\right)\right)$ and cold $\left(v_{2}+3 v_{3}\right.$ and $\left.v_{1}+v_{2}+2 v_{3}\left(3584-3831 \mathrm{~cm}^{-1}\right)\right)$ bands were calculated using EH parameters from $[40,41,47]$. The dipole moment parameters of [47] were used for the calculations of the line intensities of the cold bands. The intensities of the hot bands were calculated using unpublished parameters by Mikhailenko and Barbe.

- The results of a re-investigation of the spectral range from 3600 to $4300 \mathrm{~cm}^{-1}$ led to a large improvement of the analysis for the strongest $v_{1}+3 v_{3}$ band in this range [32]. A recent observation of the hot band $4 v_{3}-v_{3}$ [32] enabled to identify the strong anharmonic resonance with the "dark" $3 v_{1}+v_{2}$ band. As the upper (310) state is also in interaction with the (211) state, it was necessary to include seven vibration states to correctly reproduce 3389 transitions with the root mean square deviation of $3.54 \times 10^{-3} \mathrm{~cm}^{-1}$ for line positions and 1295 intensities within $8.6 \%$. Seven calculated bands in this range were included in the compilation, for a total number or 13536 updated transitions (from which 7447 are new lines in GEISA) between 2816 and $4122 \mathrm{~cm}^{-1}$. Newly included bands are summarized in the Table 3 . Figure 2 gives an overview of the added lines in the considered spectral range.

The internal GEISA code for the data described above was set to M19.

\begin{tabular}{cccc}
\hline Band & \#lines & Spectral range $\left(\mathrm{cm}^{-1}\right)$ & $\mathrm{S}_{\text {tot }}{ }^{*}(\mathrm{~cm} /$ molecule $)$ \\
\hline $030-020$ & 2558 & $598.26-804.86$ & $1.928 \mathrm{E}-21$ \\
$101-020$ & 6 & $656.12-725.68$ & $4.902 \mathrm{E}-25$ \\
$030-100$ & 20 & $956.13-1170.40$ & $1.902 \mathrm{E}-23$ \\
$030-001$ & 15 & $957.33-1201.66$ & $2.238 \mathrm{E}-24$ \\
$200-010$ & 102 & $1366.62-1541.76$ & $5.267 \mathrm{E}-24$ \\
$023-010$ & 1355 & $3564.72-3657.05$ & $3.650 \mathrm{E}-22$ \\
$122-010$ & 620 & $3584.75-3751.75$ & $3.505 \mathrm{E}-23$ \\
$400-010$ & 4 & $3623.87-3653.87$ & $6.695 \mathrm{E}-25$ \\
$005-010$ & 848 & $4128.33-4228.24$ & $2.354 \mathrm{E}-23$ \\
$311-010$ & 1018 & $4129.14-4228.62$ & $3.420 \mathrm{E}-23$
\end{tabular}




\begin{tabular}{cccc}
$104-010$ & 66 & $4146.09-4228.28$ & $6.265 \mathrm{E}-25$ \\
$023-000$ & 1192 & $4268.37-4357.21$ & $1.914 \mathrm{E}-22$ \\
$122-000$ & 724 & $4284.15-4454.93$ & $4.328 \mathrm{E}-23$ \\
$400-000$ & 8 & $4325.56-4398.58$ & $5.854 \mathrm{E}-25$ \\
$213-100$ & 63 & $4384.72-4423.50$ & $1.407 \mathrm{E}-24$ \\
$321-100$ & 126 & $4429.78-4466.82$ & $5.709 \mathrm{E}-24$ \\
$114-001$ & 306 & $4452.15-4508.72$ & $1.304 \mathrm{E}-23$ \\
$213-010$ & 503 & $4757.08-4825.80$ & $2.329 \mathrm{E}-23$ \\
\hline Total & $\mathbf{9 5 3 4}$ & $\mathbf{5 9 8 . 2 6}-\mathbf{4 8 2 5 . 8 0}$ & $\mathbf{2 . 6 9 2 8 E}-21$ \\
\hline
\end{tabular}

*: Line intensities are given for $99.29 \%{ }^{16} \mathrm{O}_{3}$ abundance.

Table 3. The list of new ${ }^{16} \mathrm{O}_{3}$ ozone bands in the GEISA-2020 release. \#lines: Number of transitions, $\mathrm{S}_{\text {tot }}$ is the sum of the line intensities.

Recent ab initio calculations by Tyuterev et al. [31], using the dipole moment functions of [48], have suggested that absolute intensities of the strongest bands in most of spectroscopic databases $[1,2,35]$ should be corrected to achieve the consistency between microwave and infrared $5 \mu \mathrm{m}$ and $10 \mu \mathrm{m}$ spectral ranges. The recommended intensity scaling corrections with respect to the HITRAN2016 data were $+3 \%,+3 \%$ and $+3.5 \%$ for the dominant rotational, $v_{3}$ and $v_{1}+v_{3}$ bands. These corrections have been found in agreement [31] with accurate Starkeffect measurements and the JPL catalogue based on these measurements in the microwave, as well with the most recent infrared FTS measurements by Barbe et al. [31], and by Jacquemart et al. (unpublished data) for $5 \mu \mathrm{m}$ and $10 \mu \mathrm{m}$. This was also consistent with DRL FTS measurements in the $10 \mu \mathrm{m}$ range reported by Wagner et al. (unpublished data) within less than 1\% for strong lines. The GEISA-2015 data being somewhat different from HITRAN2016, particularly in the $5 \mu \mathrm{m}$ range, the ab initio scaling factors of [31] with respect to GEISA-2015 were thus adapted to the three corresponding strongest bands as given in \#: internal data identification set to $\boldsymbol{T 1 9}$

Table 4.

\begin{tabular}{cccc}
\hline Spectral Region & Band & $\begin{array}{c}\text { Intensity scaling factor } \\
\text { with respect to GEISA- } \\
\end{array}$ & Nb. affected lines ${ }^{\#}$ \\
\hline Microwave & $000-000$ & 1.030 & 5493 \\
$10 \mu \mathrm{m}$ & $001-000$ & 1.027 & 7498 \\
$5 \mu \mathrm{m}$ & $101-000$ & 1.015 & 6878 \\
\hline
\end{tabular}

\#: internal data identification set to $\mathbf{T 1 9}$

Table 4. Scaling factors applied to ${ }^{16} \mathrm{O}_{3}$ intensities and number of affected lines in GEISA2020 for the three spectral regions considered. 
In total, 81773 (sum of $\mathbf{M 1 9}$ and $\mathbf{T 1 9}$ ) transitions of ${ }^{16} \mathrm{O}_{3}$ were inserted in GEISA-2020 that correspond to the integrated absorption (sum of line intensities) $\mathrm{S}_{\text {tot }}=1.5983 \mathrm{E}-17$ $\mathrm{cm} /$ molecule at $296 \mathrm{~K}$.

(ii) Ozone isotopic species

A significant update was also carried out for the ozone isotopologues ${ }^{16} \mathrm{O}^{16} \mathrm{O}^{18} \mathrm{O}$, ${ }^{16} \mathrm{O}^{16} \mathrm{O}^{17} \mathrm{O}$, and ${ }^{16} \mathrm{O}^{17} \mathrm{O}^{16} \mathrm{O}$, using linelists obtained from the analyses of Reims FTS spectra $[49,50]$ with the internal data identification set to $\boldsymbol{T} 19$.

For the asymmetric ${ }^{18} \mathrm{O}$ enriched isotopologues ${ }^{16} \mathrm{O}^{16} \mathrm{O}^{18} \mathrm{O}$ the 49148 lines of thirteen bands in the spectral range $961-3164 \mathrm{~cm}^{-1}$ are concerned by these changes with the integrated band intensity (sum of all lines) $\mathrm{S}_{\text {tot }}=6.101 \times 10^{-20} \mathrm{~cm} / \mathrm{molecule}$ at $296 \mathrm{~K}$ for the natural isotopic abundance [35]. Six bands are new with respect to GEISA-2015: these are $2 v_{2}$ and the second dyad bands $v_{2}+v_{3} / v_{1}+v_{2}$ in the range $1342-1894 \mathrm{~cm}^{-1}$, as well as $3 v_{3} / v_{1}+2 v_{3} / 2 v_{1}+v_{3}$ in the range $2930-3164 \mathrm{~cm}^{-1}$. The contributions for new bands of 668 are collected in Table 5 .

\begin{tabular}{cccc}
\hline Band & \#lines & Spectral range $\left(\mathrm{cm}^{-1}\right)$ & $\mathrm{S}_{\mathrm{tot}}{ }^{*}(\mathrm{~cm} /$ molecule $)$ \\
\hline $020-000$ & 505 & $1342.895-1398.807$ & $7.706 \mathrm{E}-25$ \\
$011-000$ & 2474 & $1644.367-1720.541$ & $2.033 \mathrm{E}-22$ \\
$110-000$ & 4188 & $1663.383-1894.671$ & $6.376 \mathrm{E}-23$ \\
$003-000$ & 1562 & $2930.525-3011.532$ & $4.316 \mathrm{E}-22$ \\
$102-000$ & 3241 & $2965.774-3123.188$ & $1.221 \mathrm{E}-22$ \\
$201-000$ & 1940 & $3103.035-3164.883$ & $3.782 \mathrm{E}-23$ \\
\hline
\end{tabular}

${ }^{*}$ Line intensities are given for the natural abundance of 0.00398194 .

Table 5. New bands of ozone ${ }^{16} \mathrm{O}^{16} \mathrm{O}^{18} \mathrm{O}$ species [50] in GEISA-2020. \#lines: Number of transitions, $\mathrm{S}_{\text {tot }}$ is the sum of the line intensities.

Another seven bands of ${ }^{16} \mathrm{O}^{16} \mathrm{O}^{18} \mathrm{O}$ were updated with respect to the previous GEISA release. This includes the first dyad $v_{1} / v_{3}\left(961-1187 \mathrm{~cm}^{-1}\right)$ and the first triad bands $2 v_{3} / v_{1}+v_{3} / 2 v_{1}\left(1897-2274 \mathrm{~cm}^{-1}\right)$, were the resonance interaction parameters have been predicted by contact transformation method using MOL_CT code [51] from the potential energy surface in order to separate resonance contributions in the A-type and B-type sub-bands [50]. The line position and intensity values were updated for 4076 transitions of cold $v_{1}+v_{2}+v_{3}$ $\left(2701-2767 \mathrm{~cm}^{-1}\right)$ and of hot $v_{1}+v_{2}+v_{3}-v_{2}\left(2015-2084 \mathrm{~cm}^{-1}\right)$ bands.

Four bands of ${ }^{17} \mathrm{O}$ enriched species were updated according new analyses of Ref. [49]. For the asymmetric ${ }^{16} \mathrm{O}^{16} \mathrm{O}^{17} \mathrm{O}$ isotopologue 2135 transitions of the $v_{1}+v_{3}\left(2045-2121 \mathrm{~cm}^{-1}\right)$ were updated, whereas for the symmetric ${ }^{16} \mathrm{O}^{17} \mathrm{O}^{16} \mathrm{O}$ species 2148 transitions of two 
fundamentals $v_{1} / v_{3}\left(968-1054 \mathrm{~cm}^{-1}\right)$ and the strongest combination band $v_{1}+v_{3}(2029-2101$ $\mathrm{cm}^{-1}$ ) were updated. The integrated absorption of these inserted lines of ${ }^{17} \mathrm{O}$ enriched species corresponds to $\mathrm{S}_{\mathrm{tot}}=5.768 \mathrm{E}-21 \mathrm{~cm} /$ molecule at $296 \mathrm{~K}$ for a sample in the natural isotopic abundance.

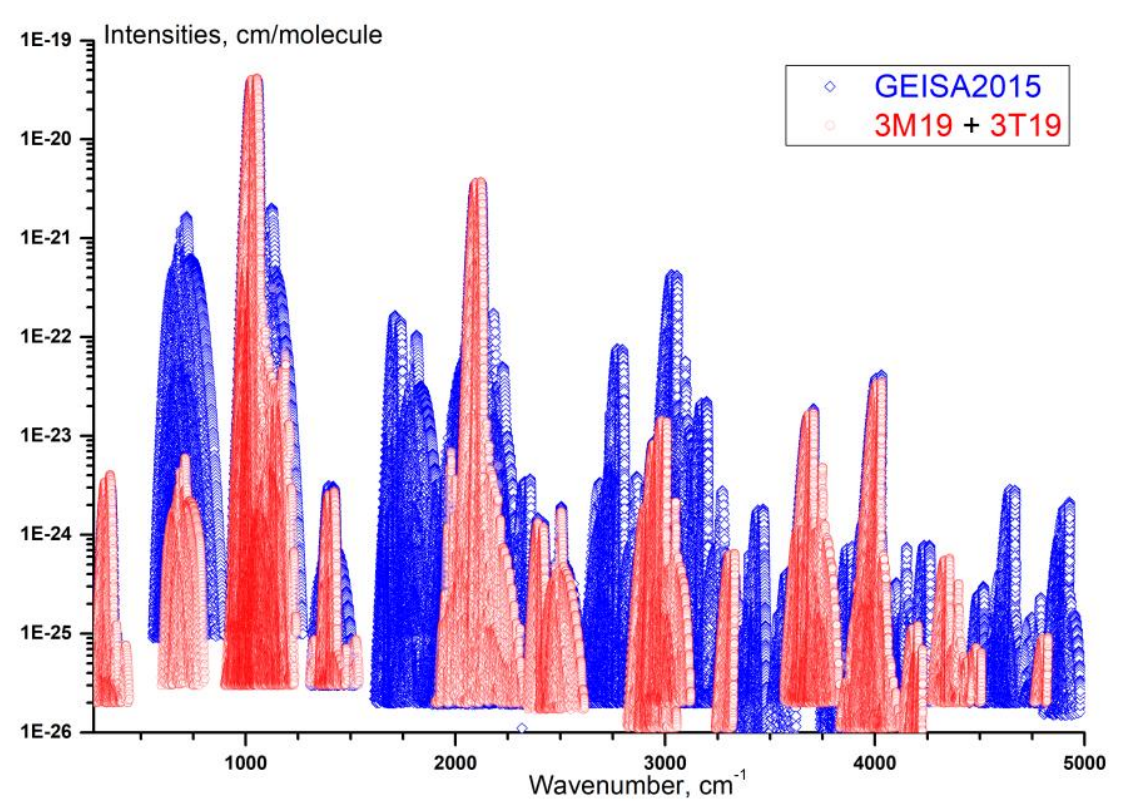

Figure 2: Overview of the updated ${ }^{16} \mathrm{O}_{3}$ lines added to GEISA 2020 (red circles), compared to the previous $\mathrm{O}_{3}$ linelist of GEISA2015 (blue diamonds).

\subsection{4 $\mathrm{N}_{2} \mathrm{O}$ (molecule 4)}

Since GEISA-2011 (no update in the GEISA-2015 version), two contributions have been studied. The first one comes from the work of Tashkun et al [52,53]. This update concerns lines with intensities at least 3 orders of magnitude lower than those in the former database. With such low values of the intensities, it is difficult to make an evaluation of the line list with the SPARTE chain. Combined to the fact, as mentioned in HITRAN 2016, that "For the line intensities from these line lists, the uncertainty code 3 (> 20\%) is adopted. ", we have decided not to retain these data for GEISA-2020 and to wait for eventual new data in 2021.

Finally, only a small update has been performed: line intensities, Einstein-A coefficients, selfand air-induced broadening parameters of the R-branch lines of the $00^{0} 2-00^{0} 0$ band of ${ }^{14} \mathrm{~N}^{14} \mathrm{~N}^{16} \mathrm{O}$ have been updated using the values in references [54], [55] and [56]. This represents 41 lines between 4418.201960 and $4439.791160 \mathrm{~cm}^{-1}$. For all these lines, the pressure shift parameters were kept unchanged from the former version of GEISA.

The corresponding internal code J has been set to $\mathbf{L 1 9}$. 


\subsubsection{CO (molecule 5)}

The new CO line list originates from the work of Li et al. [57]. In this paper, a small incompatibility issue between the definition of potential curve parameters in the LEVEL 8.0 program [58] and in the work of Coxon et al. [59] causes drifts in line positions of up to 0.03 $\mathrm{cm}^{-1}$ for high $J$ lines of the high overtone and hot bands. As discussed by Medvedev et al. [60][61], using $\mathrm{CO}$ as an example, the intensities of Li et al. initially dropped with the wavenumber exponentially as they should. However, after that plateau-like structures in dipole moment curve, their intensity calculations started to generate very small intensities $\left(<10^{-40} \mathrm{~cm}\right.$. molecule ${ }^{-1}$ ), which suggested artefacts in their dipole at very high vibrational excitations. Therefore, applying an intensity cutoff was necessary. This issue has been fixed, and the calculated line positions now agree very well with the experimental values. A few other minor changes to the original $\mathrm{Li}$ et al. line list [57] have been discussed and described in HITRAN2016 paper [2] and are also adopted here, resulting in an identical CO line list between HITRAN2016 and GEISA-2020. It corresponds to a total of 5381 lines updated between 3.401910 and $14477.377142 \mathrm{~cm}^{-1}$, of which 1470 are new lines.

The internal GEISA code for the data identification has been set to $\mathbf{L 1 9}$.

\subsection{6 $\mathrm{CH}_{4}$ (molecule 6)}

The new list of $\mathrm{CH}_{4}$ lines in the $5300-5850 \mathrm{~cm}^{-1}$ range of the tetradecad, based on the work of Nikitin et al. [62]-[63], contains more than 15000 transitions, a significant part of which includes quantum identifications. Line positions and intensities have been retrieved by nonlinear least square curve-fitting procedures from observed spectra recorded for different temperatures and pressures. The spectra in the 5695-5859 $\mathrm{cm}^{-1}$ range [62] were recorded in Grenoble (France) at room temperature and $80 \mathrm{~K}$, by differential absorption spectroscopy (DAS) with a noise equivalent absorption of about $\alpha_{\min } \approx 1.5 \times 10^{-7} \mathrm{~cm}^{-1}$ (except the 5718.8-5724.25 and 5792.36-5814.29 $\mathrm{cm}^{-1}$ intervals). In the 5300- $5695 \mathrm{~cm}^{-1}$ range [64] [63], long path (202, 602, 1604 and $1804 \mathrm{~m}$ ) room temperature spectra of natural methane samples at different pressures were recorded with a Fourier transform spectrometer in Reims (France). One cold spectrum of enriched ${ }^{12} \mathrm{CH}_{4}$ at $80 \mathrm{~K}$ has been recorded in Jet Propulsion Laboratory (JPL, Pasadena, USA). This spectrum was useful for low- $J$ line positions. Another cold spectrum at $80 \mathrm{~K}$ of enriched ${ }^{13} \mathrm{CH}_{4}$ from JPL was used to identify the isotopic species lines. Quantum assignments were made using the effective Hamiltonian based on high order contact transformation [65] and the effective dipole moment expressed in terms of irreducible tensor operators adapted to spherical top molecules. Self-broadening and air-broadening coefficient from $[66,67]$ were added to the 
final line list. In total, 8192 lines have been updated between 5300.147847 and 5849.825960 $\mathrm{cm}^{-1}$.

The corresponding internal code $\mathrm{J}$ has been set to $\mathrm{N19}$.

New data for ${ }^{13} \mathrm{CH}_{4}$ in the $2 v_{3}$ band were also implemented, based on the work of Starikova et al. [68]. This line list was generated using the line list retrieved from DAS spectra recorded at $80 \mathrm{~K}$ and room temperature. Assignments were transferred from the cold spectrum analysis of Ref. [68]. The broadening coefficients were calculated according to the methodology used for the GOSAT project $[66,67]$. When no quantitative information was determined, a default value of the lower energy level of $-0.9999 \mathrm{~cm}^{-1}$ is given (cf. Appendix B) while corresponding default values for the air- and self- broadening coefficients are $0.08100 \mathrm{~cm}^{-1} \mathrm{~atm}^{-1}$ and $0.06030 \mathrm{~cm}^{-1} \mathrm{~atm}^{-}$ ${ }^{1}$, respectively, and an air-shifting coefficient of $-0.012 \mathrm{~cm}^{-1} \mathrm{~atm}^{-1}$ is adopted. 7195 lines have thus been updated between 5853.282300 and $6200.882900 \mathrm{~cm}^{-1}$.

The corresponding internal code J has been set to $\boldsymbol{S 1 9}$.

\subsection{7 $\mathrm{O}_{2}$ (molecule 7)}

No major update was made for the $\mathrm{O}_{2}$ molecule, the main reason being that recent studies mainly considered non-Voigt profiles for the line-shape determination. However, the work from Tran et al. [69] in the ${ }^{a^{\mathbf{1}} \boldsymbol{\Lambda}_{g}-X^{\mathbf{3}} \Sigma_{\mathrm{g}}^{-}(\mathbf{0}-\mathbf{0})}$ band of $\mathrm{O}_{2}$ centered at $1.27 \mu \mathrm{m}$, and tested by comparison with high-resolution ground-based atmospheric TCCON measurements, highlighted systematic errors using air-broadened line-shift parameters from the GEISA-2015 or HITRAN 2016 databases. Therefore, we decided to partially update the GEISA-2020 database, considering only the new line intensities, line positions and air-broadened line-shift parameters determined in the work of Tran et al. [70] (cf. section 3.1.2 for an illustrative validation of these $\mathrm{O}_{2}$ data using TCCON measurements). Parameters for 223 air-broadened transitions, from 7784.797157 to $7915.856072 \mathrm{~cm}^{-1}$, were retrieved from spectra measured by a cavity ring down spectrometer referenced to a frequency comb, for a large range of pressure values, from 6.7 to $94 \mathrm{kPa}$ (50 to 700 Torr). The data published in the work of Tran et al. were originally determined using the quadratic speed dependent Nelkin-Ghatak (qsdNG) profile, but for the GEISA-2020 update (which is currently limited to Voigt profile parameters) the authors also refitted these lines using Voigt profiles from which the new air-broadened line-shift parameters are derived (unpublished data).

The corresponding internal code $\mathrm{J}$ has been set to $\boldsymbol{T} 19$. 


\subsection{8 $\mathrm{SO}_{2}$ (molecule 9)}

The ${ }^{32} \mathrm{~S}^{16} \mathrm{O}_{2}$ empirical list is mainly based on the experimental energy levels recently derived in [71] and variational intensities presented in [72]. In addition to experimental energy levels derived in [71], the new experimental energy levels obtained from the analysis of Fourier transform spectra of $\mathrm{SO}_{2}$ by ExoMol [73] were also used. In parallel with pure experimental energy levels, the predicted energy levels obtained from the effective Hamiltonian calculations performed in [71] were used for evaluation of the line positions.

Most part of the line positions (63\%) have an estimated accuracy between 0.0001 and 0.001 $\mathrm{cm}^{-1}$ in accordance with the uncertainties of the corresponding experimental energy levels reported in [71]. For 185,637 transitions (34\%) derived from the calculated energy levels the positions accuracy corresponds to the $0.001-0.01 \mathrm{~cm}^{-1}$ error range. In case of the (110)-(000), (011)-(000), (101)-(000), (111)-(010) bands the calculated intensities [72] are substituted by the recent experimental data [74],[75] when available. We estimate the quality of variational intensities as $5-10 \%$ on average.

The resulting empirical list of ${ }^{32} \mathrm{~S}^{16} \mathrm{O}_{2}$ transitions was compared both with the HITRAN 2016 database and a recent study [76] performed by the AMES group at NASA where the similar empirical lists for $\mathrm{SO}_{2}$ isotopologues have been reported based on the experimental energy levels [71] and new variational calculations. Disagreements between GEISA and HITRAN's line positions amount up to $0.01-0.16 \mathrm{~cm}^{-1}$ for 3308 lines. The calculated intensities [72] adopted in our empirical list also may differ from the HITRAN data by up to $40 \%$ for relatively strong lines and disagree by up to $60-100 \%$ for weakest lines. A comparison of our list with HITRAN and AMES data [76] is shown in Figure 3 (note that HITRAN2016 and GEISA-2015 line lists are comparable, so only HITRAN2016 is plotted, as in the original publication). It is obvious from the figure that the presently generated empirical list for ${ }^{32} \mathrm{~S}^{16} \mathrm{O}_{2}$ molecule includes a considerably large number of lines, including very strong ones (up to $5 \mathrm{E}^{-20} \mathrm{~cm} / \mathrm{molecule}$ ). Air-broadening coefficients were set to a default value of $0.11 \mathrm{~cm}^{-1} / \mathrm{atm}$, as in previous versions of GEISA. In total 549,200 lines have been added or updated between 0.035669 and $4159.945167 \mathrm{~cm}^{-1}$ 


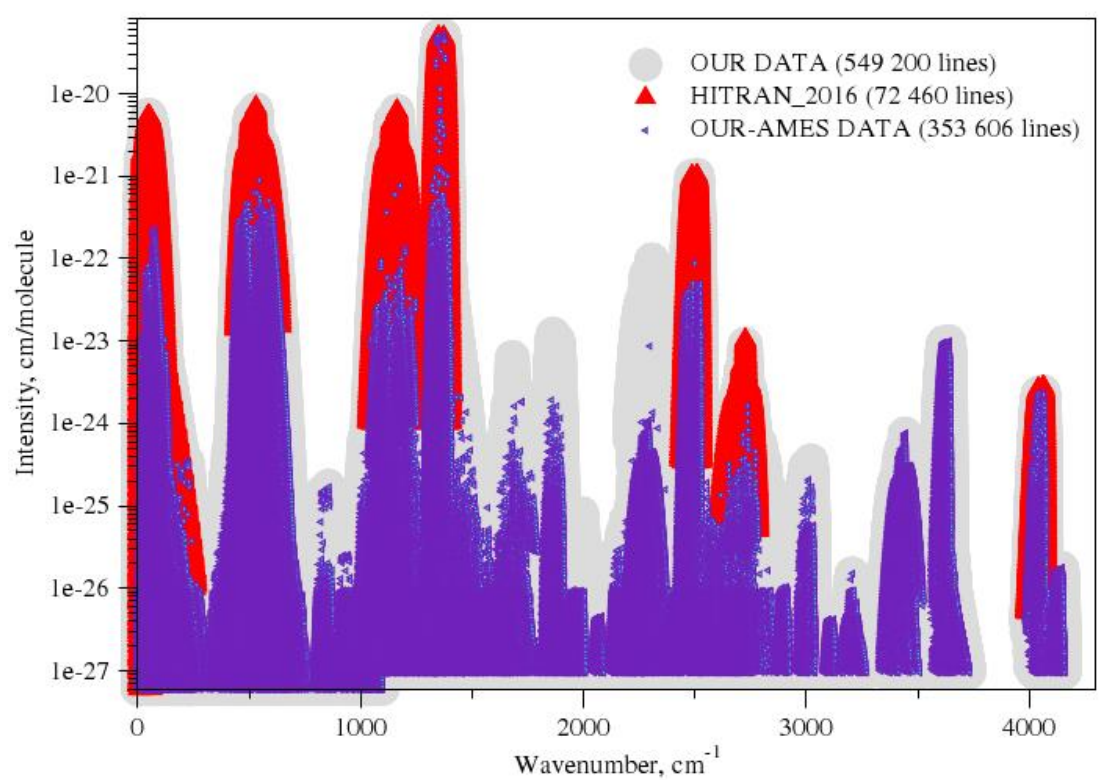

Figure 3: Comparison of the new empirical list for ${ }^{32} \mathrm{~S}^{16} \mathrm{O}_{2}$ molecule with the HITRAN 2016 (comparable to GEISA-2015 line list) and Ames [76] data.

The internal GEISA codes for the data identification have been set to:

- 1N9: positions are determined from the upper and lower experimental energy levels, intensities are calculated (variational) from [72].

- 2N9: positions are determined from the upper and lower experimental energy levels, intensities are experimental from [74].

- 3N9: positions are determined from the upper and lower experimental energy levels, intensities are experimental from [75].

- 4N9: one of the two energy levels (or both) used for position determination is predicted by the effective Hamiltonian calculation, intensities are calculated (variational) from [72].

- 5N9: pure experimental value is taken for most accurate position.

\subsection{9 $\mathrm{NO}_{2}($ molecule 10)}

For nitrogen dioxide the previous GEISA compilation included over $100,000{ }^{14} \mathrm{~N}^{16} \mathrm{O}_{2}$ lines covering 0-3074 $\mathrm{cm}^{-1}$. The new list includes 185,965 lines and covers the $0-4776 \mathrm{~cm}^{-1}$ spectral range. This new list includes lines from both the ${ }^{14} \mathrm{~N}^{16} \mathrm{O}_{2}$ and ${ }^{15} \mathrm{~N}^{16} \mathrm{O}_{2}$ isotopic species.

In two recent studies [77], [78], a list of line positions, line intensities and line shape parameters of $\mathrm{NO}_{2}$ covering the 0 to $4776 \mathrm{~cm}^{-1}$ spectral range was generated. Except for the far infrared and the $13.3 \mu \mathrm{m}$ regions, all bands in all spectral regions are significantly affected by this update. For the $6.2 \mu \mathrm{m}$ and $3.4 \mu \mathrm{m}$ spectral regions, the new list involves the main cold bands $\left(v_{1}, 2 v_{2}\right.$ and $v_{3}$ and $v_{1}+v_{3}$, respectively) together with their associated first hot bands (originating from the $(0,1,0)$ first vibrational state), and, whenever possible, hot bands 
(involving the $(1,0,0),(0,2,0)$ and $(0,0,1),(1,1,0),(2,0,0)$ or $(0,0,2)$ states as lower states). Also several weak cold bands $\left(v_{1}+v_{2}, v_{2}+v_{3}, 2 v_{1}, 2 v_{2}+v_{3}, 2 v_{3}, 2 v_{2}+v_{3}, v_{1}+v_{2}+v_{3}, 2 v_{1}+v_{3}\right.$, and $3 v_{3}$ ) were added for the first time in the GEISA database. Finally we included the $v_{3}$ [79] and $v_{1}+v_{3}$ [80] bands for ${ }^{15} \mathrm{~N}^{16} \mathrm{O}_{2}$ which is the second most abundant isotopologue of $\mathrm{NO}_{2}$ [23]. These new lists were generated using existing literature line positions or intensity parameters. When necessary, these parameters were updated using experimental data issued from high resolution Fourier transform spectra recorded at SOLEIL at 296K for this purpose [77], [78]. Also, the line broadening parameters were computed using the line shape parameters achieved for the $v_{3}$ band by Benner et al. [81].

Figure 4 gives an overview of cross sections calculated from the list of $\mathrm{NO}_{2}$ line parameters in GEISA-2020 for the $1000-4780 \mathrm{~cm}^{-1}$ spectral range and compares it to the status of HITEMP2019 [82] and of HITRAN-2016 or GEISA-2015 (old GEISA).

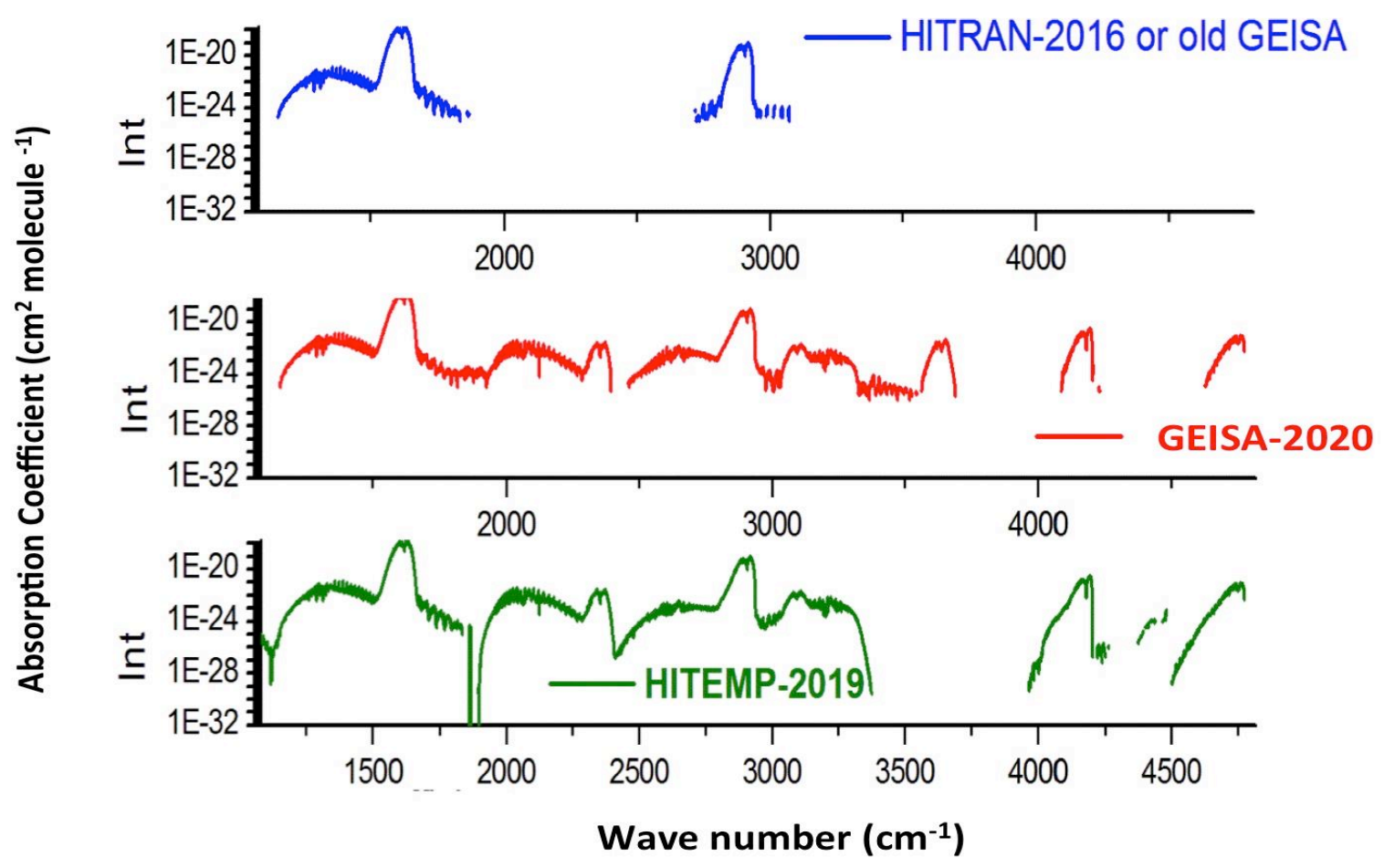

Figure 4: Calculated absorption cross sections of $\mathrm{NO}_{2}$ at $296 \mathrm{~K}$ using line lists from HITRAN-2016/GEISA-2015 (old GEISA), HITEMP-2019 and GEISA-2020.

The validation of this new update, which concerns the $1153-4776 \mathrm{~cm}^{-1}$ region, was performed through a careful comparison between computed and observed spectra using laboratory spectra recorded either during recent investigations [78], [77] or during previous analyses of the literature (see Refs. [78], [77] for detailed references). In parallel, similar inter comparisons at $\mathrm{T}=296 \mathrm{~K}$ were also performed using the most recent versions (HITRAN-2020 and HITEMP2019) of the HITRAN and HITEMP databases [82]. The results of these investigations prove 
that, for each vibrational bands, the individual lines in GEISA-2020 are more precise than those included in HITRAN-2020 or HITEMP-2019 (or those of previous versions). Concerning the number of vibrational bands, the GEISA linelist is also more extended than HITRAN-2020, but less than HITEMP-2019 which is generated for hot temperature conditions and includes lines involving very high rotational quantum numbers (up to $\mathrm{N}=100$ ) and a significant number of additional hot bands when compared to GEISA-2020. In total 185965 lines were added or updated in the $0.497999-4775.314437 \mathrm{~cm}^{-1}$ spectral range.

The internal GEISA code for the data identification has been set to $\boldsymbol{P 1 9}$.

\subsubsection{0 $\mathrm{NH}_{3}$ (molecule 11)}

GEISA-2020 includes, for the first time, a line list at $3.0 \mu \mathrm{m}$ for the first-most abundant isotopologue of ammonia, ${ }^{14} \mathrm{NH}_{3}$. The $2 v_{4}$ vibrational band for this isotopologue was added using a high resolution Fourier transform investigation performed at $3.0 \mu \mathrm{m}$ by Maaroufi et al. [83]. Absolute line intensities and self-broadening and shift coefficients were measured at room temperature, for rovibrational lines ranging from $1 \leq J \leq 11$ and $0 \leq K \leq 11$, and located in the spectral range $3078.80407-3532.50519 \mathrm{~cm}^{-1}$. This represents a total of 298 entries. The lines were fitted with a single spectrum non-linear least squares fitting procedure with a Voigt profile suited to fit the experimental line shapes without the need of considering line mixing effects, in the pressure range used. Mean accuracies of the measurements are estimated to $\pm 4 \%$ for line intensities and self-broadening coefficients and to $\pm 13 \%$ for self-shift coefficients.

The $J$ and $K$ dependences of the self-broadening coefficients $\left(\gamma_{0}\right)$ were observed and modeled using an empirical polynomial expression suggested by Nemtchinov et al. [84]:

$\gamma_{0}(m, K)=\beta_{0}+\beta_{1} m+\beta_{2} K+\beta_{3} m^{2}+\beta_{4} K^{2}+\beta_{5} m K$

where $m=|-J, J, J+1|$ for $P, Q$ and $R$ branches, and $\beta_{i}$ are the polynomial coefficients. The polynomial expression reproduced the observed self-broadening coefficients within an average accuracy of $9.6 \%$ for the $2 v_{4}$ band of ${ }^{14} \mathrm{NH}_{3}$ [83]. In total, 298 lines were added or updated between 3078.804070 and $3532.505190 \mathrm{~cm}^{-1}$.

The internal GEISA code for the data identification has been set to M19.

\subsubsection{1 $\mathrm{PH}_{3}$ (molecule 12)}

The $\mathrm{PH}_{3}$ line list in the $2733-3660 \mathrm{~cm}^{-1}$ range is based on an improved analysis of positions and intensities of phosphine spectral lines from Nikitin et al. [85]. Some 5768 positions and 1752 
intensities have been modeled with RMS deviations of $0.00185 \mathrm{~cm}^{-1}$ and $10.9 \%$, respectively. Based on an $a b$ initio potential energy surface, the full Hamiltonian of phosphine nuclear motion was reduced to an effective Hamiltonian using a high-order Contact Transformations method adapted to polyads of symmetric top $\mathrm{AB}_{3}$-type molecules with a subsequent empirical optimization of parameters. The line list also contains more than 2000 new ro-vibrational assignments for all 13 vibrational octad sublevels. A comparison of this line list with experimental spectra of PNNL [86] showed that the new set of line parameters from this work permits better simulations of observed cross-sections than GEISA-2015 or HITRAN 2016 linelists. Vibrational assignments were also added to current the GEISA line list. In total 18283 lines were added or updated between 2733.587100 and $3659.265700 \mathrm{~cm}^{-1}$.

The internal GEISA code for the data identification has been set to N19.

\subsubsection{2 $\mathrm{HNO}_{3}$ (molecule 13)}

A new investigation of laboratory spectra of nitric acid in the $7.6 \mu \mathrm{m}$ region was performed using a suitable theoretical model which involves six interacting states, instead of two in the previous computation [87]. In this way, an improved set of line positions and intensities have been generated for the $7.6 \mu \mathrm{m}$ spectral region. This new list, which includes also the $v_{3}+v_{9}-v_{9}$ for the first time was validated using atmospheric spectra recorded by the Michelson Interferometer for Passive Atmospheric Sounding (MIPAS) limb emission radiances in the 11 and $7.6 \mu \mathrm{m}$ domains [88]. Table 6 describes the new list for $\mathrm{HNO}_{3}$ and compares with the list included in GEISA-2015. In total 87906 lines have been added or updated between 1233.107220 and $1395.679470 \mathrm{~cm}^{-1}$. Note that the GEISA-2015 line list was largely extrapolated to high- $J$ value lines, characterized by significant uncertainties; we chose to limit the extrapolation for the GEISA-2020 list, explaining the reduction of the number of lines in the $v_{3}$ and $v_{4}$ bands.

Table 6: $\mathrm{HNO}_{3}$ line parameters in the $7.6 \mu \mathrm{m}$ region [\#lines is the number of lines, $\sigma_{\min }$ and $\sigma_{\max }\left(\mathrm{cm}^{-1}\right)$ are the lower and upper limits, $S_{\min }$ and $S_{\max }$ are the smallest and largest line intensity $\left(\mathrm{cm}^{-1} /\left\{\right.\right.$ molecule $\left.\mathrm{cm}^{2}\right\}$ at $\left.296 \mathrm{~K}\right)$ and $\mathrm{S}_{\text {tot }}$ is the sum of the line intensities]

\begin{tabular}{ccccccc}
\hline Band & \#lines & $\begin{array}{c}\mathrm{S}_{\text {tot }} \\
\left(10^{-18}\right)\end{array}$ & $\sigma_{\min }$ & $\sigma_{\max }$ & $\begin{array}{c}\mathrm{S}_{\min } \\
\left(10^{-25}\right)\end{array}$ & $\begin{array}{c}\mathrm{S}_{\max } \\
\left(10^{-21}\right)\end{array}$ \\
\hline \multicolumn{7}{c}{ GEISA-2020 database } \\
\hline$v_{3}$ & 16408 & 24.94 & 1252.010 & 1387.081 & 4.910 & 32.0
\end{tabular}




\begin{tabular}{ccccccc}
$v_{4}$ & 18105 & 9.834 & 1238.929 & 1387.561 & 4.020 & 21.4 \\
$2 v_{6}$ & 2451 & 0.1194 & 1243.465 & 1348.275 & 4.624 & 3.660 \\
$v_{5}+v_{9}$ & 13817 & 0.7163 & 1246.929 & 1390.071 & 2.081 & 3.543 \\
$v_{7}+v_{8}$ & 11125 & 0.7615 & 1246.422 & 1395.679 & 2.314 & 5.017 \\
$3 v_{9}$ & 13894 & 1.177 & 1233.107 & 1388.497 & 4.582 & 2.378 \\
\hline Sum & 12106 & 1.408 & 1271.050 & 1394.899 & 5.285 & 1.798 \\
\hline$v_{3}+v_{9}-v_{9}$ & & GEISA-2015 database & & \\
\hline & 21308 & 25.37 & 1098.376 & 1387.849 & 1.037 & 31.33 \\
\hline$v_{3}$ & 19584 & 12.78 & 1229.867 & 1387.561 & 1.037 & 18.67 \\
\hline$v_{4}$ & & 38.15 & & & \\
\hline Sum & & & & & \\
\hline
\end{tabular}

The Internal GEISA code for these data identification has been set to $\boldsymbol{P 1 9}$.

\subsubsection{Hydrogen Halides $\mathrm{HF}, \mathrm{HCl}, \mathrm{HBr}, \mathrm{HI}$ (resp. molecule 15, 16, 17 and 18)}

The new hydrogen halides line lists originate from refs. [89] and [90], with higher overtone bands removed due to abnormalities when intensities were extrapolated outside of experimental temperature and pressure ranges - the latter being particularly important for $\mathrm{HCl}$ which is known to have intensity depletion effects at higher pressures due to collisions induced effects. For the first time in GEISA, deuterated isotopologues of hydrogen halides $\mathrm{D}^{19} \mathrm{~F}, \mathrm{D}^{35} \mathrm{Cl}, \mathrm{D}^{37} \mathrm{Cl}$, $\mathrm{D}^{79} \mathrm{Br}, \mathrm{D}^{81} \mathrm{Br}$, and $\mathrm{D}^{127} \mathrm{I}$ have been implemented. Except for the 2-0 band of $\mathrm{HCl}$, the $\mathrm{HX}$ line lists are identical to those in HITRAN2016. For P10 to R10 lines of the HCl 2-0 band, line intensities, Einstein A-coefficients and self-induced broadenings have been updated with reference [91], whilst air-induced broadenings and shifts have been updated with reference [92]. The following spectral ranges were updated in GEISA-2020 for the four species: 13.620106 $32351.592077 \mathrm{~cm}^{-1}$ for HF (20010 lines), $5.341824-20231.245131 \mathrm{~cm}^{-1}$ for $\mathrm{HCl}$ (53252 lines), $7.656152-16033.492029 \mathrm{~cm}^{-1}$ for $\mathrm{HBr}\left(8980\right.$ lines) and $5.887799-13907.688695 \mathrm{~cm}^{-1}$ for $\mathrm{HI}$ (4751 lines).

The Internal GEISA code for these data identification has been set to $\mathbf{L 1 9}$.

\subsubsection{OCS (molecule 20)}

The $5 \mu \mathrm{m}$ spectral region is used to monitor OCS [93], which is the most abundant sulfur reservoir species in the Earth atmosphere. In the last years, Cavity Ring Down Spectroscopy 
made the near infrared spectral range more and more attractive, especially for the in situ detection of trace gases [94].

Firstly, the line list used in the HITRAN2016 database [2] has been adopted in the new GEISA2020 release. This line list was derived from Fourier transform spectra of OCS recorded in the $6170-6680 \mathrm{~cm}^{-1}$ (dominated by the $3 v_{1}+2 v_{3}$ band) and $7700-8160 \mathrm{~cm}^{-1}$ (dominated by the $2 v_{1}+3 v_{3}$ band) spectral ranges using a femto/OPO laser absorption source and cavity enhanced spectroscopy [95]. It contains 3670 lines in the ranges $6484-6660 \mathrm{~cm}^{-1}$ and $7728-7821 \mathrm{~cm}^{-}$ 1. The accuracies of the line positions and intensities (parameters A' and B', see Appendix B) have been estimated to be at best $0.001 \mathrm{~cm}^{-1}$ and 10 to $20 \%$, respectively. In total 3670 lines were added or updated in the $6484.533500-7821.108700 \mathrm{~cm}^{-1}$ spectral range.

The Internal GEISA code for these data identification has been set to $\boldsymbol{A 1 6}$.

Secondly, 104 new spectroscopic line parameters for the main isotopologue ${ }^{16} \mathrm{O}^{12} \mathrm{C}^{32} \mathrm{~S}$ have been included in GEISA-2020. The update focuses on the broadening and shift coefficients in the $4 v_{2}$ band of OCS perturbed by $\mathrm{N}_{2}, \mathrm{O}_{2}$ and Air, measured and calculated at room temperature, in the spectral region $2087.4280-2130.7584 \mathrm{~cm}^{-1}$. These data, which were derived from high resolution Fourier transform spectra, are rather accurate: the uncertainties can be estimated to be $\sim 3 \%$ for the broadening coefficients and $\sim 10 \%$ for the shift coefficients [96]. In addition, theoretical calculations of broadening and line shift coefficients were performed, using the semi classical Robert and Bonamy formalism that reproduces fairly well the experimental quantum number dependence, $m$, for the $\mathrm{N}_{2}$ and $\mathrm{O}_{2}$ broadening coefficients.

The Internal GEISA code for these data identification has been set to $\boldsymbol{G 1 9}$.

\subsubsection{5 $\mathrm{C}_{2} \mathrm{H}_{6}$ (molecule 22)}

As forecasted in GEISA-2015, the data from Moazzen-Ahmadi et al. [97] have been incorporated in GEISA-2020, with no further update since the data set listed in HITRAN 2016 [2]. To sum up, 11938 lines were added or updated between 225.044600 and $320.966100 \mathrm{~cm}^{-1}$.

The internal GEISA code for these data identification has been set to $\mathbf{M 1 9}$.

\subsubsection{6 $\mathrm{C}_{2} \mathrm{H}_{2}$ (molecule 24)}

The GEISA-2020 list of acetylene has been significantly extended compared to the GEISA2015 version [1] (see Figure 5). The changes concern four spectral regions. Three line lists in 
the far-infrared and infrared domains $\left(\Delta P=0\right.$ between 13 and $248 \mathrm{~cm}^{-1}, \Delta P=1$ between 389 and $893 \mathrm{~cm}^{-1}$ and $\Delta P=6$ between 3738 and $3993 \mathrm{~cm}^{-1}$ ) were generated based on the global model developed by Lyulin and Perevalov [98][99]. Here $P$ is a polyad number defined as $P=$ $5 \mathrm{~V}_{1}+3 \mathrm{~V}_{2}+5 \mathrm{~V}_{3}+\mathrm{V}_{4}+\mathrm{V}_{5}$ where $\mathrm{V}_{\mathrm{i}}=1-5$ are the main quantum numbers of the $\mathrm{C}_{2} \mathrm{H}_{2}$ harmonic oscillator. The prediction capability of the model in the $\Delta P=0,1$ regions was investigated experimentally in $[100,101]$ leading to line lists of calculated positions and intensities for the $\Delta P=0$ region (5479 transitions) and for the $\Delta P=1$ region (41021 transitions). A complete description of the line lists in $\Delta P=0$ and 1 regions can be found in $[100,101]$. For the $\Delta P=6$ region around $3900 \mathrm{~cm}^{-1}$, the strong $\mathrm{Q}$ branch around $3882 \mathrm{~cm}^{-1}$ as well as other weaker structures were missing in GEISA-2015. The two strong cold bands already present in GEISA have been updated and eight bands have been added based on the global model [98][99] for line positions and intensities. A summary of updated/included bands is given in Table 7 . Note that the vibrational assignment from the global model [98][99] (linear combination of vibrational basis functions) has been reformulated in order to have a unique vibrational assignment for a series of rotational transitions.
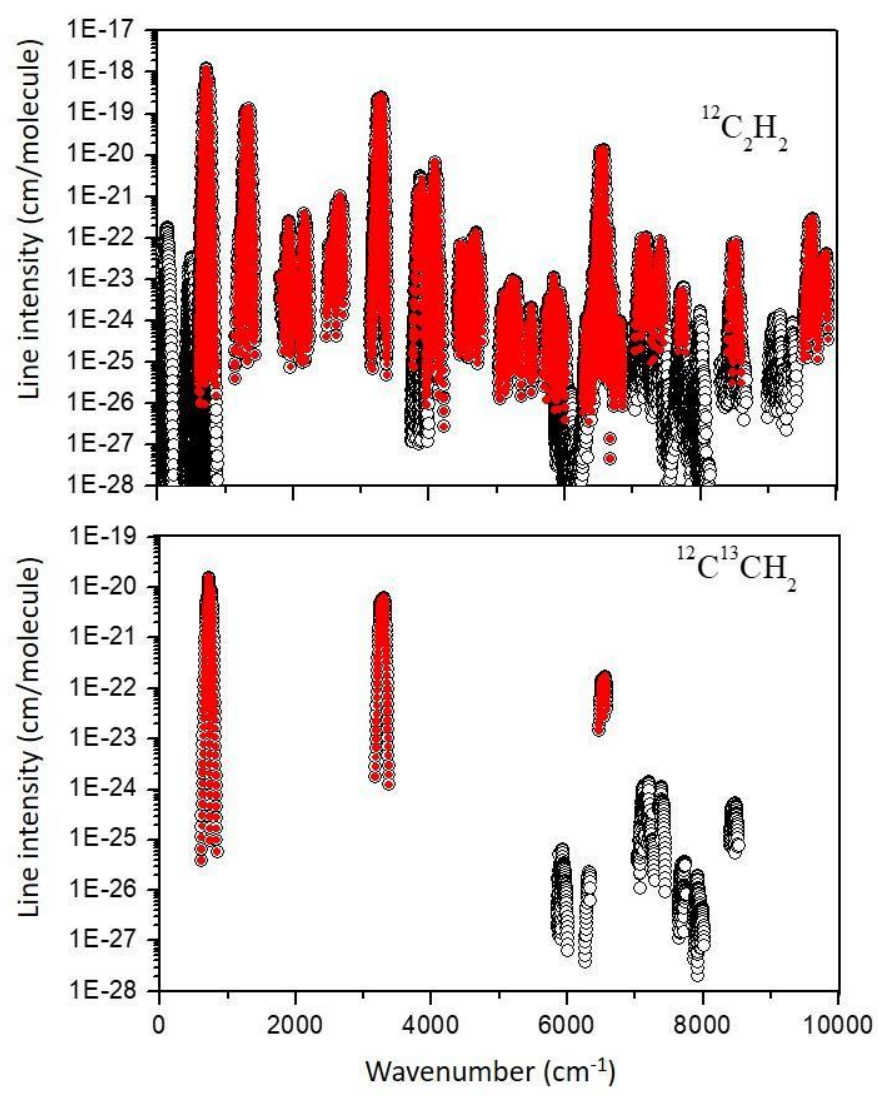

Figure 5: Overview of the GEISA-2015 (solid red circles) and GEISA-2020 (open black circles) databases for acetylene ${ }^{12} \mathrm{C}_{2} \mathrm{H}_{2}$ and ${ }^{12} \mathrm{C}^{13} \mathrm{CH}_{2}$ isotopologues.

The fourth line list is the empirical database (EDB17, hereafter) elaborated by Lyulin and Campargue [102] for the wide 5850-9415 $\mathrm{cm}^{-1}$ near-infrared region. The EDB17 covers the 
range of the $\Delta P=9-14$ series excluding the $6341-7000 \mathrm{~cm}^{-1}$ interval roughly corresponding to the $\Delta P=10$ series. The EDB17 was constructed by gathering results of three studies by Fourier transform spectroscopy [103-105] and three studies by cavity ring down spectroscopy (CRDS) [106-108]. In the regions of low absorption, the sensitivity of the CRDS technique enabled the detection of weak lines with intensities on the order of $10^{-29} \mathrm{~cm} /$ molecule. The assignment of the experimental spectra relies in great part on the predicted data of the Acetylene Spectroscopic Databank (ASD) [99]. For each branch of a given band, the line positions and line intensities were calculated for all the transitions up to a maximum $J$ value exceeding by 1 the largest $J$ value of the observations in the considered branch. Such an approach enabled smoothing the measurement errors, completing the experimental line list by interpolation and extending slightly beyond the observations. Compared to the HITRAN2016 [2] and GEISA-2015 [1] lists in the region, the number of bands and lines was increased by more than a factor of ten (see Figure 5). As a result, the EDB includes a total of 10973 lines belonging to 146 bands of ${ }^{12} \mathrm{C}_{2} \mathrm{H}_{2}$ and 29 bands of ${ }^{12} \mathrm{C}^{13} \mathrm{CH}_{2}$. For comparison the GEISA-2015 database in the same region includes 869 lines of 14 bands, all belonging to ${ }^{12} \mathrm{C}_{2} \mathrm{H}_{2}$.

For all ${ }^{12} \mathrm{C}_{2} \mathrm{H}_{2}$ and ${ }^{12} \mathrm{C}^{13} \mathrm{CH}_{2}$ isotopologues, the vibrational assignment has been changed to $\mathrm{V} 1$ $\mathrm{V} 2 \mathrm{~V} 3 \mathrm{~V} 4 \mathrm{~V} 5 \ell_{4} \ell_{5}$ from V1 V2 V3 V4 V5 $\ell$, where $\ell$ is the sum of $\ell_{4}$ and $\ell_{5}$. Indeed, the $\ell 4$ and $\ell 5$ quantum numbers are necessary to assign the various bands that include strong resonance interactions between ro-vibrational states [100-108] used to update the GEISA-2020 database. Based on the new vibrational assignment and the symmetry E/F of the rotational levels, the symmetries +/- have been generated for all transitions of both isotopologues, and symmetry $\mathrm{u} / \mathrm{g}$ have been generated only for symmetric ${ }^{12} \mathrm{C}_{2} \mathrm{H}_{2}$ isotopologue. For all transitions, Einstein- $A$ coefficients have been calculated from line intensities at $296 \mathrm{~K}$ using Eq. 20 of [109], state-independent weight $\mathrm{g}_{\mathrm{i}}=1$ and 8 respectively for ${ }^{12} \mathrm{C}_{2} \mathrm{H}_{2}$ and ${ }^{12} \mathrm{C}^{13} \mathrm{CH}_{2}$ isotopologues, and state-dependent weight $g_{s}=1$ or 3 for ${ }^{12} \mathrm{C}_{2} \mathrm{H}_{2}$ (depending on symmetries) and $\mathrm{g}_{\mathrm{s}}=1$ for ${ }^{12} \mathrm{C}^{13} \mathrm{CH}_{2}$. Total internal partition functions [110] equal to 412.45 and 1656.2 at $296 \mathrm{~K}$ have been used for the ${ }^{12} \mathrm{C}_{2} \mathrm{H}_{2}$ and ${ }^{12} \mathrm{C}^{13} \mathrm{CH}_{2}$ isotopologues respectively. Smoothed values of air-broadening coefficients (Table 5 of [111]) already in previous GEISA editions have been used for new entries since no vibrational dependence of the widths is observed.

\begin{tabular}{|c|c|c|c|c|c|c|c|c|c|c|}
\hline \multicolumn{2}{|c|}{ Vibrational Assignment } & \multirow[b]{2}{*}{ \#lines } & \multirow[b]{2}{*}{$\sigma_{\min }$} & \multirow[b]{2}{*}{$\sigma_{\max }$} & \multirow[b]{2}{*}{$S_{t o t}$} & \multirow[b]{2}{*}{$S_{\min }$} & \multirow[b]{2}{*}{$S_{\max }$} & \multirow[b]{2}{*}{$J_{\min }$} & \multirow[b]{2}{*}{$J_{\max }$} & \\
\hline Upper & Lower & & & & & & & & & \\
\hline 0011010 & 0000000 & 155 & 3738.098 & 3995.170 & $5.96 \mathrm{E}-20$ & $1.3 \mathrm{E}-27$ & $3.0 \mathrm{E}-21$ & 0 & 53 & GEISA-2015 \\
\hline $010313-1$ & 0001010 & 263 & 3744.789 & 3968.111 & $5.80 \mathrm{E}-21$ & $1.0 \mathrm{E}-27$ & $1.4 \mathrm{E}-22$ & 1 & 49 & \\
\hline $010222-2$ & 0000101 & 251 & 3749.044 & 3958.870 & $1.18 \mathrm{E}-21$ & $1.2 \mathrm{E}-27$ & $3.6 \mathrm{E}-23$ & 1 & 45 & \\
\hline $010212-1$ & 0000000 & 153 & 3752.906 & 3980.295 & $5.54 \mathrm{E}-20$ & $1.2 \mathrm{E}-27$ & $2.7 \mathrm{E}-21$ & 0 & 53 & GEISA-2015 \\
\hline 0102220 & 0000101 & 220 & 3756.621 & 3962.215 & $1.31 \mathrm{E}-21$ & $1.2 \mathrm{E}-27$ & $3.7 \mathrm{E}-23$ & 1 & 45 & \\
\hline 0012020 & 0001010 & 250 & 3770.399 & 3983.995 & $5.76 \mathrm{E}-21$ & $1.2 \mathrm{E}-27$ & $1.5 \mathrm{E}-22$ & 1 & 48 & \\
\hline 0011111 & 0000101 & 240 & 3772.294 & 3979.654 & $2.03 \mathrm{E}-21$ & $1.3 \mathrm{E}-27$ & $5.6 \mathrm{E}-23$ & 1 & 45 & \\
\hline $001111-1$ & 0000101 & 233 & 3780.389 & 3974.747 & $1.63 \mathrm{E}-21$ & $1.2 \mathrm{E}-27$ & $3.8 \mathrm{E}-23$ & 1 & 46 & \\
\hline $010311-1$ & 0001010 & 205 & 3794.438 & 3976.946 & $3.58 \mathrm{E}-21$ & $1.4 \mathrm{E}-27$ & $2.4 \mathrm{E}-22$ & 1 & 40 & \\
\hline
\end{tabular}


Table 7: Summary of bands updated or included in GEISA-2020 in the $\Delta P=6$ region. The first column corresponds to the vibrational labeling used for series of transitions (bands). \#lines is the total number of transitions belonging to a given band. Minimum and maximum wavenumbers of calculated transitions belonging to the band are given in $\mathrm{cm}^{-1}, \mathrm{~S}_{\text {tot }}$ is the sum of calculated line intensities (see text) in $\mathrm{cm}^{-1} /\left(\right.$ molecule. $\left.\mathrm{cm}^{-2}\right)$ at $296 \mathrm{~K}$ for $\mathrm{C}_{2} \mathrm{H}_{2}$ in natural abundances. $S_{\min }$ and $S_{\max }$ are respectively the minimum and maximum calculated line intensities in the band. Minimum and maximum values of $J$ in the band are given. ${ }^{3}$

For self-broadening coefficients, an improved set of parameters (given in Table 8) based on the work performed in [111] has been used for all $\mathrm{C}_{2} \mathrm{H}_{2}$ transitions in GEISA-2020. For $J$ values greater than 36 self-broadening coefficients have been fixed to $0.078 \mathrm{~cm}^{-1} / \mathrm{atm}$. Default values have been used for the temperature dependence of air-broadening coefficients (equal to 0.75 ) and for air-shifting coefficients (equal to $-0.001 \mathrm{~cm}^{-1} / \mathrm{atm}$ ).

In total, 59747 lines were added or updated in the $13.624350-9415.084280 \mathrm{~cm}^{-1}$ spectral range.

\begin{tabular}{rccccc}
\hline$m$ & $\gamma_{\text {self }}(296 \mathrm{~K})$ & $m$ & $\gamma_{\text {self }}(296 \mathrm{~K})$ & $m$ & $\gamma_{\text {self }}(296 \mathrm{~K})$ \\
\hline 1 & 0.2055 & 13 & 0.1438 & 25 & 0.1088 \\
2 & 0.1925 & 14 & 0.1407 & 26 & 0.1059 \\
3 & 0.1823 & 15 & 0.1376 & 27 & 0.1030 \\
4 & 0.1744 & 16 & 0.1347 & 28 & 0.0999 \\
5 & 0.1683 & 17 & 0.1319 & 29 & 0.0967 \\
6 & 0.1635 & 18 & 0.1291 & 30 & 0.0934 \\
7 & 0.1598 & 19 & 0.1264 & 31 & 0.0898 \\
8 & 0.1568 & 20 & 0.1225 & 32 & 0.0861 \\
9 & 0.1543 & 21 & 0.1198 & 33 & 0.0831 \\
10 & 0.1520 & 22 & 0.1171 & 34 & 0.0812 \\
11 & 0.1499 & 23 & 0.1143 & 35 & 0.0800 \\
12 & 0.1471 & 24 & 0.1117 & 36 & 0.0780 \\
\hline
\end{tabular}

Table 8: Self-broadening coefficients used in GEISA-2020 as a function of $m=|-J, J, J+1|$ for $P, Q$ and $R$ branches.

The internal GEISA code for the data identification has been set to $C 19, L 19, J 19$ and $J 20$.

\footnotetext{
${ }^{3}$ Note: The vibrational labeling for upper and lower state corresponds to $V_{1} V_{2} V_{3} V_{4} V_{5} l_{4} l_{5}$. GEISA-2015 refers to the two strongest bands already present in GEISA-2015 but updated in GEISA-2020.
} 


\subsubsection{7 $\mathrm{C}_{2} \mathrm{H}_{4}$ (molecule 25)}

The ${ }^{12} \mathrm{C}_{2} \mathrm{H}_{4}$ update in GEISA-2020 was generated using data for the $v_{10}, v_{7}$ and $v_{4}$ bands from the corrected line list of Ref. [112], however ignoring weak lines whose intensities are lower than $10^{-30} \mathrm{~cm}^{-1} /\left(\right.$ molecule $\left.\mathrm{cm}^{-2}\right)$ at $296 \mathrm{~K}$. Note that errors in the degeneracies provided for the rotational levels in the $10^{1}$ and $7^{1}$ vibrational levels in the linelists of Refs. [112] and [113] were corrected (I. Gordon is acknowledged for bringing them to our attention). The positions and intensities of the $v_{12}$ band lines were taken from GEISA-2015, excluding 187 lines having an intensity smaller than $10^{-30} \mathrm{~cm}^{-1} /\left(\right.$ molecule $\left.\mathrm{cm}^{-2}\right)$ at $296 \mathrm{~K}$ to be consistent with the information provided for the $v_{10}, v_{7}$ and $v_{4}$ bands. For all the lines, the self-broadening coefficients were calculated using the empirical expressions reported in Ref. [114], the air-broadening coefficients were generated as described in [115], and the temperature dependence exponent $n$ was set to 0.76 , following the suggestion from Ref. [113]. In total, 52655 lines have been added or updated between 620.057948 and $1524.702536 \mathrm{~cm}^{-1}$.

The internal GEISA code for the data identification has been set to $\boldsymbol{A 1 9}$.

\subsubsection{8 $\mathrm{GeH}_{4}$ (molecule 26)}

Germane $\left(\mathrm{GeH}_{4}\right)$ is a molecule that has been detected in giant gas planets like Jupiter and Saturn [116], [117]. The current Juno mission has renewed its spectroscopy interest especially in the $4.5-5.0 \mu \mathrm{m}$ window where an accurate model is needed for radiative transfer computations. The former version of GEISA only contained lines for ${ }^{74} \mathrm{GeH}_{4}$. A first complete analysis of the $v_{1} / \nu_{3}$ stretching dyad region for all natural five isotopologues $\left({ }^{70} \mathrm{GeH}_{4},{ }^{72} \mathrm{GeH}_{4},{ }^{73} \mathrm{GeH}_{4},{ }^{74} \mathrm{GeH}_{4}\right.$ and ${ }^{76} \mathrm{GeH}_{4}$ ) was recently performed by Boudon et al. [118] for line positions and absolute line intensities. This study led to a set of 32,378 calculated lines, covering the range $1929 \mathrm{~cm}^{-1}$ to $2266 \mathrm{~cm}^{-1}$, that have been introduced in the new GeCaSDa [119][120] database in Dijon and in the present version of GEISA.

In total, 32372 lines have been added or updated between 1928.902023 and $2265.677939 \mathrm{~cm}^{-1}$.

The Internal GEISA code for the data identification has been set to $\boldsymbol{B} 19$.

\subsubsection{NO+ (molecule 45)}

Nitrosylium, $\mathrm{NO}^{+}$, was detected in the Earth's ionosphere as an important trace species [121] and tentatively in the interstellar medium [122]. The rovibrational transitions have been introduced into GEISA-2020, based on version 2 of the CDMS [123] entry (tag 030512). Rotational transition frequencies [122],[124] were fitted together with rovibrational data 
[121],[125]. The dipole moments are $0.368 \mathrm{D}$ and $0.380 \mathrm{D}$ in $\mathrm{v}=0$ and 1 , respectively [126]. In total, 247 lines have been added or updated between 3.938076 and $4742.008075 \mathrm{~cm}^{-1}$.

The Internal GEISA code for the data identification has been set to $\mathbf{M 1 8}$.

\subsubsection{0 $\mathrm{CF}_{4}$ (molecule 49)}

Carbon tetrafluoride $\left(\mathrm{CF}_{4}\right)$ is a strong greenhouse gas of both natural and anthropogenic origin whose concentration is monitored using, among other techniques, solar occultation measurements from space [127]. It has been shown that, up to now, the line-by-line databases were quite incomplete because of missing hot bands lines expected for polyatomic species [128]. Recently, a systematic study of many low-lying energy levels was undertaken by the SOLEIL/AILES and Dijon groups to deal with this problem, resulting in a global analysis that enabled to simulate the major hot bands in the strongly absorbing $v_{3} \mathrm{C}-\mathrm{F}$ stretching region [129]. Moreover, line positions and intensities for purely rotational transitions in the $v_{3}=1$ state were recorded and fitted in the far infrared (THz) region, thanks to synchrotron radiation [130]. These last two studies are used for the present update of ${ }^{12} \mathrm{CF}_{4}$ lines in GEISA. We also adapted the line intensity thresholds in each spectral region to avoid unwanted inaccurate extrapolated lines of very low intensity (in $\mathrm{cm}^{-1} /$ molecule. $\mathrm{cm}^{-2}: 1 \mathrm{E}^{-30}$ in the $0-100 \mathrm{~cm}^{-1}$ region, $1 \mathrm{E}^{-24}$ in the 500 $700 \mathrm{~cm}^{-1}$ region and $1 \mathrm{E}^{-22}$ above $12000 \mathrm{~cm}^{-1}$ ). These line lists contain 258,208 lines and are included in the new TFMeCaSDa [120,131] Dijon's database, as well as in the present version of GEISA. In total, 258208 lines have been added or updated between 1.173350 and $1329.697261 \mathrm{~cm}^{-1}$.

The Internal GEISA code for the data identification has been set to $\boldsymbol{B} 19$.

\subsubsection{HONO (new molecule 53)}

Using spectroscopic data collected in the literature, a linelist of positions and intensities has been generated for the $11 \mu \mathrm{m}$ region of $\mathrm{HONO}$ [132] which correspond to the $v_{6}$ bands located at 790.117 and $851.943 \mathrm{~cm}^{-1}$ for the Cis- and Trans- isomers, respectively.

For the computation of line positions, the vibrational energies and rotational constants quoted in Refs. [133] and [134] were used for the upper and lower state energies. On the other hand the line intensities were calibrated relatively to band intensities measured by Kagann and Maki [135]. The problem of the uncertainties associated to these intensities was discussed in details in Ref. [132]. Indeed, in usual laboratory conditions nitrous acid exists only in the form of an equilibrium mixture with other species like $\mathrm{NO}, \mathrm{NO}_{2}$ and $\mathrm{H}_{2} \mathrm{O}$, together with smaller quantities 
of $\mathrm{N}_{2} \mathrm{O}_{3}, \mathrm{~N}_{2} \mathrm{O}_{5}$, and $\mathrm{HNO}_{3}$ [135]. Due to these difficulties, one may estimate an overall uncertainty on the absolute intensities between $20 \%$ to $30 \%$, while, on the relative scale, one may expect the intensities of the Trans- and Cis species at $296 \mathrm{~K}$ to be rather consistent, with an uncertainty of $5 \%$ on average, and of $10 \%$ for the weaker lines.

To our knowledge, line shape parameters are absent in the literature for HONO. As the permanent dipole moment of Trans-HONO and Cis-HONO have values similar to those of water, HONO line shape parameters adopted "a priori" values similar to those of water. More explicitly,

$$
\gamma_{\text {Air }}=0.1 \mathrm{~cm}^{-1} / \text { Atm, } \gamma_{\text {Self }}=0.4 \mathrm{~cm}^{-1} / \text { Atm, and } \mathrm{n}_{\text {Air }}=0.7
$$

were implemented for the air-broadened half width, self-broadened half-width and for the ntemperature dependent coefficient, respectively.

\begin{tabular}{|c|c|c|c|c|c|c|c|}
\hline Species & $\#$ lines & $\sigma_{\min }$ & $\sigma_{\max }$ & $\mathrm{S}_{\max }^{\#}$ & Total_A $^{\#}$ & Total_B $^{\#}$ & Stot $^{\#}$ \\
& & & & $\times 10^{-17}$ & $\times 10^{-17}$ & $\times 10^{-17}$ & $\times 10^{-17}$ \\
\hline Trans- HONO & 7621 & 724.39 & 838.57 & 0.166 & 1.218 & 0.0 & 1.218 \\
\hline Cis-HONO & 18420 & 722.53 & 996.28 & 0.148 & 1.115 & 0.1338 & 1.249 \\
\hline All & 26041 & & & & & & 2.467 \\
\hline
\end{tabular}

${ }^{\#}$ All intensities in $\mathrm{cm}^{-1} /\left(\right.$ molecule. $\left.\mathrm{cm}^{-2}\right)$ at $296 \mathrm{~K}$.

Table 9: The HONO linelist in GEISA. The following abbreviations are used: \#lines: number of lines; $\sigma_{\min } / \sigma_{\max } ;$ minimum and maximum sigma values (in $\mathrm{cm}^{-1}$ ); $\mathrm{S}_{\max }$ : Maximum intensity; Total-A/Total_B: sum of the intensities for A- type and B- type transitions, respectively; $\mathrm{S}_{\text {tot }}$ : sum of the individual intensity for the Trans and Cis species, TransInt $\left(v_{4}, T=296 K\right)$ and CisInt $\left(v_{4}, \mathrm{~T}=296 \mathrm{~K}\right)$, respectively.

The minimum of intensity retained is $0.510^{-24} \mathrm{~cm}^{-1} /\left(\right.$ molecule. $\left.\mathrm{cm}^{-2}\right)$. In total, 26041 lines have been added between 722.533940 and $996.280840 \mathrm{~cm}^{-1}$. Note that

The internal GEISA code for the data identification has been set to $\boldsymbol{P 1 8}$.

\subsubsection{2 $\mathrm{COFCl}$ (new molecule 54)}

Carbonylchlorofluoride $(\mathrm{COFCl})$ is a new molecule identified as molecule 54 in the GEISA notation. A list of line positions and of line intensities was implemented for the $v_{1}, v_{2}$, and $v_{3}$ fundamental bands of the ${ }^{12} \mathrm{C}^{16} \mathrm{OF}^{35} \mathrm{Cl}$ and ${ }^{12} \mathrm{C}^{16} \mathrm{OF}^{37} \mathrm{Cl}$ isotopologues of carbonylchlorofluoride, located at 5.3, 9.1, and $13.1 \mu \mathrm{m}$, respectively [136]. In addition, for the 
most abundant isotopologue ${ }^{12} \mathrm{C}^{16} \mathrm{OF}^{35} \mathrm{Cl}$, this line list includes also the contributions from the first two associated hot bands. The parameters included in this database were generated by combining the results of previous experimental analyses [137] and ab initio calculations [138]. To our knowledge, no line broadening or shifting parameters data exists in the literature for COFCl. Therefore, default values for the self and air-broadening coefficients of $0.1 \mathrm{~cm}^{-1} \mathrm{~atm}^{-1}$ and temperature dependence of $n=0.75$ are given in the present database. This COFCl linelist was generated in order to improve the quality of remote sensing of the atmosphere in the midIR. Analyses of atmospheric solar occultation spectra measured by the JPL MkIV interferometer [136] show that the new line list not only improves the quality of retrievals of $\mathrm{COFCl}$, but also of several other overlapping gases. In total, 215639 lines have been added between 734.996930 and $1912.632380 \mathrm{~cm}^{-1}$.

The internal code for the data identification has been set to $\boldsymbol{P 1 9}$.

\subsubsection{3 $\mathrm{CH}_{3} \mathrm{I}$ (new molecule 55)}

Methyl iodide $\left(\mathrm{CH}_{3} \mathrm{I}\right)$ is a new molecule identified as molecule 55 in the GEISA notation. The line list in GEISA involves the $v_{6}$ and $2 v_{3}$ interacting bands at $11 \mu \mathrm{m}$. For the computation of the line positions and intensities, the hyperfine structure due to the iodine nuclear quadrupole moment was accounted for explicitly, together with the vibration-rotation resonances. Analyses of line positions and line intensities, based on effective models adjustment, is described in Refs. [139] and [140], respectively. In addition, detailed self- $\mathrm{N}_{2}$ [141] and $\mathrm{O}_{2}$ [142] line shape parameters were measured. In total, 70291 lines have been added between 693.022430 and $1125.254590 \mathrm{~cm}^{-1}$.

\begin{tabular}{|c|c|c|c|c|c|c|c|}
\hline Band & \#lines & $\mathrm{S}_{\text {tot }}$ & $\mathrm{S}_{\max }$ & $\sigma_{\min }$ & $\sigma_{\max }$ & $\mathrm{J}_{\max }$ & $\mathrm{K}_{\max }$ \\
\hline & & $\times 10^{-19}$ & $\times 10^{-23}$ & & & & \\
\hline$v_{6}$ & 49603 & 12.3 & 220 & 693.02 & 1125.25 & 88 & 24 \\
\hline $2 v_{3}$ & 20688 & 0.181 & 3.3 & 985.67 & 1076.68 & 88 & 21 \\
\hline Total & 70291 & 12.5 & & & & & \\
\hline
\end{tabular}

Table 10: Linelist for Methyl iodide $\left({ }^{12} \mathrm{CH}_{3} \mathrm{I}\right)$ in the $11 \mu \mathrm{m}$ region for GEISA-2020. \#lines is the number of lines. $S_{\text {tot }}$ and $S_{\max }$ (maximum value of the computed line intensities) are in $\mathrm{cm}^{-}$ $1 /\left(\right.$ molecule $\left.\mathrm{cm}^{-2}\right) . \sigma_{\min }$ and $\sigma_{\max }$ are the minimum and maximum values of the computed line positions (in $\mathrm{cm}^{-1}$ ), respectively.

The Internal GEISA code for the data identification has been set to $\boldsymbol{P 1 9}$. 


\subsubsection{4 $\mathrm{CH}_{3} \mathrm{~F}$ (new molecule 56)}

Methyl fluoride $\left(\mathrm{CH}_{3} \mathrm{~F}\right)$ is present as traces in the Earth atmosphere. A line list for the $v_{6}$ band around $1200 \mathrm{~cm}^{-1}$ is now included for the first time in GEISA, based on the work of Papoušek et al. [143] for line positions, on the work of Jacquemart and Guinet [144] for line intensities and self-broadening coefficients, and on the work of Ramchani et al. [145] for $\mathrm{N}_{2}$-broadening coefficients. In total, 1499 lines have been added between 1067.375090 and $1290.254930 \mathrm{~cm}^{-}$ 1.

The internal GEISA code for data identification has been set to $\mathbf{J 1 9}$.

\subsubsection{5 $\mathrm{RuO}_{4}$ (new molecule 57)}

Ruthenium tetroxide is a molecule of importance for nuclear power plant security and other industrial applications (see [146], [147], [148] and references therein). In natural abundance, it possesses seven isotopologues, due to the different ruthenium isotopes (we do not consider here oxygen isotopes): ${ }^{97} \mathrm{RuO}_{4},{ }^{98} \mathrm{RuO}_{4},{ }^{99} \mathrm{RuO}_{4},{ }^{100} \mathrm{RuO}_{4},{ }^{101} \mathrm{RuO}_{4},{ }^{102} \mathrm{RuO}_{4}$ (the main one) and

${ }^{104} \mathrm{RuO}_{4}$. There are also two radioactive, short-lived, isotopologues, ${ }^{103} \mathrm{RuO}_{4}$ and ${ }^{106} \mathrm{RuO}_{4}$. In Ref. [146], the $v_{3}$ band for all observable isotopologues was analyzed, and the parameters for the radioactive ones were extrapolated. Absolute line intensities were also analyzed in Ref. [148] for ${ }^{102} \mathrm{RuO}_{4}$. In this work we assumed that the dipole moment derivative parameters do not change significantly for the different isotopologues, so that the dipole moment parameters determined for ${ }^{102} \mathrm{RuO}_{4}$ were used to calculate the line lists for the other eight isotopologues. These line lists contain 30,205 lines and are included in the new RuCaSDa [120,149] Dijon's database, as well as in the present version of GEISA.

When the broadening parameters are unknow, in general, a default value is given (as $0.1 \mathrm{~cm}^{-}$ $1 /$ atm for the air). Please note that in this update, and to specifically indicate that these values are unknown, the air and self-broadening have been set to -.9999 and -9.9999 , respectively. In total, 30250 lines have been added between 889.986739 and $948.138145 \mathrm{~cm}^{-1}$.

The Internal GEISA code for the data identification has been set to $\boldsymbol{B} 19$.

\subsubsection{6 $\mathrm{H}_{2} \mathrm{C}_{3} \mathrm{H}_{2}$ (new molecule 58, Allene, isomer of $\left.\mathrm{C}_{3} \mathrm{H}_{4}\right)$}

$\mathrm{H}_{2} \mathrm{C}_{3} \mathrm{H}_{2}$ (Allene, isomer of $\mathrm{C}_{3} \mathrm{H}_{4}$ ) is the last new molecule added to GEISA-2020, and identified as molecule 58 in the GEISA notation. This linelist includes the $v_{11}$ far infrared band near 352 $\mathrm{cm}^{-1}$ as well as the $v_{10} / v_{9}$ region peaking at $845 \mathrm{~cm}^{-1}$. It is a result of the search for allene (also called propadiene) in Titan's atmosphere using the CIRS (Composite InfraRed Spectrometer) instrument on board the Cassini-mission [150] that was positively concluded by a clear detection using high resolution observations from the ground [151]. No allene linelist was 
available neither in HITRAN nor in GEISA but the linelist of propyne $\left(\mathrm{C}_{3} \mathrm{H}_{4}\right)$ which is an isomer of allene has been provided by GEISA for a long time [1].

Coustenis et al. [152] started to investigate the detectability of allene in Titan's atmosphere using spectroscopic parameters by Chazelas et al. [153] for the $v_{10}$ band and from Pliva and Kauppinen for $v_{11}$ [154]. Line intensities could be obtained from band intensity measurements by Koga et al. [155]. Later Jolly et al. [156] used the same spectroscopic study but also added spectroscopic parameters obtained by high resolution studies by Nissen et al. [157] and Hegelund et al. [158] which also include spectroscopic parameters for the hot bands. The hot band contribution is particularly important at room temperature and needs to be included in order to compare the calculated line lists with room temperature spectra. No new highresolution measurements were needed to establish this new linelist. It is essentially based on the sub-band analysis from previously mentioned authors but has also been validated against new measurements.

As described in Lombardo et al. [150], calculated band profiles have been compared to room and high temperature cross section measurements recorded at $0.08 \mathrm{~cm}^{-1}$ resolution in the $v_{10} / v_{9}$ wavenumber range [159]. All sub-band intensities could be fitted using those intensity calibrated measurements. Concerning the far infrared region where the $v_{11}$ band of allene can be observed, room temperature spectra were recorded at the resolution of $0.1 \mathrm{~cm}^{-1}$ at the SOLEIL-AILES synchrotron beamline as described in Jolly et al [156]. Band intensities were found to be in agreement with Koga et al. [156]

This linelist that we have adopted is the same that was used for the search and detection of allene on Titan. It provides for each line the position, the intensity and the lower energy but does not provide any quantum assignment. Pressure shift is fixed to the undefined value $0.0 \mathrm{~cm}^{-}$ $1 / \mathrm{atm}$ and self-broadening to a constant value $0.71 \mathrm{using}$ the same values as for allene's isomere $\mathrm{C}_{3} \mathrm{H}_{4}$ (propyne). In total, 31686 lines have been added between 296.315900 and 1192.445800 $\mathrm{cm}^{-1}$.

The internal GEISA code for the data identification has been set to $\boldsymbol{J 1 9}$.

\section{Quality assessment of the spectroscopic parameters}

The process of updating or expanding spectroscopic databases in order to provide the users with a database that insures an optimal characterization of spectral properties of molecular 
absorption is challenging. To help making the most relevant choices and updates, the Spectroscopic Parameters And Radiative Transfer Evaluation (SPARTE) chain [8] was developed at LMD and applied for the first time to the GEISA-2015 release. Figure 6 presents the general principles of the SPARTE chain.

SPARTE relies on the comparison between forward radiative transfer simulations made by the $4 \mathrm{~A}$ radiative transfer code [10,160], using a given spectroscopic database as input, and various remote sensing observations for several thousands of well-characterized atmospheric situations. Assuming that observed spectra come from instruments characterized by high radiometric and spectral stabilities, each individual residual can be the sum of a random errors coming from the imperfect description of the atmospheric state or from the radiometric noise of the instruments, with systematic errors linked in general to the spectra calculation (spectroscopic parameters, line shape, line mixing, continua, etc.). Averaging the resulting 'calculated-observed' spectral residuals thus minimizes the random errors and enables the detection of error features that may come from an imperfect knowledge of lines parameters (see Figure 7 of Ref. [8] for the typical shapes of the 'calculated-observed' residuals originating from an error in a given line parameter).

In the following, 'clear-sky' observations from two well established instruments have been used: the space-borne IASI instrument (15 to $3.7 \mu \mathrm{m})$ and ground-based Fourier Transform Spectrometers (FTS) instruments at the Park Falls Total Carbon Column Observing Network [9] (TCCON, 2.5 to $0.7 \mu \mathrm{m}$ ). For IASI, more than 15000 numbers of observations, spanning the period 2019/01-2019/12, have been used. Atmospheric state determinations that are collocated with IASI observations are from Analyzed RadioSoundings Archive (ARSA) developed and maintained at LMD (https://ara.lmd.polytechnique.fr/index.php?page=arsa). Clear sky observations - i.e. «free from clouds and aerosols » - are selected through a sophisticated procedure combining microwave and infrared radiances measured by AMSU-A and IASI, both on Metop satellites, respectively. For TCCON, clear-sky observations have been selected to each PI's station. Here, a set of more than 300 spectra from Park Falls facility, selected based on a good representation of the airmass (i.e. solar zenith angle) as well as period of the year, are used. Atmospheric states that are collocated with TCCON observations are coming from the TCCON procedure and delivered together with the spectra.

When possible (i.e. for matching spectral coverage and a significant spectral signature of the spectroscopic change), the SPARTE chain was used for the update of GEISA-2020 in a 3-step procedure: (i) to identify improperly described lines (position, intensity, width, pressure shift, 
etc.); (ii) to provide feedback and suggest revised values to the contributing spectroscopy research teams; and (iii) to finalize the validation of the updated parameters.

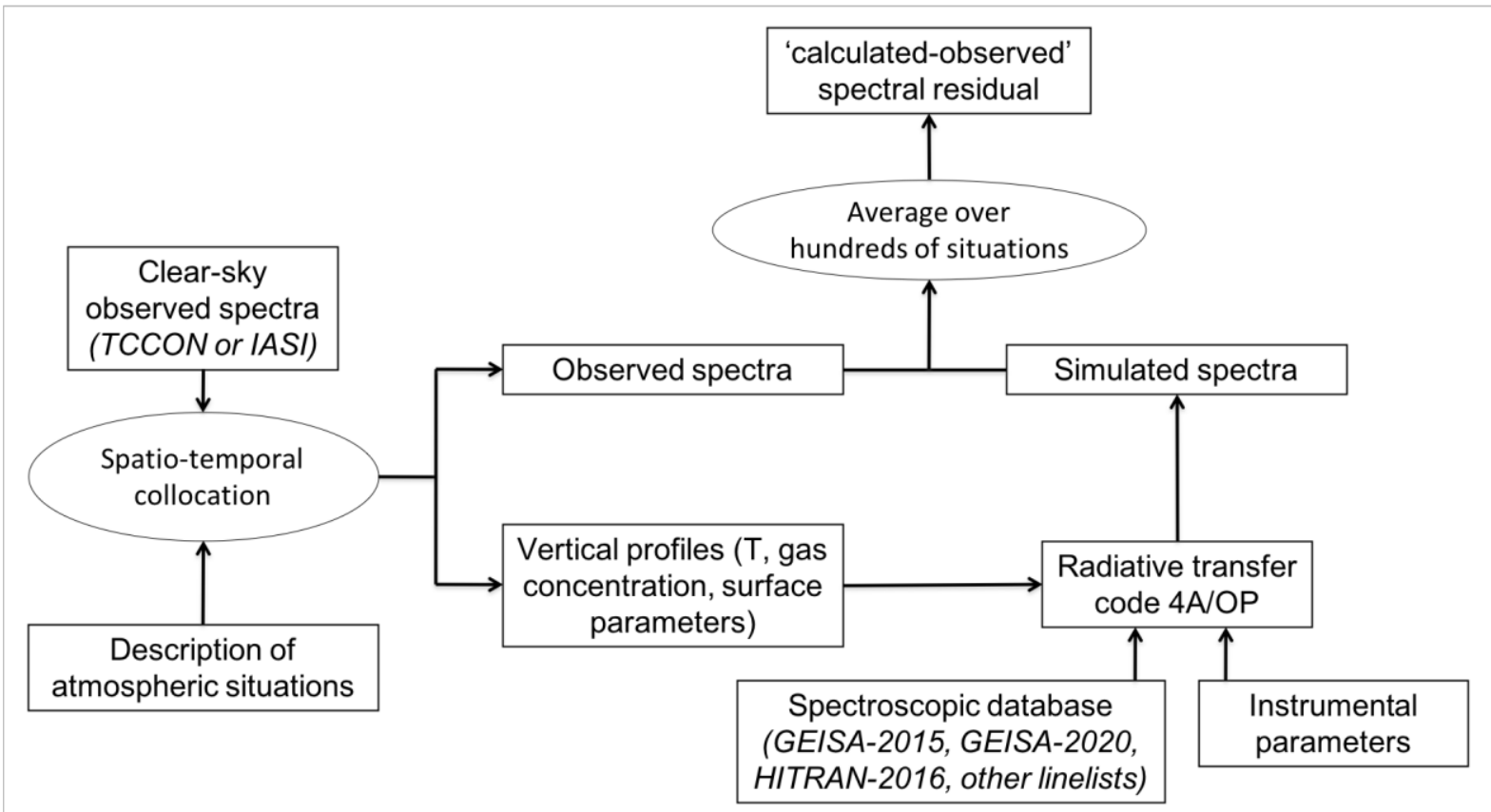

Figure 6. The general principle of the SPARTE chain.

\section{Four applications and impact on the GEISA-2020 version}

\section{$3.1 .1 \mathrm{H}_{2} \mathrm{O}$ evaluation in the $6600-6616 \mathrm{~cm}^{-1}$ and $7550-7575 \mathrm{~cm}^{-1}$ spectral region}

As stated in section 2.1.1.1, the major update on $\mathrm{H}_{2}{ }^{16} \mathrm{O}$ was based on the work of Mikhailenko et al. [12] (referenced as Mikhailenko 2016 in the following), who published a linelist of $\mathrm{H}_{2} \mathrm{O}$ parameters between 5830 and $8340 \mathrm{~cm}^{-1}$ based on a collection of several data. More recently they published refined line positions and shifts with respect to their former linelist [13] (included in GEISA-2020 update). Although much of these new data helped to improve line parameters in the GEISA database, the validation process using SPARTE based on TCCON observations highlighted a few remaining issues or artefacts in the SWIR domain. In the following, we present a selection of three representative cases that illustrate the benefit of a careful further evaluation of the spectroscopic parameters as nominally delivered by the spectroscopist research team.

The first case is the most straightforward as it concerns 'wide-range' issues, i.e. systematic errors on one or several line parameters that affect wide ranges of the TCCON spectrum. Figure 7 summarizes the comparisons of the 'calculated-observed' residuals between TCCON and 4A/OP [10] when three different spectroscopic databases are used: GEISA-2015 (red), Mikhailenko 2016 (blue) and GEISA-2020 (green). The upper panel shows the spectrum of atmospheric transmission measured by TCCON in the regions $6600-6616 \mathrm{~cm}^{-1}$ and $7550-7575$ 
$\mathrm{cm}^{-1}$. The corresponding residuals (differences of transmissions averaged on the 325 TCCON spectra) are shown in the lower panels. In the left figure, the calculations using the line list from Mikhailenko 2016 results in unexpectedly bad 'calculated-observed' values: negative (left panel) or positive (right panel). This wide range behavior, affecting several lines over tens of $\mathrm{cm}^{-1}$, combined with the typical 'line intensity' residual shape, suggests systematic lineintensity issues in the data reported in the Mikhailenko 2016 list. This is also supported by the fact that the GEISA-2015 residuals - which did not include Mikhailenko 2016 results - not only were smaller but also did not exhibit similar behavior. An analysis of the affected lines showed that they were all coming from Regalia et al. [161] work. Removing all the occurrence of this work in the Mikhailenko 2016 linelist enabled to solve these issues. A work is in progress to assess the origin of these systematic intensity-like issues in Regalia et al. data.

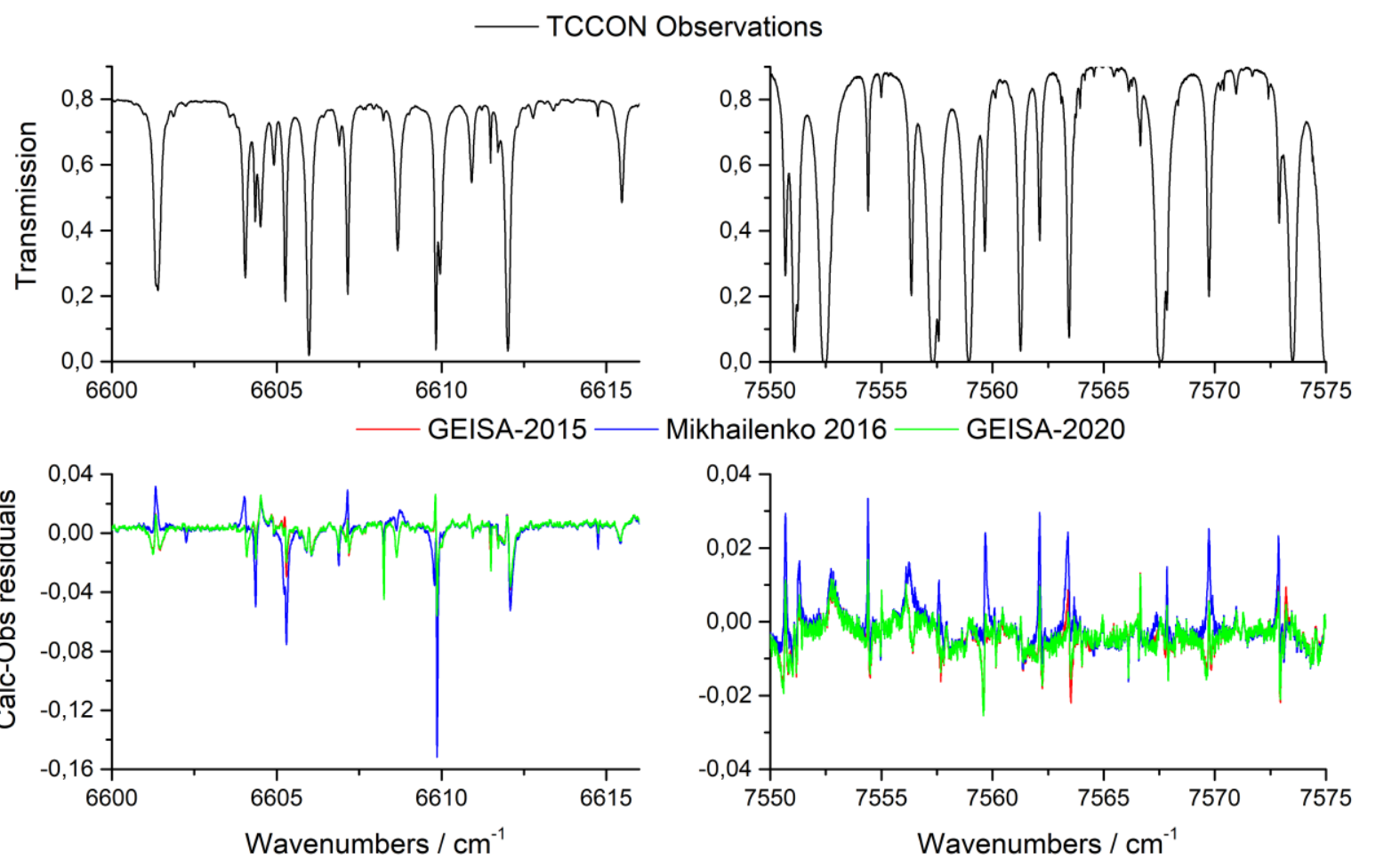

Figure 7: Comparison between GEISA-2015, Mikhailenko 2016 [12] and GEISA-2020. Upper panel: Transmission spectrum observed at Park Falls TCCON site (average over 325 spectra). Lower panel: 'Calculated-observed' residuals generated by the SPARTE chain for GEISA2015 (red), Mikhailenko 2016 (blue) and GEISA-2020 (green). Left: 6600-6616 cm-1. Right: $7550-7575 \mathrm{~cm}^{-1}$.

Figure 8 illustrates a similar case. It shows comparisons of the 'calculated-observed' residuals obtained from simulations using the three different spectroscopic line lists in the 6615-6616 $\mathrm{cm}^{-1}$, 6669-6672 $\mathrm{cm}^{-1}$ and 6710-6712 $\mathrm{cm}^{-1}$ regions, and the corresponding TCCON observations. Significant deviations are observed on the residuals when using Mikhailenko 
2016 linelist on some isolated lines of the spectrum, with a deterioration of the situation with regard to GEISA-2015. Careful study of the line parameters gathered in

\begin{tabular}{ccccccc}
\hline \multirow{2}{*}{$\begin{array}{c}\text { Position } \\
\mathrm{cm}^{-1}\end{array}$} & \multicolumn{3}{c}{$\begin{array}{c}\text { Intensity } \\
\mathrm{cm} / \mathrm{atm}\end{array}$} & & \multicolumn{3}{c}{$\begin{array}{c}\text { Air-broadening } \\
\mathrm{cm} / \mathrm{cm}^{-1}\end{array}$} \\
\cline { 2 - 7 } & GEISA-2015 & Ref. [12] & GEISA-2020 & GEISA-2015 & Ref. [12] & GEISA-2020 \\
\hline 6615.451320 & $\mathbf{1 . 7 6 E - 2 5}$ & $\mathbf{2 . 4 9 E - 2 5}$ & $\mathbf{1 . 7 6 E - 2 5}$ & 0.0729 & 0.0729 & 0.0729 \\
6670.485430 & $\mathbf{5 . 0 4 E}-24$ & $\mathbf{2 . 5 2 E}-23$ & $\mathbf{5 . 0 4 E}-24$ & 0.0360 & 0.0360 & 0.0360 \\
6711.331920 & $\mathbf{1 . 0 4 E 2 4}$ & $\mathbf{1 . 3 2 E - 2 4}$ & $\mathbf{1 . 0 4 E - 2 4}$ & 0.0330 & 0.0330 & 0.0330 \\
6031.899200 & $7.13 \mathrm{E}-26$ & $7.13 \mathrm{E}-26$ & $7.13 \mathrm{E}-26$ & $\mathbf{0 . 0 3 8 0}$ & $\mathbf{0 . 0 0 7 8}$ & $\mathbf{0 . 0 3 0 0}$ \\
7804.608830 & $6.60 \mathrm{E}-26$ & $6.87 \mathrm{E}-26$ & $6.87 \mathrm{E}-26$ & $\mathbf{0 . 0 0 9 2}$ & $\mathbf{0 . 0 0 9 2}$ & $\mathbf{0 . 0 4 7 8}$ \\
7851.277170 & $3.90 \mathrm{E}-26$ & $4.13 \mathrm{E}-26$ & $4.13 \mathrm{E}-26$ & $\mathbf{0 . 0 0 8 9}$ & $\mathbf{0 . 0 0 8 9}$ & $\mathbf{0 . 0 3 0 0}$ \\
\hline
\end{tabular}

Table 11 shows that the main differences come from line intensities of some strong lines. For these lines, the data from Macko et al. [162] were considered in Mikhailenko 2016. However, the CRDS setup used in [162], being very efficient for the measurement of weak lines but less suitable for the measurement of strong lines, leads to significant uncertainties on these line intensities. As a consequence, the choice has been made in GEISA-2015 and GEISA-2020 to use the line intensities determined by Toth et al. [163] using a Fourier Transform spectrometer. Other parameters were updated using the data from references [12] and [13]. 

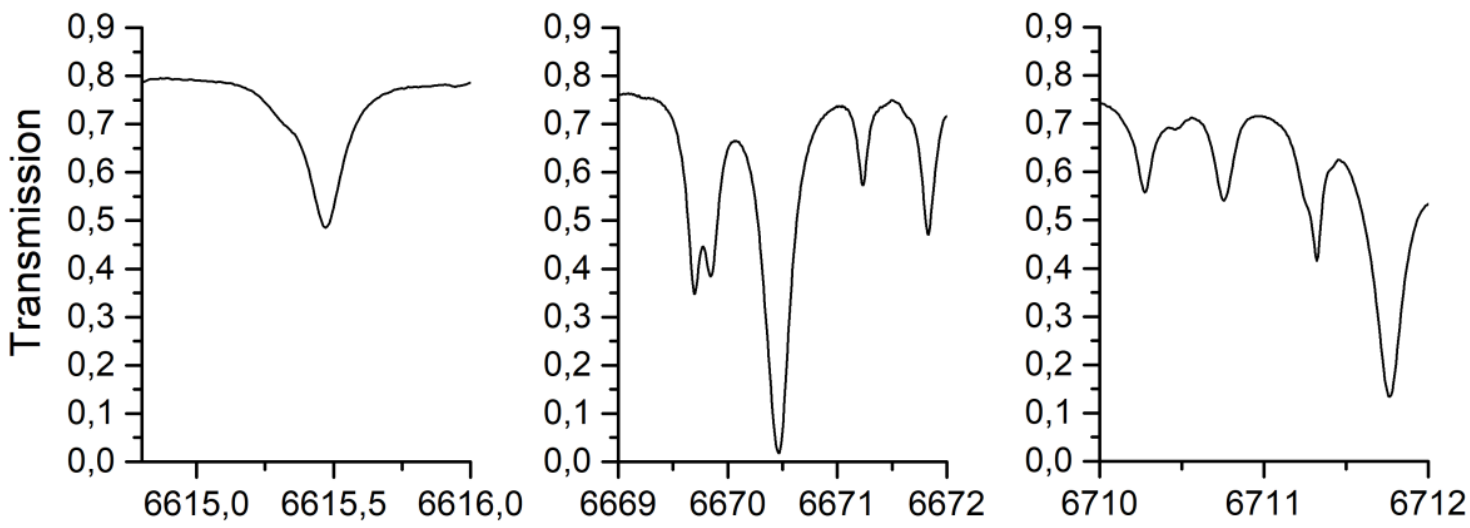

GEISA-2015 - Mikhailenko 2016

GEISA-2020
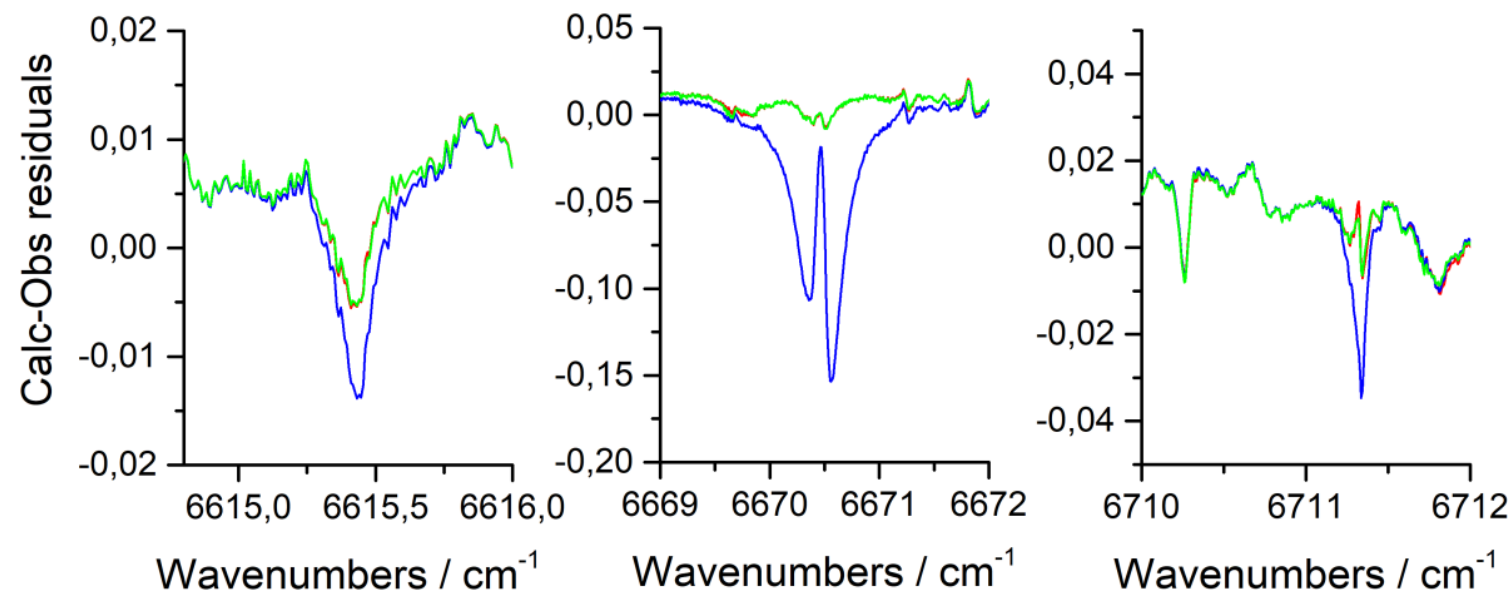

Wavenumbers $/ \mathrm{cm}^{-1}$

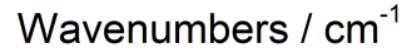

Wavenumbers $/ \mathrm{cm}^{-1}$

Figure 8: Comparison between GEISA-2015, Mikhailenko 2016 [12] and GEISA-2020. Upper panel: Transmission spectrum observed by TCCON, as input (average over 325 spectra). Lower panel: 'Calculated-observed' residuals generated by the SPARTE chain for GEISA-2015 (red), Mikhailenko 2016 (blue) and GEISA-2020 (green).

Finally, Figure 9 presents comparisons of the 'calc-obs' residuals obtained from the three different spectroscopic line lists in the $6631.5-6632.5 \mathrm{~cm}^{-1}, 7804-7805 \mathrm{~cm}^{-1}$ and $7850.5-7851.5$ $\mathrm{cm}^{-1}$ regions, and the corresponding TCCON observations. Again, significant deviations are observed on the residuals when using Mikhailenko 2016 linelist on some isolated lines of the spectrum, but also using GEISA-2015, a notable exception being the line in $6032.9 \mathrm{~cm}^{-1}$ for which GEISA-2015 is far better. This time, the residual shapes indicates a significant difference between the air-broadening coefficients of the three line lists, as illustrated in

\begin{tabular}{ccccccc}
\hline $\begin{array}{c}\text { Position } \\
\mathrm{cm}^{-1}\end{array}$ & \multicolumn{3}{c}{$\begin{array}{c}\text { Intensity } \\
\mathrm{cm} / \mathrm{atm}\end{array}$} & & \multicolumn{3}{c}{$\begin{array}{c}\text { Air-broadening } \\
\mathrm{cm} / \mathrm{cm}^{-1}\end{array}$} \\
\cline { 2 - 7 } & GEISA-2015 & Ref. [12] & GEISA-2020 & GEISA-2015 & Ref. [12] & GEISA-2020 \\
\hline 6615.451320 & $\mathbf{1 . 7 6 E - 2 5}$ & $\mathbf{2 . 4 9 E - 2 5}$ & $\mathbf{1 . 7 6 E - 2 5}$ & 0.0729 & 0.0729 & 0.0729 \\
6670.485430 & $\mathbf{5 . 0 4 E}-24$ & $\mathbf{2 . 5 2 E - 2 3}$ & $\mathbf{5 . 0 4 E}-24$ & 0.0360 & 0.0360 & 0.0360 \\
6711.331920 & $\mathbf{1 . 0 4 E 2 4}$ & $\mathbf{1 . 3 2 E - 2 4}$ & $\mathbf{1 . 0 4 E - 2 4}$ & 0.0330 & 0.0330 & 0.0330 \\
6031.899200 & $7.13 \mathrm{E}-26$ & $7.13 \mathrm{E}-26$ & $7.13 \mathrm{E}-26$ & $\mathbf{0 . 0 3 8 0}$ & $\mathbf{0 . 0 0 7 8}$ & $\mathbf{0 . 0 3 0 0}$
\end{tabular}


Table 11 (a slight difference on line intensities is also seen for the two lines at 7804.61 and $7851.28 \mathrm{~cm}^{-1}$, but cannot explain the large deviations seen in Figure 9). The values of these parameters reported in GEISA-2015 and Mikhailenko 2016, and determined in a former work of Gamache et al. (updated version of Refs. $[164,165]$ ), turned out to be too weak, leading to large errors in the 'calc-obs' residuals. In this particular case, we gave a feedback to Gamache and coworkers so that they can rework on a revised set of data. The new line parameters were used to correct the problematic lines in GEISA-2020, as stated in section 2.1.1.1. Thus, Figure 9 shows that the residuals obtained using the GEISA-2020 release give much better results than the two other line lists. Also note that SPARTE was able to detect inconsistencies on parameters of very weak lines (e.g. the line centered at $7804.5 \mathrm{~cm}^{-1}$ ).

\section{- TCCON Observations}
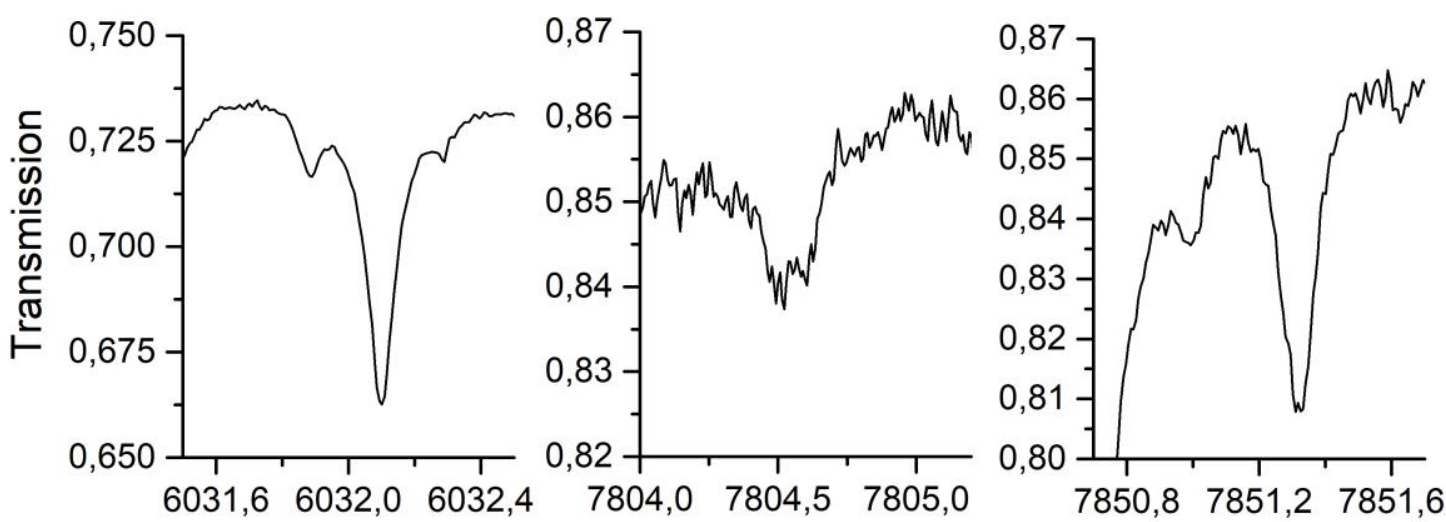

GEISA-2015 — Mikhailenko 2016

GEISA-2020
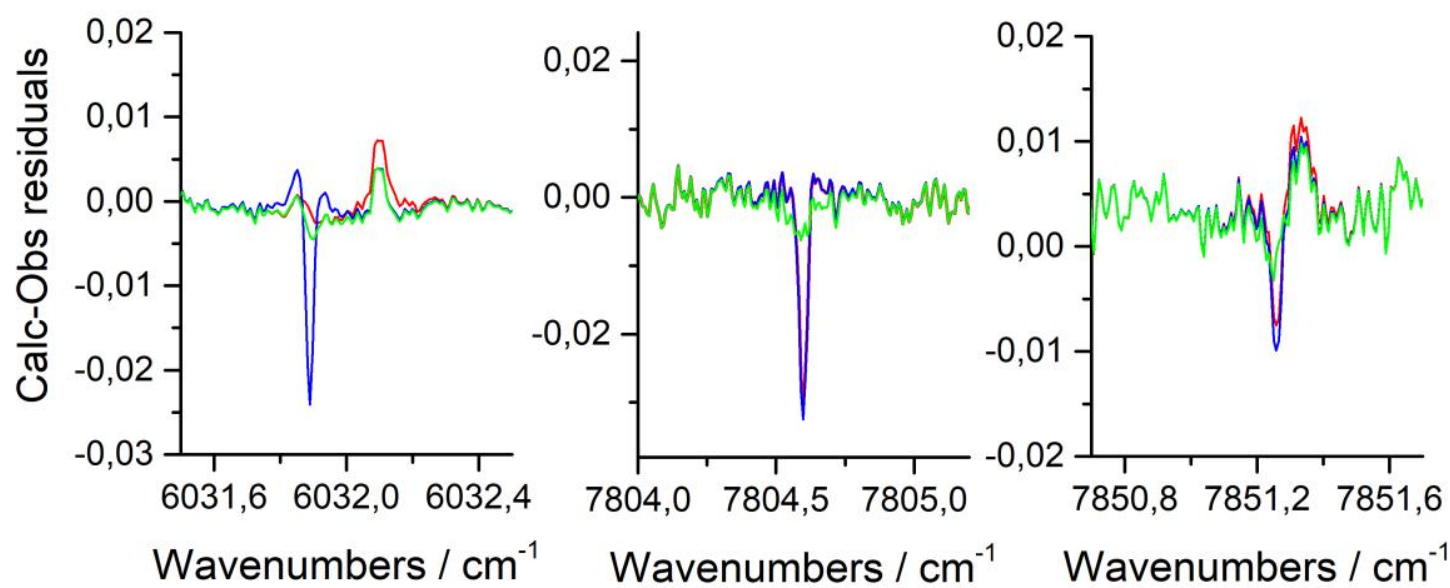

Figure 9: Comparison between GEISA-2015, Mikhailenko 2016 [12] and GEISA-2020. Upper panel: Transmission spectrum observed by TCCON, as input (average over 325 spectra). Lower 
panel: 'Calculated-observed' residuals generated by the SPARTE chain for GEISA-2015 (red), Mikhailenko 2016 (blue) and GEISA-2020 (green).

\begin{tabular}{ccccccc}
\hline $\begin{array}{c}\text { Position } \\
\mathrm{cm}^{-1}\end{array}$ & \multicolumn{3}{c}{$\begin{array}{c}\text { Intensity } \\
\mathrm{cm} / \mathrm{atm}\end{array}$} & & \multicolumn{3}{c}{$\begin{array}{c}\text { Air-broadening } \\
\mathrm{cm} / \mathrm{cm}^{-1}\end{array}$} \\
\cline { 2 - 7 } & GEISA-2015 & Ref. [12] & GEISA-2020 & GEISA-2015 & Ref. [12] & GEISA-2020 \\
\hline 6615.451320 & $\mathbf{1 . 7 6 E - 2 5}$ & $\mathbf{2 . 4 9 E - 2 5}$ & $\mathbf{1 . 7 6 E - 2 5}$ & 0.0729 & 0.0729 & 0.0729 \\
6670.485430 & $\mathbf{5 . 0 4 E - 2 4}$ & $\mathbf{2 . 5 2 E - 2 3}$ & $\mathbf{5 . 0 4 E - 2 4}$ & 0.0360 & 0.0360 & 0.0360 \\
6711.331920 & $\mathbf{1 . 0 4 E 2 4}$ & $\mathbf{1 . 3 2 E - 2 4}$ & $\mathbf{1 . 0 4 E - 2 4}$ & 0.0330 & 0.0330 & 0.0330 \\
6031.899200 & $7.13 \mathrm{E}-26$ & $7.13 \mathrm{E}-26$ & $7.13 \mathrm{E}-26$ & $\mathbf{0 . 0 3 8 0}$ & $\mathbf{0 . 0 0 7 8}$ & $\mathbf{0 . 0 3 0 0}$ \\
7804.608830 & $6.60 \mathrm{E}-26$ & $6.87 \mathrm{E}-26$ & $6.87 \mathrm{E}-26$ & $\mathbf{0 . 0 0 9 2}$ & $\mathbf{0 . 0 0 9 2}$ & $\mathbf{0 . 0 4 7 8}$ \\
7851.277170 & $3.90 \mathrm{E}-26$ & $4.13 \mathrm{E}-26$ & $4.13 \mathrm{E}-26$ & $\mathbf{0 . 0 0 8 9}$ & $\mathbf{0 . 0 0 8 9}$ & $\mathbf{0 . 0 3 0 0}$ \\
\hline
\end{tabular}

Table 11: Line parameters contained in the 3 spectroscopic databases GEISA-2015, Mikhailenko 2016 and GEISA-2020 for several absorption lines located in the spectral range considered in Figure 8 and Figure 9. Parameters written in italic-bold are those identified as responsible for strong departures in the 'calculated-observed' residuals (see text for details).

\subsection{2 $\mathrm{O}_{2}$ evaluation}

As stated in section 2.2.7, no major update of the $\mathrm{O}_{2}$ database was made in GEISA-2020. However, a recent work from Tran et al. [70] highlighted several errors in the $1.27 \mu \mathrm{m}$ band using ${ }^{16} \mathrm{O}_{2}$ air-broadened line-shift parameters from GEISA-2015 or HITRAN2016 databases. To illustrate these errors, Figure 10 summarizes the comparisons of the 'calculated-observed' residuals between the 325 TCCON spectra recorded at Park Falls and 4A/OP when three different spectroscopic databases are used: GEISA-2015 taking into account the Pressure Shift (red, marked GEISA-2015 WPS), GEISA-2015 with ${ }^{16} \mathrm{O}_{2}$ pressure shifts set to zero (blue, marked GEISA-2015 WOPS) and GEISA-2020 (green). Figure 10a shows the atmospheric transmission spectrum measured by TCCON in the region $7785-7915 \mathrm{~cm}^{-1}$. The corresponding 'calc-obs' residuals are shown in Figure 10b, c, d, for GEISA-2015 WPS, GEISA-2015 WOPS and GEISA-2020, respectively. Comparisons of the residuals between GEISA-2015 WPS and GEISA-2015 WOPS shows that systematic deviations seen in GEISA-2015 are due to erroneous values of the ${ }^{16} \mathrm{O}_{2}$ pressure shifts, as they are mainly addressed when setting these parameters to zero. Figure 10d shows that the new data from Tran et al. [70] included in GEISA2020 (see section 2.1.7) greatly improves these 'calculated-observed' deviations. However, several features remain in the residuals, mainly due to the fact that currently GEISA is only referencing Voigt profile parameters. The work of Tran et al. [70] using quadratic Speeddependent Voigt profile along with first order line-mixing parameters greatly improves the 
residuals in this region. The future releases of GEISA will be designed to gather such high-level information.

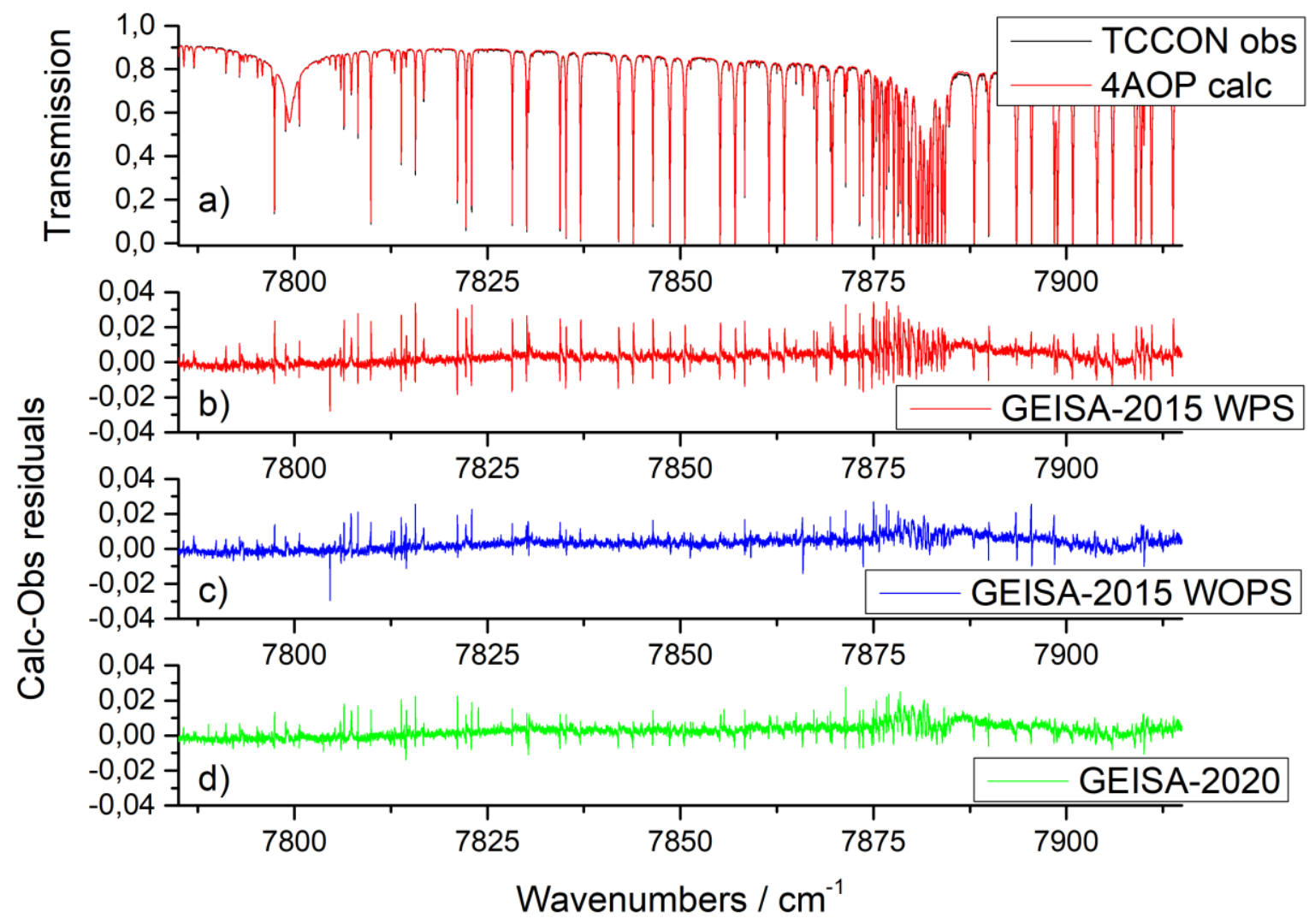

Figure 10: Comparison between GEISA-2015 (WPS), GEISA-2015 with ${ }^{16} \mathrm{O}_{2}$ pressure shifts set to zero (GEISA-2015 WOPS) and GEISA-2020. (a) Transmission spectrum observed by TCCON, as input. (b) 'Calculated-observed' residuals generated by the SPARTE chain for GEISA-2015 WPS (red), (c) GEISA-2015 WOPS (blue) and GEISA-2020 (green). Please note that this band has been investigated and improved by Tran et al. [64] using non-Voigt profiles (not included in GEISA at this time).

\subsection{3 $\mathrm{O}_{3}$ evaluation}

As described in section 2.1.3, a significant update has been made for the 2020 version of GEISA, notably by the application of intensity scaling factors in three vibrational bands, namely the 000-000, 001-000 and 101-000 bands, respectively in the microwave, $10 \mu \mathrm{m}$ and $5 \mu \mathrm{m}$ spectral regions. Impact of such scaling factors may be evaluated by comparison of simulated spectra generated by the SPARTE chain with observed IASI spectra.

The impact of the release has been studied on the whole IASI spectral range, but a significant impact has been only observed for the $9.6 \mu \mathrm{m}$ band only. Figure 11 shows the comparisons of 'calculated-observed' residuals obtained with the SPARTE chain applied on IASI spectra using the two databases GEISA-2015 (in blue) and GEISA-2020 (in red), in this corresponding 
spectral range 975-1075 $\mathrm{cm}^{-1}$, for the 'Tropical' atmospheres collocated with IASI. Figure 11 shows significantly worse results with GEISA-2020 than those obtained with GEISA-2015. When solicited, the spectroscopists have largely documented and justified (by private communications) the changes made in this spectral region, so the reason for such a behavior displayed in Figure 11 can only come from SPARTE. Since the same fixed version of 4A/OP has been used for the results displayed in Figure 11, the reason of this deterioration of the residuals using GEISA-2020 can only come from the ozone profiles. So far, as described in [8], $\mathrm{O}_{3}$ atmospheric profiles originate from the ERA Interim reanalysis [166] that are space and time collocated with each individual quality controlled radiosonde profile retained in the ARSA database. As a consequence, we decided to study the impact of a different set of ozone profiles, especially the new ECMWF reanalysis product, ERA5 [167], which is an improvement of the former ERA Interim product. Because the ERA5 database is large $(0.25 \times 0.25$ degrees, every hour), as a first step, we estimated the differences between ERA Interim and ERA 5 by comparing the bias for the whole 2019 period, and for the 'tropical' atmospheres only, as shown in Figure 11. The most significant change between the two ERA products being a bias of $8 \%$ between 2 and 25 mbars, we evaluated the impact on SPARTE by shifting the ERA Interim profiles by $8 \%$ in the pressure range considered in SPARTE. The corresponding residuals are also shown on the Figure 11 in green.

As can be easily seen, the previous bias obtained using ERA Interim profiles along with GEISA2020 has been largely removed. The remaining spectral residuals can be explained by the fact that the best approach is to collocate each ARSA radiosounding with the corresponding ERA5 ozone profile, an adaptation of SPARTE that will be done in the coming weeks. But, from this evaluation, we estimated that the demonstration of the good quality of the new ozone line list is made here, and thus we decided to keep this new version of ozone spectroscopic parameters in GEISA-2020. 


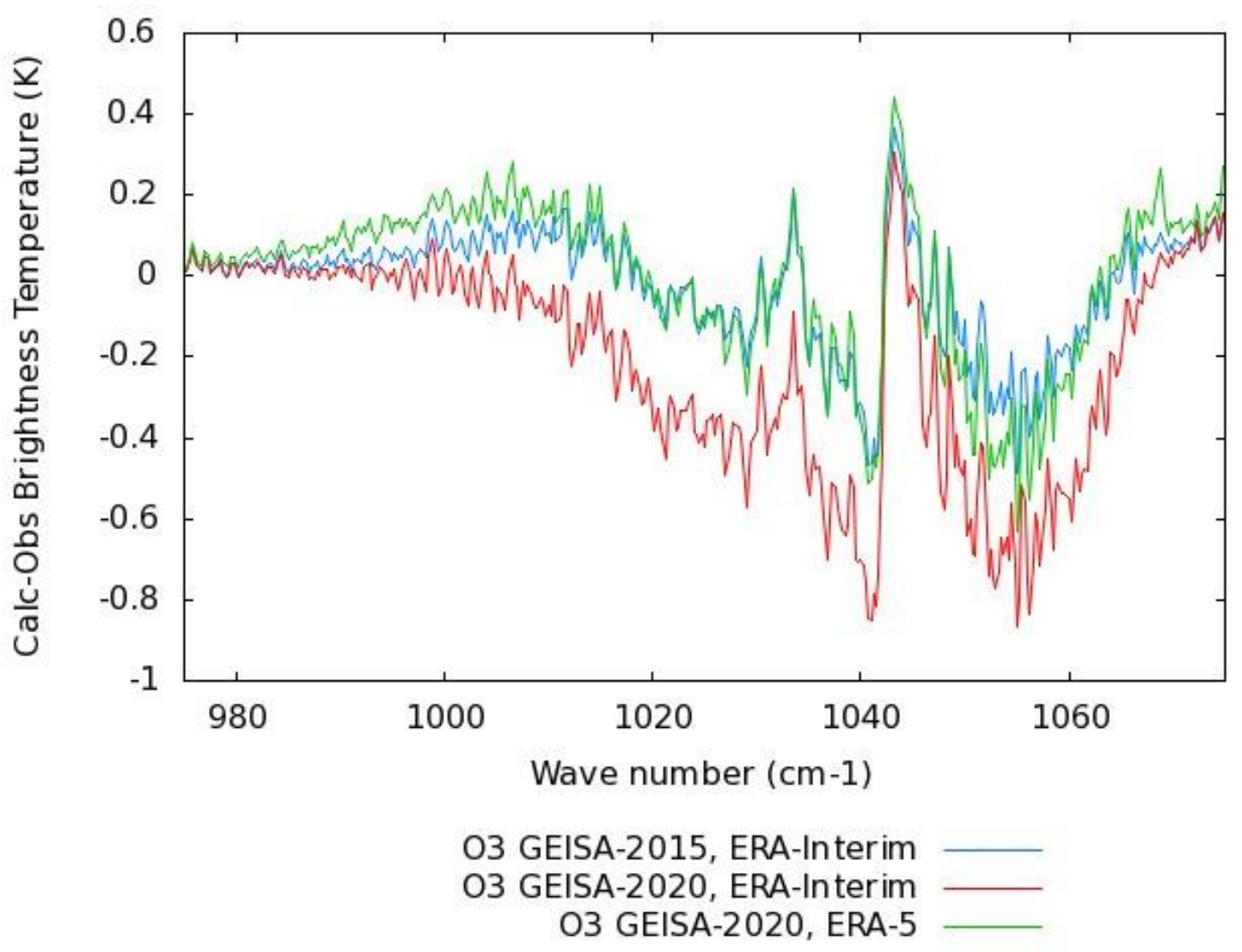

Figure 11: Comparison of 'calculated-observed' IASI residuals in the $975-1075 \mathrm{~cm}-1$ spectral range and for tropical atmospheres, obtained using GEISA-2015 and GEISA-2020 $\mathrm{O}_{3}$ line parameters and with different sources of ozone profiles used in the SPARTE chain: GEISA2015 and ERA in blue, GEISA-2020 and ERA Interim in red and GEISA-2020 and ERA-5 in green).

\subsubsection{Discussion on $\mathrm{SF}_{6}$}

.Contrary to the species describe in the section $2, \mathrm{SF}_{6}$ has not been updated in the current version of GEISA, although new data were provided by Ke et al. from the Dijon's database SheCaSDa [168]. Indeed, recent data from Nikitin et al. [169] consisting of a complete line list based of extensive $a b$ initio calculations (from TheoReTS database [170]) leads to significantly different results. The direct comparison of the different available databases with experimental absorption from GEISA-2015 cross-sections database [1] justify why we made the choice not to update the GEISA-2020 database with new data from Dijon.

Figure 12 shows a comparison of $\mathrm{SF}_{6}$ cross sections at room temperature (296K). The data from the GEISA-2015 cross-sections database are plotted along with simulated spectra derived from GEISA-2015 [1], HITRAN2016 [2], Dijon SheCaSDa [120] and TheoReTS [169] line list databases. Note that we also compared with the widely used PNNL spectra [83], which are similar than to GEISA-2015 cross-sections from Varanasi of et al. (Ref. [170] and private 
communication), but the latter contains data at higher resolution $\left(0.03 \mathrm{vs} .0 .112 \mathrm{~cm}^{-1}\right)$ and was retained in the Figure 12. As mentioned by Nikitin et al. [169] it appears that ab initio cross sections agree much better with the observations than the simulations using $\mathrm{SF}_{6}$ line lists constructed from effective models as available in HITRAN2016, SheCaSDa and GEISA-2015 line parameters databases. The main reason relies on the fact that effective models, generally derived from cold spectra over a limited set of ground vibrational states, fail to extrapolate data at room temperature which requires an account of more significant contributions of hot bands involving higher vibrational states. On the other hand, ab initio calculations succeed in giving a qualitative agreement with experimental data (Nikitin et al. mentioned that their calculation should be extended [169]). For this reason, we plan to generalize in future GEISA releases the use of ab initio data both as a point of comparison with experimentally derived effective models but also to improve or complete existing data.

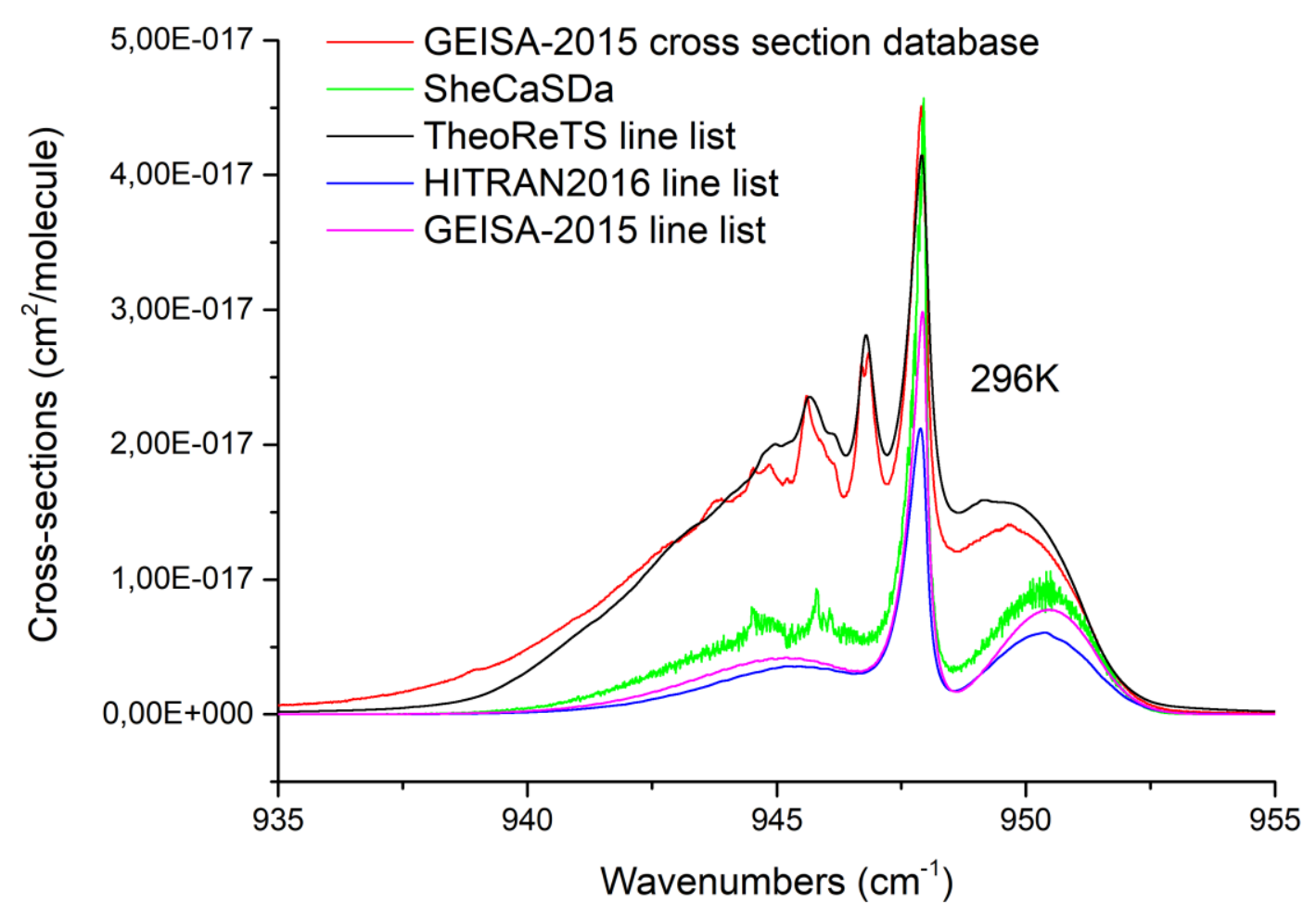

Figure 12: Comparison of $\mathrm{SF}_{6}$ cross-sections at $296 \mathrm{~K}$ from the GEISA-2015 cross-sections database [1] (red), the line list of TheoReTS [169] (black), the theoretical calculation of Dijon SheCaSDa [168] (green), and simulations from the line lists of GEISA-2015 [1] (magenta), and HITRAN2016 databases [2] (blue). The GEISA-2015 cross-sections based on the work Varanasi of et al. (Ref. [171] and private communication) are comparable to the widely used PNNL cross-sections [86], but contains data at higher resolution $\left(0.03 \mathrm{vs} .0 .112 \mathrm{~cm}^{-1}\right)$. 


\section{Conclusion and perspectives}

Since its creation in the mid-1970s, and in order to meet the needs of researchers and international space agencies, GEISA has undergone 6 updates. This was done by collecting, archiving, and distributing the most up to date as well as accurate spectroscopic information and by concomitantly evolving the associated management softwares and quality control tools. Accordingly, the GEISA-2020 edition reported in this paper contains important updates and additions to the line parameters sub-database. With the addition of 6 new molecules (HONO, $\mathrm{COFCl}, \mathrm{CH}_{3} \mathrm{~F}, \mathrm{CH}_{3} \mathrm{I}, \mathrm{RuO}_{4}, \mathrm{H}_{2} \mathrm{C}_{3} \mathrm{H}_{2}$ ), it now involves 58 molecular species - 145 isotopologues (which 27 are new entries) - representing 6,746,987 entries in the database, which span the spectral range from $10^{-6}$ to $35877 \mathrm{~cm}^{-1}$. In close relation with space missions (IASI, IASI-NG, Merlin, MicroCarb) and taking advantage of ground-based observations (here TCCON FTS), noticeable efforts have been made to improve the validation of the updates for species relevant for the Earth's atmosphere, such as $\mathrm{H}_{2} \mathrm{O}, \mathrm{O}_{2}, \mathrm{O}_{3}, \mathrm{CO}_{2}$ and $\mathrm{CH}_{4}$. Part of this work was enabled by the systematic use of the validation chain SPARTE to evaluate individual line parameters, detect problematic line parameters and consolidate the choices made by the GEISA team.

While the update presented in this paper highly upgrades the previous GEISA2015 release, there is still significant room for improvement. One of the most important aspects of our work is to make available the results of the quality controls we made during the phase of acquisition and delivery processes of new or updated spectroscopic data. The SPARTE chain proves to be a powerful tool to validate and select data for major species of the Earth's atmosphere, but it is still limited for evaluating more exotic species or species having too small spectral signatures. The improvement of some parts of the SPARTE chain through improvement of underlying models (4A/OP), reference spaceborne observations (ACE-FTS limb measurements) or databases (ARSA, ECMWF Reanalyses...) is under progress. General and systematic crosscomparisons with other databases will also be done in future versions of GEISA. In parallel, we plan to generalize, when possible, the use of ab initio data, in collaboration with other teams, both as a point of comparison with experimentally derived effective models traditionally used in spectroscopic databases, but also to improve or complete existing data.

Considering the line parameter database, a crucial path of improvement is the consideration of non-Voigt line-shape parameters. Even though the amount of measurements and calculations involving the recommended Hartmann-Tran profile [172] remains limited so far, the level of precision achieved by the sophisticated non-Voigt profiles is ever increasingly demanded by ground-based or spaceborne instruments. The future releases of GEISA will be designed to gather such high-level information. 
The current GEISA-2020 as well as the GEISA-2015 compilations can be accessed through https://geisa.aeris-data.fr/. Thanks to an updated user-friendly interface, the operations of selection, extraction, sorting, filtering, graphical representation, statistical analysis of the most characteristic spectroscopic parameters are more attractive than in the previous web version. 


\section{Acknowledgements.}

IASI has been developed and built under the responsibility of CNES. It is flown onboard the Metop satellites as part of the EUMETSAT Polar System. The IASI L1 data are received through the EUMETCast near real time data distribution service. We particularly wish to thank the Mésocentre ESPRI services for their help in getting IASI data. TCCON data were obtained from the TCCON Data Archive, hosted by the Carbon Dioxide Information Analysis Center (CDIAC) - tccon.onrl.gov. Calculations were performed using the resources of IDRIS, the computing centre of CNRS and of the IPSL data and computing centre Mésocentre ESPRI. This work has been funded by CNES. The authors thank the CNES MicroCarb team for support and fruitful discussions. The authors are thankful to ECMWF for making the ERA-I and ERA5 outputs available through the ECMWF Data Server.

We also thank the AERIS/IPSL/CNES atmospheric data and computing centre for ensuring a friendly access to the GEISA international community and for managing the website.

Pr. R.R. Gamache is pleased to acknowledge support of this research by the National Science Foundation through Grant No. AGS-1156862.

The researches from V.E. Zuev Institute of Atmospheric Optics of Siberian Branch of Russian Academy of Sciences were supported by the Ministry of Science and Higher Education of the Russian Federation.

The financial support of the Natural Sciences and Engineering Research Council of Canada is gratefully acknowledged by Pr. N. Moazzen-Ahmadi.

The work of Tomsk group on ozone spectroscopy was supported by the Russian Science Foundation RNF grant no. 19-12-00171. GSMA Reims and LiPhy Grenoble acknowledge a support from the French-Russian collaboration program LIA CNRS "SAMIA". V. Ebert and G. Li acknowledge support of the work by the EUMETRISPEC project (www.eumetrispec.org) within the European Metrology Research Program (EMRP).

Last but not least, our warmest thanks go to Nicole Jacquinet who has recently retired. Nicole has devoted more than 40 years of her life to the promotion of GEISA around the world and, more generally, of the need for up-to-date spectroscopy in order to benefit from innovate remote sensing observations.

This work could not stop after that. 


\section{Appendix A. List of acronyms}

$4 \mathrm{~A}$

4A/OP

AERIS

AFGL

ARA/ABC(t)

ASD

CAL/VAL

CDMS

CDSD

CIRS

CNRS

CNES

CRB

CRDS

CVRQD

DAS

DMS

DVR-3D

FT-CEAS

$\mathrm{EH}$

ENVISAT

EUMETSAT

FTIR

FTS

GEISA

GOSAT

GS

GSMA

HITRAN

HWHM

IAO

IASI

IASI/NG

ICB

ID

IDRIS

INSU

IPSL

IR

ISSWG

JPL

KIT

LIPhy
Atlas Automatisé des Absorptions Atmosphériques ;

Automatized Atmospheric Absorption Atlas

4A/OPerational release

Atmosphere and service data pole (CNES, CNRS, IPSL), France

Air Force Geophysics Laboratory

Atmospheric Radiation Analysis/Atmosphère-Biosphère-Climat

(télédétection)

Acetylene Spectroscopic Databank

Calibration/Validation

Cologne Database for Molecular Spectroscopy

Carbon Dioxide Spectroscopic Databank

Composite InfraRed Spectrometer

Centre National de la Recherche Scientifique (France)

Centre National d'Etudes Spatiales (France)

Complex Robert-Bonamy

Cavity ring-down spectroscopy

name of the adiabatic semiglobal PESs of water isotopologues

Differential laser Absorption Spectroscopy

Dipole Moment Surface-3D

Discrete Variable Representation

Continuous Wave-Cavity Absorption Spectroscopy

Effective Hamiltonian

ENVIronmental SATellite

European Organisation for the Exploitation of Meteorological

Satellites

Fourier Transformed InfraRed spectroscopy

Fourier Transform Spectrometer

Gestion et Etude des Informations Spectroscopiques Atmosphériques;

Management and study of Atmospheric Spectroscopic Information

Greenhouse Observing SATellite project

Ground State

Groupe de Spectroscopie Moléculaire et Atmosphérique (France)

HIgh-resolution TRANsmission molecular absorption database

Half Width at Half Maximum

Institute of Atmospheric Optics (Russia)

Infrared Atmospheric Sounder Interferometer

Infrared Atmospheric Sounder Interferometer/New Generation

Institut Carnot de Bourgogne

Identification code

Institut du développement et des ressources en informatique

scientifique

Institut National des Sciences de l'Univers (France)

Institut Pierre Simon Laplace

InfraRed

IASI Sounding Science Working Group

Jet Propulsion Laboratory (USA)

Institute for Meteorology and Climate Research Centre Karlsruhe,

(Germany)

Laboratoire Interdisciplinaire de Physique (France) 
LISA

LMD

MCRB

MERLIN

MICROCARB

MIPAS

Metop

NASA

NCAR

NIR

PES

SPARTE

S\&MPO

SWIR

TIR

VAMDC
Laboratoire Inter-Universitaire des Systèmes Atmosphériques

(France)

Laboratoire de Météorologie Dynamique (France)

Modified Complex Robert-Bonamy

Methane Remote Sensing Lidar Mission

MICROsatellite mission to monitor the fluxes of CARBon dioxide Michelson Interferometer for Passive Atmospheric Sounding

Meteorological operational satellite

National Aeronautics and Space Administration (USA)

National Center for Atmospheric research (USA)

Near-InfraRed

Potential Energy Surface

Spectroscopic Parameters And Radiative Transfer Evaluation

Spectroscopy \& molecular properties of Ozone

ShortWave Infrared

Thermal InfraRed

Virtual Atomic and Molecular Data Centre 


\section{Appendix B. Description of the format used for the line parameters stored in the GEISA-2020 edition:}

The format of each entry is described in the following Table 12.

Each entry is a 252-character record to describe the 31 spectroscopic line parameters.

First line of Table 12: the 31 Spectroscopic line parameters are listed in the 31 columns and their description is given below.

Line 2 and line 3 display the field length and the FORTRAN format descriptor, respectively.

Line 4 displays the standard_default values associated to each parameter.

Line 5 displays a cumulative index indicating the position of the last character of the record associated to each of the 31 spectroscopic line parameters.

The standard default values for fields «O'», « $\mathrm{T} »$ and « $\mathrm{T}$ ' », have been changed and set to "zero". This modification was made to avoid potential misunderstanding and thus improper use of these parameters in some applications especially related to forward radiative transfer. Value in field "M" is documented in GEISA only if it is directly provided by the author of the spectroscopic line entry.

Table 12: Format of each entry in GEISA-2015

\begin{tabular}{|c|c|c|c|c|c|c|c|c|c|c|c|c|}
\hline Parameter & $\mathbf{A}$ & B & $\mathbf{C}$ & D & E1 & E2 & E3 & E4 & $\mathbf{F}$ & G & I & $\mathbf{J}$ \\
\hline Field length & 12 & 11 & 6 & 10 & 25 & 25 & 15 & 15 & 4 & 3 & 3 & 3 \\
\hline Fortran descriptor & F12.6 & 1PD11.4 & 0PF6.4 & F10.4 & A25 & A25 & A15 & A15 & F4.2 & I3 & I3 & A3 \\
\hline Undefined values & NR & -9.9999D-01 & -.9999 & -0.9999 & $*$ & * & $*$ & $*$ & -.99 & -99 & -99 & $*$ \\
\hline Record counting & 12 & 23 & 29 & 39 & 64 & 89 & 104 & 119 & 123 & 126 & 129 & 132 \\
\hline
\end{tabular}

\begin{tabular}{c|c|c|c|c|c|c|c|c|c|}
\hline K & L & M & N & O & R & $A^{\prime}$ & $B^{\prime}$ & $C^{\prime}$ & $F^{\prime}$ \\
\hline 2 & 1 & 10 & 7 & 9 & 6 & 10 & 11 & 6 & 4 \\
\hline I2 & I1 & 1 PE10.3 & 0PF7.4 & F9.6 & F6.4 & F10.6 & 1 PD11.4 & 0PF6.4 & F4.2 \\
\hline-9 & O & $-9.999 E-01$ & -9.9999 & 0.000000 & -.9999 & -0.999999 & $-9.9999 D-01$ & -.9999 & -.99 \\
\hline 134 & 135 & 145 & 152 & 161 & 167 & 177 & 188 & 194 & 198 \\
\hline
\end{tabular}

\begin{tabular}{|c|c|c|c|c|c|c|c|c|}
\hline $\mathbf{O}^{\prime}$ & $\mathbf{R}^{\prime}$ & $\mathbf{N}^{\prime}$ & $\mathbf{S}$ & $S^{\prime}$ & $\mathbf{T}$ & $\mathbf{T}^{\prime}$ & $\mathbf{U}$ & $\mathbf{U}^{\prime}$ \\
\hline 9 & 6 & 7 & 4 & 4 & 8 & 8 & 4 & 4 \\
\hline F9.6 & F6.4 & F7.4 & F4.2 & F4.2 & F8.6 & F8.6 & F4.2 & F4.2 \\
\hline 0.000000 & -.9999 & -9.9999 & -.99 & -.99 & 0.000000 & 0.000000 & $\mid-.99$ & -.99 \\
\hline 207 & 213 & 220 & 224 & 228 & 236 & 244 & 248 & 252 \\
\hline
\end{tabular}

A: wave number $\left(\mathrm{cm}^{-1}\right)$ of the line

B: intensity of the line in $\left(\mathrm{cm}^{-1} /\left(\right.\right.$ molecule. $\left.\mathrm{cm}^{-2}\right)$ at $296 \mathrm{~K}$

C: Air broadening pressure halfwidth $(\mathrm{HWHM})\left(\mathrm{cm}^{-1} \mathrm{~atm}^{-1}\right)$ at $296 \mathrm{~K}$

D: Energy of the lower transition level $\left(\mathrm{cm}^{-1}\right)$

Ei $(i=1,2,3,4)$ : Transition quantum identifications for the lower and upper state of the transition

E1: upper state vibrational identification E2: lower state vibrational identification

E3: upper state rotationnal identification E4: lower state rotationnal identification

$\mathrm{F}$ : temperature dependence coefficient $\mathrm{n}$ of the air broadening halfwidth 
G: identification code for isotopologue as in GEISA

I: identification code for molecule as in GEISA

$\mathrm{J}$ : Internal GEISA code for the data identification

$\mathrm{K}$ : Molecule number as in HITRAN

L: isotopologue number ( $1=$ most abundant, $2=$ second...etc $)$ as in HITRAN

M: Einstein A-coefficient

$\mathrm{N}$ : self-broadening pressure halfwidth (HWHMself) $\left(\mathrm{cm}^{-1} \mathrm{~atm}^{-1}\right)$ at $296 \mathrm{~K}$

O: air pressure shift of the line transition $\left(\mathrm{cm}^{-1}\right)$ at $296 \mathrm{~K}$

$\mathrm{R}$ : temperature dependence coefficient of the air pressure shift

$\mathrm{A}^{\prime}$ : estimated accuracy $\left(\mathrm{cm}^{-1}\right)$ on the line position

$\mathrm{B}^{\prime}$ : estimated accuracy on the intensity of the line in $\left(\mathrm{cm}^{-1} /\left(\right.\right.$ molecule. $\left.\mathrm{cm}^{-2}\right)$

$C^{\prime}$ : estimated accuracy on the air collision halfwidth (HWHM) $\left(\mathrm{cm}^{-1} \mathrm{~atm}^{-1}\right)$

$\mathrm{F}^{\prime}$ : estimated accuracy on the temperature dependence coefficient of the air broadening halfwidth

$\mathrm{O}^{\prime}$ : estimated accuracy on the air pressure shift of the line transition $\left(\mathrm{cm}^{-1}\right)$ at $296 \mathrm{~K}$

$\mathrm{R}^{\prime}$ : estimated accuracy on the temperature dependence coefficient of the air pressure shift

$\mathrm{N}^{\prime}$ : estimated accuracy on the self-broadened (HWHM) $\left(\mathrm{cm}^{-1} \mathrm{~atm}^{-1}\right)$ at $296 \mathrm{~K}$

$\mathrm{S}$ : temperature dependence coefficient of the self-broadening halfwidth

$\mathrm{S}^{\prime}$ : estimated accuracy on the temperature dependence coefficient of the self-broadening halfwidth

$\mathrm{T}$ : self pressure shift of the line transition $\left(\mathrm{cm}^{-1}\right)$ at $296 \mathrm{~K}$

$T^{\prime}$ : estimated accuracy on the self pressure shift of the line transition $\left(\mathrm{cm}^{-1}\right)$ at $296 \mathrm{~K}$

$\mathrm{U}$ : temperature dependence coefficient of the self pressure shift

U': estimated accuracy on the temperature dependence coefficient of the self pressure shift

As shown in line 4 of Table 12 GEISA undefined values are attributed to the line parameter entries when no value is available from the data provider (missing data).

\section{Appendix C. Molecules and isotopologues in GEISA-2015}

Description of molecule and isotopologue codes in GEISA-2020 are given in Table 13. The molecule names and associated codes are in the two first columns; for each molecule, the isotopologue codes and the corresponding detailed formula are in columns 3 and 4 respectively. The abundance used in GEISA is given in the $5^{\text {th }}$ column.

Table 13: Description of the molecule and isotopologue codes in GEISA-2020

\begin{tabular}{|c|c|c||c|c|}
\hline Molecule & $\begin{array}{c}\text { Molecule } \\
\text { Code }\end{array}$ & I Code & Formula & Abundance \\
\hline \multirow{3}{*}{$\mathrm{H}_{2} \mathrm{O}$} & \multirow{3}{*}{1} & 161 & $\mathbf{H}^{16} \mathrm{OH}$ & 0.997317 \\
\cline { 3 - 5 } & & 181 & $\mathbf{H}^{18} \mathrm{OH}$ & 0.002000 \\
\cline { 3 - 5 } & & 171 & $\mathbf{H}^{17} \mathrm{OH}$ & $3.718840 \times 10^{-4}$ \\
\cline { 3 - 5 } & & 262 & $\mathbf{D}^{16} \mathrm{O}$ & $2.419700 \times 10^{-8}$ \\
\hline
\end{tabular}




\begin{tabular}{|c|c|c|c|c|}
\hline Molecule & $\begin{array}{l}\text { Molecule } \\
\text { Code }\end{array}$ & I Code & Formula & Abundance \\
\hline & & 282 & $\mathrm{D}_{2}{ }^{18} \mathrm{O}$ & $4.852080 \times 10^{-11}$ \\
\hline & & 272 & $\mathbf{D}_{2}{ }^{17} \mathrm{O}$ & $9.022841 \times 10^{-12}$ \\
\hline \multirow{12}{*}{$\mathrm{CO}_{2}$} & \multirow{12}{*}{2} & 626 & ${ }^{16} \mathrm{O}^{12} \mathrm{C}^{16} \mathrm{O}$ & 0.9842 \\
\hline & & 636 & ${ }^{16} \mathrm{O}^{13} \mathrm{C}^{16} \mathrm{O}$ & $1.106 \times 10^{-2}$ \\
\hline & & 628 & ${ }^{16} \mathrm{O}^{12} \mathrm{C}^{18} \mathrm{O}$ & $3.947 \times 10^{-3}$ \\
\hline & & 627 & ${ }^{16} \mathrm{O}^{12} \mathrm{C}^{17} \mathrm{O}$ & $7.339 \times 10^{-4}$ \\
\hline & & 638 & ${ }^{16} \mathrm{O}^{13} \mathrm{C}^{18} \mathrm{O}$ & $4.434 \times 10^{-5}$ \\
\hline & & 637 & ${ }^{16} \mathrm{O}^{13} \mathrm{C}^{17} \mathrm{O}$ & $8.246 \times 10^{-6}$ \\
\hline & & 828 & ${ }^{18} \mathrm{O}^{12} \mathrm{C}^{18} \mathrm{O}$ & $3.957 \times 10^{-6}$ \\
\hline & & 728 & ${ }^{17} \mathrm{O}^{12} \mathrm{C}^{18} \mathrm{O}$ & $1.472 \times 10^{-6}$ \\
\hline & & 727 & ${ }^{17} \mathrm{O}^{12} \mathrm{C}^{17} \mathrm{O}$ & $1.430 \times 10^{-7}$ \\
\hline & & 838 & ${ }^{18} \mathrm{O}^{13} \mathrm{C}^{18} \mathrm{O}$ & $4.446 \times 10^{-8}$ \\
\hline & & 738 & ${ }^{17} \mathrm{O}^{13} \mathrm{C}^{18} \mathrm{O}$ & $1.654 \times 10^{-8}$ \\
\hline & & 737 & ${ }^{17} \mathrm{O}^{13} \mathrm{C}^{17} \mathrm{O}$ & $1.55 \times 10^{-9}$ \\
\hline \multirow{5}{*}{$\mathbf{O}_{3}$} & \multirow{5}{*}{3} & 666 & ${ }^{16} O^{16} O^{16} O$ & 0.992901 \\
\hline & & 668 & ${ }^{16} \mathrm{O}^{16} \mathrm{O}^{18} \mathrm{O}$ & 0.003982 \\
\hline & & 686 & ${ }^{16} \mathrm{O}^{18} \mathrm{O}^{16} \mathrm{O}$ & 0.001991 \\
\hline & & 667 & ${ }^{16} O^{16} O^{17} O$ & $7.404750 \times 10^{-4}$ \\
\hline & & 676 & ${ }^{16} O^{17} O^{16} O$ & $3.702370 \times 10^{-4}$ \\
\hline \multirow{8}{*}{$\mathbf{N}_{2} \mathbf{O}$} & \multirow{8}{*}{4} & 446 & ${ }^{14} \mathbf{N}^{14} \mathbf{N}^{16} \mathrm{O}$ & 0.990333 \\
\hline & & 456 & ${ }^{14} N^{15} N^{16} O$ & 0.003641 \\
\hline & & 546 & ${ }^{15} \mathbf{N}^{14} \mathbf{N}^{16} \mathrm{O}$ & 0.003641 \\
\hline & & 448 & ${ }^{14} N^{14} N^{18} O$ & 0.001986 \\
\hline & & 458 & ${ }^{14} N^{14} N^{18} O$ & $7.300807 \times 10^{-4}$ \\
\hline & & 548 & ${ }^{15} N^{14} N^{18} O$ & $7.300807 \times 10^{-4}$ \\
\hline & & 447 & ${ }^{14} \mathbf{N}^{14} \mathbf{N}^{17} \mathbf{O}$ & $3.692800 \times 10^{-4}$ \\
\hline & & 556 & ${ }^{15} N^{15} N^{16} O$ & $1.338574 \times 10^{-5}$ \\
\hline \multirow{6}{*}{$\mathrm{CO}$} & \multirow{6}{*}{5} & 26 & ${ }^{12} \mathrm{C}^{16} \mathrm{O}$ & 0.986544 \\
\hline & & 36 & ${ }^{13} \mathrm{C}^{16} \mathrm{O}$ & 0.011084 \\
\hline & & 28 & ${ }^{12} \mathrm{C}^{18} \mathrm{O}$ & 0.001978 \\
\hline & & 27 & ${ }^{12} C^{17} O$ & $3.678670 \times 10^{-4}$ \\
\hline & & 38 & ${ }^{13} \mathrm{C}^{18} \mathrm{O}$ & $2.222500 \times 10^{-5}$ \\
\hline & & 37 & ${ }^{13} C^{17} \mathrm{O}$ & $4.132920 \times 10^{-6}$ \\
\hline \multirow{2}{*}{$\mathrm{CH}_{4}$} & \multirow{2}{*}{6} & 211 & ${ }^{12} \mathrm{CH}_{4}$ & 0.988274 \\
\hline & & 311 & ${ }^{13} \mathrm{CH}_{4}$ & 0.011103 \\
\hline \multirow{3}{*}{$\mathbf{O}_{2}$} & \multirow{3}{*}{7} & 66 & ${ }^{16} \mathrm{O}^{16} \mathrm{O}$ & 0.995262 \\
\hline & & 68 & ${ }^{16} \mathrm{O}^{18} \mathrm{O}$ & 0.003991 \\
\hline & & 67 & ${ }^{16} \mathrm{O}^{17} \mathrm{O}$ & $7.422350 \times 10^{-4}$ \\
\hline
\end{tabular}




\begin{tabular}{|c|c|c|c|c|}
\hline Molecule & $\begin{array}{l}\text { Molecule } \\
\text { Code }\end{array}$ & I Code & Formula & Abundance \\
\hline \multirow{3}{*}{ NO } & \multirow{3}{*}{8} & 46 & ${ }^{14} \mathrm{~N}^{16} \mathrm{O}$ & 0.993974 \\
\hline & & 56 & ${ }^{15} \mathrm{~N}^{16} \mathrm{O}$ & 0.003654 \\
\hline & & 48 & ${ }^{14} \mathbf{N}^{18} \mathrm{O}$ & 0.001993 \\
\hline \multirow{2}{*}{$\mathrm{SO}_{2}$} & \multirow{2}{*}{9} & 626 & ${ }^{32} \mathrm{~S}^{16} \mathrm{O}_{2}$ & 0.945678 \\
\hline & & 646 & ${ }^{34} \mathrm{~S}^{16} \mathrm{O}_{2}$ & 0.041950 \\
\hline \multirow{2}{*}{$\mathrm{NO}_{2}$} & \multirow{2}{*}{10} & 646 & ${ }^{14} \mathbf{N}^{16} \mathrm{O}_{2}$ & 0.991616 \\
\hline & & 656 & ${ }^{15} \mathbf{N}^{16} \mathrm{O}_{2}$ & 0.003646 \\
\hline \multirow{2}{*}{$\mathbf{N H}_{3}$} & \multirow{2}{*}{11} & 411 & ${ }^{14} \mathrm{NH}_{3}$ & 0.995872 \\
\hline & & 511 & ${ }^{15} \mathrm{NH}_{3}$ & 0.003661 \\
\hline $\mathrm{PH}_{3}$ & 12 & 131 & ${ }^{31} \mathrm{PH}_{3}$ & 0.999533 \\
\hline \multirow{2}{*}{$\mathrm{HNO}_{3}$} & \multirow{2}{*}{13} & 146 & $\mathrm{H}^{14} \mathbf{N}^{16} \mathrm{O}$ & 0.989110 \\
\hline & & 156 & $\mathrm{H}^{15} \mathrm{~N}^{16} \mathrm{O}$ & 0.003636 \\
\hline \multirow{3}{*}{$\mathbf{O H}$} & \multirow{3}{*}{14} & 61 & ${ }^{16} \mathrm{OH}$ & 0.997473 \\
\hline & & 81 & ${ }^{18} \mathrm{OH}$ & 0.002000 \\
\hline & & 62 & ${ }^{16} \mathrm{OD}$ & $1.553710 \times 10^{-4}$ \\
\hline \multirow{2}{*}{ HF } & \multirow{2}{*}{15} & 19 & $\mathbf{H}^{19} \mathbf{F}$ & 0.999844 \\
\hline & & 29 & $D^{19} F$ & $1.557410 \times 10^{-4}$ \\
\hline \multirow{4}{*}{$\mathrm{HCl}$} & \multirow{4}{*}{16} & 15 & $\mathrm{H}^{35} \mathrm{Cl}$ & 0.757587 \\
\hline & & 17 & $\mathrm{H}^{37} \mathrm{Cl}$ & 0.242257 \\
\hline & & 25 & $\mathrm{D}^{35} \mathrm{Cl}$ & $1.180050 \times 10^{-4}$ \\
\hline & & 27 & $\mathrm{D}^{37} \mathrm{Cl}$ & $3.773500 \times 10^{-5}$ \\
\hline \multirow{4}{*}{$\mathrm{HBr}$} & \multirow{4}{*}{17} & 19 & $\mathrm{H}^{79} \mathrm{Br}$ & 0.506781 \\
\hline & & 11 & $\mathrm{H}^{81} \mathrm{Br}$ & 0.493063 \\
\hline & & 29 & $\mathrm{D}^{79} \mathrm{Br}$ & $7.893840 \times 10^{-5}$ \\
\hline & & 21 & $\mathrm{D}^{81} \mathrm{Br}$ & $7.680160 \times 10^{-5}$ \\
\hline \multirow{2}{*}{ HI } & \multirow{2}{*}{18} & 17 & $\mathbf{H}^{127} \mathbf{I}$ & 0.999844 \\
\hline & & 27 & $D^{127} I$ & $1.557410 \times 10^{-4}$ \\
\hline \multirow{2}{*}{$\mathrm{ClO}$} & \multirow{2}{*}{19} & 56 & ${ }^{35} \mathrm{Cl}^{16} \mathrm{O}$ & 0.755908 \\
\hline & & 76 & ${ }^{37} \mathrm{Cl}^{16} \mathrm{O}$ & 0.241720 \\
\hline \multirow{6}{*}{ OCS } & \multirow{6}{*}{20} & 622 & ${ }^{16} O^{12} C^{32} S$ & 0.937395 \\
\hline & & 624 & ${ }^{16} O^{12} C^{34} S$ & 0.041583 \\
\hline & & 632 & ${ }^{16} O^{13} C^{32} S$ & 0.010531 \\
\hline & & 623 & ${ }^{16} O^{12} C^{33} S$ & 0.007399 \\
\hline & & 822 & ${ }^{18} O^{12} C^{32} S$ & 0.001880 \\
\hline & & 634 & ${ }^{16} O^{13} C^{34} S$ & $4.671757 \times 10^{-4}$ \\
\hline \multirow{3}{*}{$\mathrm{H}_{2} \mathrm{CO}$} & & 126 & $\mathrm{H}_{2}{ }^{12} \mathrm{C}^{16} \mathrm{O}$ & 0.986237 \\
\hline & 21 & 136 & $\mathrm{H}_{2}{ }^{13} \mathrm{C}^{16} \mathrm{O}$ & 0.011080 \\
\hline & & 128 & $\mathrm{H}_{2}{ }^{12} \mathrm{C}^{18} \mathrm{O}$ & 0.001978 \\
\hline GU & 29 & 226 & ${ }^{12} \mathrm{C}_{2} \mathrm{H}_{6}$ & 0.976990 \\
\hline$C_{216}$ & 22 & 236 & ${ }^{12} \mathrm{C}^{13} \mathrm{CH}_{6}$ & 0.021953 \\
\hline CU & 2 & 212 & ${ }^{12} \mathrm{CH}_{3} \mathrm{D}$ & $6.157510 \times 10^{-4}$ \\
\hline CH3D & 23 & 312 & ${ }^{13} \mathrm{CH}_{3} \mathrm{D}$ & $6.917850 \times 10^{-6}$ \\
\hline $\mathrm{C}_{2} \mathrm{H}_{2}$ & 24 & 221 & ${ }^{12} \mathrm{C}_{2} \mathrm{H}_{2}$ & 0.977599 \\
\hline
\end{tabular}




\begin{tabular}{|c|c|c|c|c|}
\hline Molecule & $\begin{array}{c}\text { Molecule } \\
\text { Code }\end{array}$ & I Code & Formula & Abundance \\
\hline & & 231 & ${ }^{12} \mathrm{C}^{13} \mathrm{CH}_{2}$ & 0.021966 \\
\hline \multirow{2}{*}{$\mathrm{C}_{2} \mathrm{H}_{4}$} & \multirow{2}{*}{25} & 211 & ${ }^{12} \mathrm{C}_{2} \mathrm{H}_{4}$ & 0.977294 \\
\hline & & 311 & ${ }^{12} \mathrm{C}^{13} \mathrm{CH}_{4}$ & 0.021959 \\
\hline \multirow{5}{*}{$\mathrm{GeH}_{4}$} & \multirow{5}{*}{26} & 411 & ${ }^{74} \mathrm{GeH}_{4}$ & 1.000000 \\
\hline & & 211 & ${ }^{72} \mathrm{GeH}_{4}$ & 1.000000 \\
\hline & & 011 & ${ }^{70} \mathrm{GeH}_{4}$ & 1.000000 \\
\hline & & 311 & ${ }^{73} \mathrm{GeH}_{4}$ & 1.000000 \\
\hline & & 611 & ${ }^{76} \mathrm{GeH}_{4}$ & 1.000000 \\
\hline \multirow{4}{*}{$\mathrm{HCN}$} & \multirow{4}{*}{27} & 124 & $H^{12} C^{14} N$ & 0.985114 \\
\hline & & 134 & $H^{13} C^{14} N$ & 0.011068 \\
\hline & & 125 & $H^{12} C^{15} N$ & 0.003622 \\
\hline & & 224 & $D^{12} C^{14} N$ & $1.534456 \times 10^{-4}$ \\
\hline $\mathrm{C}_{3} \mathrm{H}_{8}$ & 28 & 221 & ${ }^{12} \mathrm{C}_{3} \mathrm{H}_{8}$ & 0.965835 \\
\hline $\mathrm{C}_{2} \mathrm{~N}_{2}$ & 29 & 224 & ${ }^{12} \mathrm{C}_{2}{ }^{14} \mathrm{~N}_{2}$ & 0.970752 \\
\hline $\mathrm{C}_{4} \mathrm{H}_{2}$ & 30 & 211 & ${ }^{12} \mathrm{C}_{4} \mathrm{H}_{2}$ & 0.955998 \\
\hline $\mathrm{HC}_{3} \mathrm{~N}$ & 31 & 124 & $\mathrm{H}^{12} \mathrm{C}_{3}{ }^{14} \mathrm{~N}$ & 0.963346 \\
\hline \multirow{2}{*}{ HOCl } & \multirow{2}{*}{32} & 165 & $\mathrm{H}^{16} \mathrm{O}^{35} \mathrm{Cl}$ & 0.755790 \\
\hline & & 167 & $\mathrm{H}^{16} \mathrm{O}^{37} \mathrm{Cl}$ & 0.241683 \\
\hline $\mathbf{N}_{2}$ & 33 & 44 & ${ }^{14} \mathbf{N}^{14} \mathbf{N}$ & 0.992687 \\
\hline \multirow{2}{*}{$\mathrm{CH}_{3} \mathrm{Cl}$} & \multirow{2}{*}{34} & 215 & ${ }^{12} \mathrm{CH}_{3}{ }^{35} \mathrm{Cl}$ & 0.748937 \\
\hline & & 217 & ${ }^{12} \mathrm{CH}_{3}{ }^{37} \mathrm{Cl}$ & 0.239491 \\
\hline $\mathrm{H}_{2} \mathrm{O}_{2}$ & 35 & 166 & $\mathrm{H}_{2}{ }^{16} \mathrm{O}^{16} \mathrm{O}$ & 0.994952 \\
\hline \multirow{3}{*}{$\mathbf{H}_{2} \mathrm{~S}$} & \multirow{3}{*}{36} & 121 & $\mathbf{H}_{2}{ }^{32} \mathbf{S}$ & 0.949884 \\
\hline & & 141 & $\mathbf{H}_{2}{ }^{34} \mathrm{~S}$ & 0.042137 \\
\hline & & 131 & $\mathbf{H}_{2}{ }^{33} \mathbf{S}$ & 0.007498 \\
\hline НСООН & 37 & 261 & $\mathrm{H}^{12} \mathrm{C}^{16} \mathrm{O}^{16} \mathrm{OH}$ & 0.983898 \\
\hline$\overline{\mathrm{COF}_{2}}$ & 38 & 269 & ${ }^{12} \mathrm{C}^{16} \mathrm{O}^{19} \mathrm{~F}_{2}$ & 0.986544 \\
\hline $\mathrm{SF}_{6}$ & 39 & 29 & ${ }^{32} S^{19} F_{6}$ & 0.950180 \\
\hline $\mathrm{C}_{3} \mathrm{H}_{4}$ & 40 & 341 & ${ }^{12} \mathrm{C}_{3} \mathrm{H}_{6}$ & 0.966587 \\
\hline $\mathrm{HO}_{2}$ & 41 & 166 & $\mathrm{H}^{16} \mathrm{O}_{2}$ & 0.995107 \\
\hline \multirow{2}{*}{$\mathrm{ClONO}_{2}$} & \multirow{2}{*}{42} & 564 & ${ }^{15} \mathrm{Cl}^{16} \mathrm{O}^{14} \mathrm{~N}^{16} \mathrm{O}_{2}$ & 0.749570 \\
\hline & & 764 & ${ }^{17} \mathrm{Cl}^{16} \mathrm{O}^{14} \mathrm{~N}^{16} \mathrm{O}_{2}$ & 0.239694 \\
\hline \multirow{2}{*}{$\mathrm{CH}_{3} \mathrm{Br}$} & \multirow{2}{*}{43} & 79 & ${ }^{12} \mathrm{CH}_{3}{ }^{79} \mathrm{Br}$ & 0.500995 \\
\hline & & 81 & ${ }^{12} \mathrm{CH}_{3}{ }^{81} \mathrm{Br}$ & 0.487433 \\
\hline $\mathrm{CH}_{3} \mathrm{OH}$ & 44 & 216 & ${ }^{12} \mathrm{CH}_{3}{ }^{16} \mathrm{OH}$ & 0.985930 \\
\hline $\mathrm{NO}^{+}$ & 45 & 46 & ${ }^{14} \mathbf{N}^{16} \mathrm{O}+$ & 0.993974 \\
\hline HNC & 46 & 142 & $\mathrm{H}^{14} \mathbf{N}^{12} \mathrm{C}$ & 0.985114 \\
\hline $\mathrm{C}_{6} \mathrm{H}_{6}$ & 47 & 266 & ${ }^{12} \mathrm{C}_{6} \mathrm{H}_{6}$ & 0.934291 \\
\hline $\mathrm{C}_{2} \mathrm{HD}$ & 48 & 122 & ${ }^{12} \mathrm{C}_{2} \mathrm{HD}$ & $3.045500 \times 10^{-4}$ \\
\hline $\mathrm{CF}_{4}$ & 49 & 291 & ${ }^{12} C^{19} F_{4}$ & 0.988890 \\
\hline $\mathrm{CH}_{3} \mathrm{CN}$ & 50 & 234 & ${ }^{12} \mathrm{CH}_{3}{ }^{12} \mathrm{C}^{14} \mathrm{~N}$ & 0.973866 \\
\hline \multirow{2}{*}{ HDO } & \multirow{2}{*}{51} & 162 & $\mathrm{H}^{16} \mathrm{OD}$ & $3.106930 \times 10^{-4}$ \\
\hline & & 182 & $\mathrm{H}^{18} \mathrm{OD}$ & $6.230030 \times 10^{-7}$ \\
\hline
\end{tabular}




\begin{tabular}{|c|c|c|c|c|}
\hline Molecule & $\begin{array}{l}\text { Molecule } \\
\text { Code }\end{array}$ & I Code & Formula & Abundance \\
\hline & & 172 & $\mathrm{H}^{17} \mathrm{OD}$ & $1.158530 \times 10^{-7}$ \\
\hline $\mathrm{SO}_{3}$ & 52 & 26 & ${ }^{32} \mathrm{~S}^{16} \mathrm{O}_{3}$ & 0.943400 \\
\hline HONO & 53 & 646 & $H^{16} O^{14} N^{16} O$ & 0.9937102 \\
\hline \multirow{2}{*}{ COFCl } & \multirow{2}{*}{54} & 265 & ${ }^{12} \mathrm{C}^{16} \mathrm{OF}^{35} \mathrm{Cl}$ & 1.000000 \\
\hline & & 267 & ${ }^{12} \mathrm{C}^{16} \mathrm{OF}^{37} \mathrm{Cl}$ & 1.000000 \\
\hline $\mathrm{CH}_{3} \mathrm{I}$ & 55 & 217 & ${ }^{12} \mathrm{CH}_{3}{ }^{127} \mathrm{I}$ & 1.000000 \\
\hline $\mathrm{CH}_{3} \mathrm{~F}$ & 56 & 219 & $12 \mathrm{CH}_{3}{ }^{19} \mathrm{~F}$ & 1.000000 \\
\hline \multirow{9}{*}{$\mathrm{RuO}_{4}$} & \multirow{9}{*}{57} & 102 & ${ }^{102} \mathrm{Ru}^{16} \mathrm{O4}$ & 1.000000 \\
\hline & & 104 & ${ }^{104} \mathrm{Ru}^{16} \mathrm{O} 4$ & 1.000000 \\
\hline & & 101 & ${ }^{101} \mathrm{Ru}^{16} \mathrm{O4}$ & 1.000000 \\
\hline & & 99 & ${ }^{99} \mathrm{Ru}^{16} \mathrm{O} 4$ & 1.000000 \\
\hline & & 100 & ${ }^{100} \mathrm{Ru}^{16} \mathrm{O4}$ & 1.000000 \\
\hline & & 97 & ${ }^{97} \mathrm{Ru}^{16} \mathrm{O4}$ & 1.000000 \\
\hline & & 98 & ${ }^{98} \mathrm{Ru}^{16} \mathrm{O} 4$ & 1.000000 \\
\hline & & 106 & ${ }^{106} \mathrm{Ru}^{16} \mathrm{O} 4$ & 1.000000 \\
\hline & & 103 & ${ }^{103} \mathrm{Ru}^{16} \mathrm{O} 4$ & 1.000000 \\
\hline $\mathrm{H}_{2} \mathrm{C}_{3} \mathrm{H}_{2}$ & 58 & 121 & $\mathrm{H}_{2}{ }^{12} \mathrm{C}_{3} \mathrm{H}_{2}$ & 1.000000 \\
\hline
\end{tabular}


Bibliography

[1] N. Jacquinet-Husson, R. Armante, N.A. Scott, A. Chédin, L. Crépeau, C. Boutammine, A. Bouhdaoui, C. Crevoisier, V. Capelle, C. Boonne, N. Poulet-Crovisier, A. Barbe, D. Chris Benner, V. Boudon, L.R. Brown, J. Buldyreva, A. Campargue, L.H. Coudert, V.M. Devi, M.J. Down, B.J. Drouin, A. Fayt, C. Fittschen, J.-M. Flaud, R.R. Gamache, J.J. Harrison, C. Hill, Ø. Hodnebrog, S.-M. Hu, D. Jacquemart, A. Jolly, E. Jiménez, N.N. Lavrentieva, A.-W. Liu, L. Lodi, O.M. Lyulin, S.T. Massie, S. Mikhailenko, H.S.P. Müller, O.V. Naumenko, A. Nikitin, C.J. Nielsen, J. Orphal, V.I. Perevalov, A. Perrin, E. Polovtseva, A. Predoi-Cross, M. Rotger, A.A. Ruth, S.S. Yu, K. Sung, S.A. Tashkun, J. Tennyson, V.G. Tyuterev, J. Vander Auwera, B.A. Voronin, A. Makie, The 2015 edition of the GEISA spectroscopic database, J. Mol. Spectrosc. 327 (2016). https://doi.org/10.1016/j.jms.2016.06.007.

[2] I.E. Gordon, L.S. Rothman, C. Hill, R. V. Kochanov, Y. Tan, P.F. Bernath, M. Birk, V. Boudon, A. Campargue, K. V. Chance, B.J. Drouin, J.M. Flaud, R.R. Gamache, J.T. Hodges, D. Jacquemart, V.I. Perevalov, A. Perrin, K.P. Shine, M.A.H. Smith, J. Tennyson, G.C. Toon, H. Tran, V.G. Tyuterev, A. Barbe, A.G. Császár, V.M. Devi, T. Furtenbacher, J.J. Harrison, J.M. Hartmann, A. Jolly, T.J. Johnson, T. Karman, I. Kleiner, A.A. Kyuberis, J. Loos, O.M. Lyulin, S.T. Massie, S.N. Mikhailenko, N. Moazzen-Ahmadi, H.S.P. Müller, O. V. Naumenko, A. V. Nikitin, O.L. Polyansky, M. Rey, M. Rotger, S.W. Sharpe, K. Sung, E. Starikova, S.A. Tashkun, J. Vander Auwera, G. Wagner, J. Wilzewski, P. Wcisło, S. Yu, E.J. Zak, The HITRAN2016 molecular spectroscopic database, J. Quant. Spectrosc. Radiat. Transf. 203 (2017) 3-69. https://doi.org/10.1016/j.jqsrt.2017.06.038.

[3] A. Chedin, N. Husson, N. Scott, Une banque de données pour l'étude des phénomènes de transfert radiatif dans les atmosphères planétaires: la banque GEISA, Bull. d'Information Du Cent. Données Stellaires, Fr. 22 (1982) 21-121.

[4] N. Husson, B. Bonnet, N.A. Scott, A. Chedin, Management and study of spectroscopic information: The GEISA program, J. Quant. Spectrosc. Radiat. Transf. 48 (1992) 509-518. https://doi.org/10.1016/0022-4073(92)90116-L.

[5] N. Jacquinet-Husson, E. Arié, J. Ballard, A. Barbe, G. Bjoraker, B. Bonnet, L.R. Brown, C. Camy-Peyret, J.P. Champion, A. Chédin, A. Chursin, C. Clerbaux, G. Duxbury, J.-M. Flaud, N. Fourrié, A. Fayt, G. Graner, R. Gamache, A. Goldman, V. Golovko, G. Guelachvili, J.M. Hartmann, J.C. Hilico, J. Hillman, G. Lefèvre, E. Lellouch, S.N. Mikhaïlenko, O. V Naumenko, V. Nemtchinov, D.A. Newnham, A. Nikitin, J. Orphal, A. Perrin, D.C. Reuter, C.P. Rinsland, L. Rosenmann, L.S. Rothman, N.A. Scott, J. Selby, L.N. Sinitsa, J.M. Sirota, A.M. Smith, K.M. Smith, V.G. Tyuterev, R.H. Tipping, S. Urban, P. Varanasi, M. Weber, The 1997 spectroscopic GEISA databank, J. Quant. Spectrosc. Radiat. Transf. 62 (1999) 205-254. https://doi.org/10.1016/S0022-4073(98)00111-3.

[6] N. Jacquinet-Husson, N.A. Scott, A. Chédin, L. Crépeau, R. Armante, V. Capelle, J. Orphal, A. Coustenis, C. Boonne, N. Poulet-Crovisier, A. Barbe, M. Birk, L.R. Brown, C. CamyPeyret, C. Claveau, K. Chance, N. Christidis, C. Clerbaux, P.F. Coheur, V. Dana, L. Daumont, M.R. De Backer-Barilly, G. Di Lonardo, J.M. Flaud, A. Goldman, A. Hamdouni, M. Hess, M.D. Hurley, D. Jacquemart, I. Kleiner, P. Köpke, J.Y. Mandin, S. Massie, S. Mikhailenko, V. Nemtchinov, A. Nikitin, D. Newnham, A. Perrin, V.I. Perevalov, S. Pinnock, L. Régalia-Jarlot, C.P. Rinsland, A. Rublev, F. Schreier, L. Schult, K.M. Smith, S.A. Tashkun, J.L. Teffo, R.A. Toth, V.G. Tyuterev, J. Vander Auwera, P. Varanasi, G. Wagner, The GEISA spectroscopic database: Current and future archive for Earth and planetary atmosphere studies, J. Quant. Spectrosc. Radiat. Transf. 109 (2008) 1043-1059. https://doi.org/10.1016/j.jqsrt.2007.12.015. 
[7] N. Jacquinet-Husson, L. Crepeau, R. Armante, C. Boutammine, A. Chédin, N.A. Scott, C. Crevoisier, V. Capelle, C. Boone, N. Poulet-Crovisier, A. Barbe, A. Campargue, D. Chris Benner, Y. Benilan, B. Bézard, V. Boudon, L.R. Brown, L.H. Coudert, A. Coustenis, V. Dana, V.M. Devi, S. Fally, A. Fayt, J.-M. Flaud, A. Goldman, M. Herman, G.J. Harris, D. Jacquemart, A. Jolly, I. Kleiner, A. Kleinböhl, F. Kwabia-Tchana, N. Lavrentieva, N. Lacome, L.-H. Xu, O.M. Lyulin, J.-Y. Mandin, A. Maki, S. Mikhailenko, C.E. Miller, T. Mishina, N. Moazzen-Ahmadi, H.S.P. Müller, A. Nikitin, J. Orphal, V. Perevalov, A. Perrin, D.T. Petkie, A. Predoi-Cross, C.P. Rinsland, J.J. Remedios, M. Rotger, M.A.H. Smith, K. Sung, S. Tashkun, J. Tennyson, R.A. Toth, A.-C. Vandaele, J. Vander Auwera, The 2009 edition of the GEISA spectroscopic database, J. Quant. Spectrosc. Radiat. Transf. 112 (2011) 2395-2445. https://doi.org/10.1016/j.jqsrt.2011.06.004.

[8] R. Armante, N. Scott, C. Crevoisier, V. Capelle, L. Crepeau, N. Jacquinet, A. Chédin, Evaluation of spectroscopic databases through radiative transfer simulations compared to observations. Application to the validation of GEISA 2015 with IASI and TCCON, J. Mol. Spectrosc. 327 (2016) 180-192. https://doi.org/10.1016/j.jms.2016.04.004.

[9] D. Wunch, G.C. Toon, J.F.L. Blavier, R.A. Washenfelder, J. Notholt, B.J. Connor, D.W.T. Griffith, V. Sherlock, P.O. Wennberg, The total carbon column observing network, Philos. Trans. R. Soc. A Math. Phys. Eng. Sci. 369 (2011) 2087-2112.

https://doi.org/10.1098/rsta.2010.0240.

[10] A. Scott, N.A. and Chédin, A Fast Line-by-Line Method for Atmospheric Absorption Computations: The Automatized Atmospheric Absorption Atlas, J. Appl. Meteorol. 20 (1981) 802-812.

[11] R.R. Gamache, B. Vispoel, M. Rey, A. Nikitin, V. Tyuterev, O. Egorov, I.E. Gordon, V. Boudon, Total internal partition sums for the HITRAN2020 database, J. Quant. Spectrosc. Radiat. Transf. 271 (2021) 107713. https://doi.org/10.1016/j.jqsrt.2021.107713.

[12] S.N. Mikhailenko, S. Kassi, D. Mondelain, R.R. Gamache, A. Campargue, A spectroscopic database for water vapor between 5850 and $8340 \mathrm{~cm}-1$, J. Quant. Spectrosc. Radiat. Transf. 179 (2016) 198-216. https://doi.org/10.1016/j.jqsrt.2016.03.035.

[13] S.N. Mikhailenko, S. Kassi, D. Mondelain, A. Campargue, Water vapor absorption between 5690 and $8340 \mathrm{~cm}^{-1}$ : Accurate empirical line centers and validation tests of calculated line intensities, J. Quant. Spectrosc. Radiat. Transf. 245 (2020) 106840.

https://doi.org/10.1016/j.jqsrt.2020.106840.

[14] B. Vispoel, J.H. Cavalcanti, R.R. Gamache, Modified complex Robert-Bonamy calculations of line shape parameters and their temperature dependence for water vapor in collision with N2, J. Quant. Spectrosc. Radiat. Transf. 228 (2019) 79-89.

https://doi.org/10.1016/j.jqsrt.2019.02.023.

[15] B. Vispoel, J.H. Cavalcanti, E.T. Paige, R.R. Gamache, Vibrational dependence, temperature dependence, and prediction of line shape parameters for the H2O-N2 collision system, J. Quant. Spectrosc. Radiat. Transf. 253 (2020) 107030. https://doi.org/10.1016/j.jqsrt.2020.107030.

[16] A. Campargue, S. Kassi, A. Yachmenev, A.A. Kyuberis, J. Küpper, S.N. Yurchenko, Observation of electric-quadrupole infrared transitions in water vapor, Phys. Rev. Res. 2 (2020) 23091. https://doi.org/10.1103/PhysRevResearch.2.023091.

[17] A. Campargue, A.M. Solodov, A.A. Solodov, A. Yachmenev, S.N. Yurchenko, Detection of electric-quadrupole transitions in water vapour near 5.4 and $2.5 \mu \mathrm{m}$, Phys. Chem. Chem. 
Phys. 22 (2020) 12476-12481. https://doi.org/10.1039/D0CP01667E.

[18] J. Tennyson, P.F. Bernath, L.R. Brown, A. Campargue, M.R. Carleer, A.G. Császár, R.R. Gamache, J.T. Hodges, A. Jenouvrier, O. V Naumenko, O.L. Polyansky, L.S. Rothman, R.A. Toth, A.C. Vandaele, N.F. Zobov, L. Daumont, A.Z. Fazliev, T. Furtenbacher, I.E. Gordon, S.N. Mikhailenko, S. V Shirin, IUPAC critical evaluation of the rotational-vibrational spectra of water vapor. Part I-Energy levels and transition wavenumbers for $\mathrm{H} 217 \mathrm{O}$ and H218O, J. Quant. Spectrosc. Radiat. Transf. 110 (2009) 573-596.

https://doi.org/10.1016/j.jqsrt.2009.02.014.

[19] A.A. Kyuberis, N.F. Zobov, O. V. Naumenko, B.A. Voronin, O.L. Polyansky, L. Lodi, A. Liu, S.M. Hu, J. Tennyson, Room temperature line lists for deuterated water, J. Quant. Spectrosc. Radiat. Transf. 203 (2017) 175-185. https://doi.org/10.1016/j.jqsrt.2017.06.026.

[20] S. V. Shirin, N.F. Zobov, O.L. Polyansky, Theoretical line list of D216O up to 16,000 cm-1 with an accuracy close to experimental, J. Quant. Spectrosc. Radiat. Transf. 109 (2008) 549558. https://doi.org/10.1016/j.jqsrt.2007.07.010.

[21] R.R. Gamache, J.-M. Hartmann, An intercomparison of measured pressure-broadening and pressure-shifting parameters of water vapor, Can. J. Chem. 82 (2004) 1013-1027. https://doi.org/10.1139/v04-069.

[22] L.H. Coudert, The bending potential energy function of HDO obtained from high-resolution data, J. Mol. Spectrosc. 330 (2016) 112-119. https://doi.org/10.1016/j.jms.2016.07.008.

[23] P. Biévre, M. Gallet, N.E. Holden, I.L. Barnes, Isotopic Abundances and Atomic Weights of the Elements, J. Phys. Chem. Ref. Data. 13 (1984) 809-891. https://doi.org/10.1063/1.555720.

[24] S.N. Yurchenko, B.A. Voronin, R.N. Tolchenov, N. Doss, O. V. Naumenko, W. Thiel, J. Tennyson, Potential energy surface of HDO up to $25000 \mathrm{~cm}-1$, J. Chem. Phys. 128 (2008) 1-13. https://doi.org/10.1063/1.2806165.

[25] M.J. Down, Assignment of Trace Atmospheric Species, University College London, 2014. https://discovery.ucl.ac.uk/id/eprint/1419269/.

[26] S.A. Tashkun, V.I. Perevalov, R.R. Gamache, J. Lamouroux, CDSD-296, high-resolution carbon dioxide spectroscopic databank: An update, J. Quant. Spectrosc. Radiat. Transf. 228 (2019) 124-131. https://doi.org/10.1016/J.JQSRT.2019.03.001.

[27] S.A. Tashkun, V.I. Perevalov, R.R. Gamache, J. Lamouroux, CDSD-296, high resolution carbon dioxide spectroscopic databank: Version for atmospheric applications, J. Quant. Spectrosc. Radiat. Transf. 152 (2015) 45-73. https://doi.org/10.1016/J.JQSRT.2014.10.017.

[28] ftp://ftp.iao.ru/pub/CDSD-296/, (n.d.).

[29] V. Wilquet, A. Mahieux, A.C. Vandaele, V.I. Perevalov, S.A. Tashkun, A. Fedorova, O. Korablev, F. Montmessin, R. Dahoo, J.-L. Bertaux, Line parameters for the 01111-00001 band of $12 \mathrm{C} 16 \mathrm{O} 18 \mathrm{O}$ from SOIR measurements of the Venus atmosphere, J. Quant. Spectrosc. Radiat. Transf. 109 (2008) 895-905. https://doi.org/10.1016/J.JQSRT.2007.12.021.

[30] G.L. Villanueva, M.J. Mumma, R.E. Novak, T. Hewagama, Identification of a new band system of isotopic $\mathrm{CO} 2$ near $3.3 \mu \mathrm{m}$ : Implications for remote sensing of biomarker gases on Mars, Icarus. 195 (2008) 34-44. https://doi.org/10.1016/j.icarus.2007.11.014. 
[31] V.G. Tyuterev, A. Barbe, D. Jacquemart, C. Janssen, S.N. Mikhailenko, E.N. Starikova, Ab initio predictions and laboratory validation for consistent ozone intensities in the MW, 10 and $5 \mu \mathrm{m}$ ranges, J. Chem. Phys. 150 (2019). https://doi.org/10.1063/1.5089134.

[32] S. Mikhailenko, A. Barbe, High resolution infrared spectrum of 16O3: The 3600-4300 cm-1 range reinvestigated, J. Quant. Spectrosc. Radiat. Transf. 244 (2020). https://doi.org/10.1016/j.jqsrt.2019.106823.

[33] V. Kokoouline, D. Lapierre, A. Alijah, V. Tyuterev, Localized and delocalized bound states of the main isotopologue $48 \mathrm{O} 3$ and of $18 \mathrm{O}$-enriched $50 \mathrm{O} 3$ isotopomers of the ozone molecule near the dissociation threshold, Phys. Chem. Chem. Phys. 22 (2020) 15885-15899. https://doi.org/10.1039/D0CP02177F.

[34] S. Vasilchenko, A. Barbe, E. Starikova, S. Kassi, D. Mondelain, A. Campargue, V. Tyuterev, Detection and assignment of ozone bands near $95 \%$ of the dissociation threshold: Ultrasensitive experiments for probing potential energy function and vibrational dynamics, Phys. Rev. A. 102 (2020) 52804. https://doi.org/10.1103/PhysRevA.102.052804.

[35] Y.L. Babikov, S.N. Mikhailenko, A. Barbe, V.G. Tyuterev, S\&MPO - An information system for ozone spectroscopy on the WEB, J. Quant. Spectrosc. Radiat. Transf. 145 (2014) 169-196. https://doi.org/10.1016/j.jqsrt.2014.04.024.

[36] A. Barbe, S. Mikhailenko, E. Starikova, M.-R. De Backer, V.G. Tyuterev, D. Mondelain, S. Kassi, A. Campargue, C. Janssen, S. Tashkun, R. Kochanov, R. Gamache, J. Orphal, Ozone spectroscopy in the electronic ground state: High-resolution spectra analyses and update of line parameters since 2003, J. Quant. Spectrosc. Radiat. Transf. 130 (2013) 172-190. https://doi.org/10.1016/j.jqsrt.2013.06.007.

[37] A. Barbe, S. Mikhailenko, Starikova E., V. Tyuterev, Ozone FTS spectra in the infrared range revisited, J. Quant. Spectrosc. Radiat. Transf. to be publ (2021).

[38] S\&MPO website, (n.d.). https://smpo.iao.ru.

[39] J.M. Flaud, A. Barbe, C. Camy-Peyret, J.J. Plateaux, High resolution analysis of the 5v3, $3 v 1+v 2+v 3$, and $v 1+4 v 3$ bands of 16O3: line positions and intensities, J. Mol. Spectrosc. 177 (1996) 34-39. https://doi.org/10.1006/jmsp.1996.0114.

[40] J.-M. Flaud, C. Camy-Peyret, V.M. Devi, C.P. Rinsland, M.A.H. Smith, The $v 1$ and v3 bands of 16O3: Line positions and intensities, J. Mol. Spectrosc. 124 (1987) 209-217. https://doi.org/10.1016/0022-2852(87)90135-4.

[41] J.-M. Flaud, C. Camy-Peyret, C.P. Rinsland, M.A.H. Smith, V. Malathy Devi, Line

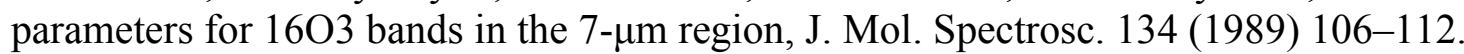
https://doi.org/10.1016/0022-2852(89)90132-X.

[42] A. Barbe, A. Chichery, V.. Tyuterev, S. Taskhun, S. Mikhailenko, The $2 v 2$ and $3 v 2-v 2$ bands of ozone, Spectrochim. Acta Part A Mol. Biomol. Spectrosc. 54 (1998) 1935-1945. https://doi.org/10.1016/S1386-1425(98)00156-5.

[43] H.M. Pickett, E.A. Cohen, L.R. Brown, C.P. Rinsland, M.A.H. Smith, V.M. Devi, A. Goldman, A. Barbe, B. Carli, M. Carlotti, The vibrational and rotational spectra of ozone for the $(0,1,0)$ and $(0,2,0)$ states, J. Mol. Spectrosc. 128 (1988) 151-171. https://doi.org/10.1016/0022-2852(88)90214-7.

[44] J.M. Flaud, G. Wagner, M. Birk, C. Camy-Peyret, C. Claveau, M.R. De Backer-Barilly, A. 
Barbe, C. Piccolo, Ozone absorption around $10 \mu \mathrm{m}$, J. Geophys. Res. Atmos. 108 (2003). https://doi.org/10.1029/2002JD002755.

[45] M. Birk, G. Wagner, J.M. Flaud, D. Hausamann, Linestrengths in the $v 3-v 2$ Hot Band of Ozone, J. Mol. Spectrosc. 163 (1994) 262-275. https://doi.org/10.1006/jmsp.1994.1022.

[46] A. Barbe, O. Sulakshina, J.J. Plateaux, A. Hamdouni, S. Bouazza, High-Resolution Infrared Spectra of Ozone in the 2300-2600 cm-1 Region, J. Mol. Spectrosc. 170 (1995) 244-250. https://doi.org/10.1006/jmsp.1995.1068.

[47] S. Bouazza, S. Mikhailenko, B. A, L. Regalia, V. Tyuterev, P. J.J, The nu1+nu2+2nu 3 and nu2+3nu3 Bands of 16O3, J. Mol. Spectrosc. 174 (1995) 510-519.

[48] V.G. Tyuterev, R. V Kochanov, S.A. Tashkun, Accurate ab initio dipole moment surfaces of ozone: First principle intensity predictions for rotationally resolved spectra in a large range of overtone and combination bands, J. Chem. Phys. 146 (2017) 64304. https://doi.org/10.1063/1.4973977.

[49] A. Barbe, E. Starikova, M.-R. De Backer, High resolution infrared spectra of the $16 \mathrm{O} 16 \mathrm{O} 17 \mathrm{O}$ and the $16 \mathrm{O} 17 \mathrm{O} 16 \mathrm{O}$ ozone isotopic species. The 5 and 10 micron spectral ranges revisited, J. Quant. Spectrosc. Radiat. Transf. 203 (2017) 293-299. https://doi.org/10.1016/j.jqsrt.2017.03.034.

[50] A. Barbe, E. Starikova, M.R. De Backer, V.G. Tyuterev, Analyses of infrared FT spectra of asymmetric ozone isotopologue 160160180 in the range $950-3850 \mathrm{~cm}-1$, J. Quant. Spectrosc. Radiat. Transf. 218 (2018) 231-247. https://doi.org/10.1016/j.jqsrt.2018.06.022.

[51] V.G. Tyuterev, S.A. Tashkun, H. Seghir, High-order contact transformations: general algorithm, computer implementation, and triatomic tests, in: L.N. Sinitsa, S.N. Mikhailenko (Eds.), Proc. SPIE - Int. Soc. Opt. Eng., SPIE, 2004: pp. 164-175. https://doi.org/10.1117/12.545641.

[52] S.A. Tashkun, V.I. Perevalov, A.W. Liu, S.M. Hu, Global modeling of the 15 N216O line positions within the framework of the polyad model of effective Hamiltonian and a room temperature 15N216O line list, J. Quant. Spectrosc. Radiat. Transf. 175 (2016) 1-7. https://doi.org/10.1016/j.jqsrt.2016.01.038.

[53] S.A. Tashkun, V.I. Perevalov, E. V. Karlovets, S. Kassi, A. Campargue, High sensitivity cavity ring down spectroscopy of $\mathrm{N} 2 \mathrm{O}$ near $1.22 \mu \mathrm{m}$ : (II) $14 \mathrm{~N} 216 \mathrm{O}$ line intensity modeling and global fit of 14N218O line positions, J. Quant. Spectrosc. Radiat. Transf. 176 (2016) 6269. https://doi.org/10.1016/j.jqsrt.2016.02.020.

[54] V. Werwein, J. Brunzendorf, A. Serdyukov, O. Werhahn, V. Ebert, First measurements of nitrous oxide self-broadening and self-shift coefficients in the 0002-0000 band at $2.26 \mu \mathrm{m}$ using high resolution Fourier transform spectroscopy, J. Mol. Spectrosc. 323 (2016) 28-42. https://doi.org/10.1016/J.JMS.2016.01.010.

[55] V. Werwein, J. Brunzendorf, G. Li, A. Serdyukov, O. Werhahn, V. Ebert, High-resolution Fourier transform measurements of line strengths in the 0002-0000 main isotopologue band of nitrous oxide, Appl. Opt. 56 (2017) E99. https://doi.org/10.1364/AO.56.000E99.

[56] V. Werwein, G. Li, A. Serdyukov, J. Brunzendorf, O. Werhahn, V. Ebert, High-resolution Fourier transform measurements of air-induced broadening and shift coefficients in the 0002-0000 main isotopologue band of nitrous oxide, J. Mol. Spectrosc. 348 (2018) 68-78. https://doi.org/10.1016/J.JMS.2017.07.002. 
[57] G. Li, I.E. Gordon, L.S. Rothman, Y. Tan, S.-M. Hu, S. Kassi, A. Campargue, E.S.

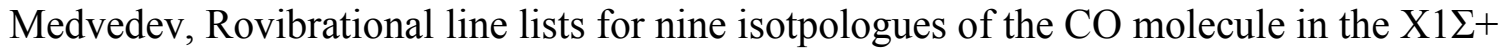
ground electronic state, Astrophys. J. Suppl. Ser. 216 (2015) 15. https://doi.org/10.1088/0067-0049/216/1/15.

[58] R.J. Le Roy, LEVEL: A computer program for solving the radial Schrödinger equation for bound and quasibound levels, J. Quant. Spectrosc. Radiat. Transf. 186 (2017) 167-178. https://doi.org/10.1016/j.jqsrt.2016.05.028.

[59] J.A. Coxon, P.G. Hajigeorgiou, Direct potential fit analysis of the X1 $1+$ ground state of CO, J. Chem. Phys. 121 (2004) 2992-3008. https://doi.org/10.1063/1.1768167.

[60] E.S. Medvedev, V. V Meshkov, A. V Stolyarov, V.G. Ushakov, I.E. Gordon, Impact of the dipole-moment representation on the intensity of high overtones, J. Mol. Spectrosc. 330 (2016) 36-42. https://doi.org/10.1016/j.jms.2016.06.013.

[61] E. Medvedev, V. Meshkov, A. Stolyarov, I. Gordon, Peculiarities of high-overtone transition probabilities in carbon monoxide revealed by high-precision calculation, J. Chem. Phys. 143 (2015) 154301. https://doi.org/10.1063/1.4933136.

[62] M. Ghysels, D. Mondelain, S. Kassi, A. V. Nikitin, M. Rey, A. Campargue, The methane absorption spectrum near $1.73 \mu \mathrm{m}(5695-5850 \mathrm{~cm}-1)$ : Empirical line lists at $80 \mathrm{~K}$ and $296 \mathrm{~K}$ and rovibrational assignments, J. Quant. Spectrosc. Radiat. Transf. 213 (2018) 169-177. https://doi.org/10.1016/j.jqsrt.2018.04.007.

[63] A. V. Nikitin, X. Thomas, L. Daumont, M. Rey, K. Sung, G.C. Toon, M.A.H. Smith, A.W. Mantz, A.E. Protasevich, S.A. Tashkun, V.G. Tyuterev, Assignment and modelling of $12 \mathrm{CH} 4$ spectra in the 5550-5695, 5718-5725 and 5792-5814 cm-1 regions, J. Quant. Spectrosc. Radiat. Transf. 219 (2018) 323-332. https://doi.org/10.1016/j.jqsrt.2018.08.006.

[64] A. V. Nikitin, X. Thomas, L. Daumont, M. Rey, K. Sung, G.C. Toon, M.A.H. Smith, A.W. Mantz, S.A. Tashkun, V.G. Tyuterev, Measurements and modeling of long-path 12CH4 spectra in the 5300-5550 cm-1 region, J. Quant. Spectrosc. Radiat. Transf. 202 (2017) 255264. https://doi.org/10.1016/j.jqsrt.2017.07.030.

[65] V. Tyuterev, S. Tashkun, M. Rey, R. Kochanov, A. Nikitin, T. Delahaye, Accurate spectroscopic models for methane polyads derived from a potential energy surface using high-order contact transformations, J. Phys. Chem. A. 117 (2013). https://doi.org/10.1021/jp408116j.

[66] O.M. Lyulin, A. V. Nikitin, V.I. Perevalov, I. Morino, T. Yokota, R. Kumazawa, T. Watanabe, Measurements of N2- and O2-broadening and shifting parameters of methane spectral lines in the 5550-6236 cm-1 region, J. Quant. Spectrosc. Radiat. Transf. 110 (2009) 654-668. https://doi.org/10.1016/j.jqsrt.2009.02.012.

[67] A. V. Nikitin, O.M. Lyulin, S.N. Mikhailenko, V.I. Perevalov, N.N. Filippov, I.M. Grigoriev, I. Morino, Y. Yoshida, T. Matsunaga, GOSAT-2014 methane spectral line list, J. Quant. Spectrosc. Radiat. Transf. 154 (2015) 63-71. https://doi.org/10.1016/j.jqsrt.2014.12.003.

[68] E. Starikova, A. V. Nikitin, M. Rey, S.A. Tashkun, D. Mondelain, S. Kassi, A. Campargue, V.G. Tyuterev, Assignment and modeling of the absorption spectrum of $13 \mathrm{CH} 4$ at $80 \mathrm{~K}$ in the region of the $2 v 3$ band (5853-6201 cm-1), J. Quant. Spectrosc. Radiat. Transf. 177 (2016) 170-180. https://doi.org/10.1016/j.jqsrt.2015.12.023.

[69] D.D. Tran, V.T. Sironneau, J.T. Hodges, R. Armante, J. Cuesta, H. Tran, Prediction of high- 
order line-shape parameters for air-broadened $\mathrm{O} 2$ lines using requantized classical molecular dynamics simulations and comparison with measurements, J. Quant. Spectrosc. Radiat. Transf. 222-223 (2019). https://doi.org/10.1016/j.jqsrt.2018.10.013.

[70] D.D. Tran, H. Tran, S. Vasilchenko, S. Kassi, A. Campargue, D. Mondelain, High sensitivity spectroscopy of the $\mathrm{O} 2$ band at $1.27 \mu \mathrm{m}$ : (II) air-broadened line profile parameters, J. Quant. Spectrosc. Radiat. Transf. 240 (2020) 106673. https://doi.org/10.1016/j.jqsrt.2019.106673.

[71] R. Tóbiás, T. Furtenbacher, A.G. Császár, O. V Naumenko, J. Tennyson, J.-M. Flaud, P. Kumar, B. Poirier, Critical evaluation of measured rotational-vibrational transitions of four sulphur isotopologues of S16O2, J. Quant. Spectrosc. Radiat. Transf. 208 (2018) 152-163. https://doi.org/10.1016/j.jqsrt.2018.01.006.

[72] D.S. Underwood, J. Tennyson, S.N. Yurchenko, X. Huang, D.W. Schwenke, T.J. Lee, S. Clausen, A. Fateev, ExoMol molecular line lists - XIV. The rotation-vibration spectrum of hot SO2, Mon. Not. R. Astron. Soc. 459 (2016) 3890-3899.

https://doi.org/10.1093/mnras/stw849.

[73] I. Kovacs, High Resolution Molecular Spectroscopy, 1976. https://doi.org/10.1051/epn/19760712009.

[74] O.N. Ulenikov, E.S. Bekhtereva, O. V Gromova, V.-M. Horneman, C. Sydow, S. Bauerecker, High resolution FTIR spectroscopy of sulfur dioxide in the $1550-1950 \mathrm{~cm}-1$ region: First analysis of the $v 1+v 2 / v 2+v 3$ bands of $32 \mathrm{~S} 16 \mathrm{O} 18 \mathrm{O}$ and experimental line intensities of ro-vibrational transitions in the $v 1+v 2 / v 2+v 3$ bands of $32 \mathrm{~S} 16 \mathrm{O} 2,34 \mathrm{~S} 16 \mathrm{O} 2$, 32S18O2 and, J. Quant. Spectrosc. Radiat. Transf. 203 (2017) 377-391. https://doi.org/10.1016/j.jqsrt.2017.02.005.

[75] Y.G. Borkov, O.M. Lyulin, T.M. Petrova, A.M. Solodov, A.A. Solodov, V.M. Deichuli, V.I. Perevalov, CO2-broadening and shift coefficients of sulfur dioxide near $4 \mu \mathrm{m}$, J. Quant. Spectrosc. Radiat. Transf. 225 (2019) 119-124. https://doi.org/10.1016/j.jqsrt.2018.12.030.

[76] X. Huang, D.W. Schwenke, T.J. Lee, Quantitative validation of Ames IR intensity and new line lists for 32/33/34S16O2, 32S18O2 and 16O32S18O, J. Quant. Spectrosc. Radiat. Transf. 225 (2019) 327-336. https://doi.org/10.1016/j.jqsrt.2018.11.039.

[77] A. Perrin, L. Manceron, F. Kwabia Tchana, New line positions analysis of the $2 v 1$ and $v 1+$ v3 bands of NO2 at 3637.848 and $2906.070 \mathrm{~cm}-1$, Mol. Phys. 8976 (2020). https://doi.org/10.1080/00268976.2019.1711235.

[78] A. Perrin, L. Manceron, J.-M. Flaud, F. Kwabia-Tchana, R. Armante, P. Roy, D. Doizi, The new nitrogen dioxide (NO2) linelist in the GEISA database and first identification of the $v 1+2 v 3-v 3$ band of 14N16O2, J. Mol. Spectrosc. 376 (2020) 111394. https://doi.org/10.1016/j.jms.2020.111394.

[79] A. Perrin, G. Toon, J. Orphal, Detection of atmospheric 15NO2 in the $v 3$ spectral region $(6.3 \mu \mathrm{m})$, J. Quant. Spectrosc. Radiat. Transf. 154 (2015) 91-97. https://doi.org/10.1016/j.jqsrt.2014.12.006.

[80] S. Miljanic, A. Perrin, J. Orphal, New high-resolution analysis of the $v 1+v 3$ band of the $15 \mathrm{~N} 16 \mathrm{O} 2$ isotopomer of nitrogen dioxide: Line positions and intensities, J. Mol. Spectrosc. 242 (2007) 176-181. https://doi.org/10.1016/j.jms.2007.02.024.

[81] D.C. Benner, T.A. Blake, L.R. Brown, V.M. Devi, M.A.H. Smith, R.A. Toth, Air-broadening parameters in the $\mathrm{v} 3$ band of $14 \mathrm{~N} 16 \mathrm{O} 2$ using a multispectrum fitting technique, J. Mol. 
Spectrosc. 228 (2004) 593-619. https://doi.org/10.1016/j.jms.2004.07.006.

[82] R.J. Hargreaves, I.E. Gordon, L.S. Rothman, S.A. Tashkun, V.I. Perevalov, A.A. Lukashevskaya, S.N. Yurchenko, J. Tennyson, H.S.P. Müller, Spectroscopic line parameters of NO, NO2, and N2O for the HITEMP database, J. Quant. Spectrosc. Radiat. Transf. 232 (2019) 35-53. https://doi.org/10.1016/j.jqsrt.2019.04.040.

[83] N. Maaroufi, C. Jalleli, F.K. Tchana, X. Landsheere, H. Aroui, Absolute line intensities and first measurements of self-collisional broadening and shift coefficients in the $2 v 4$ band of NH3, J. Mol. Spectrosc. 354 (2018) 24-31. https://doi.org/10.1016/j.jms.2018.09.003.

[84] V. Nemtchinov, K. Sung, P. Varanasi, Measurements of line intensities and half-widths in the 10- $\mu \mathrm{m}$ bands of 14NH3, J. Quant. Spectrosc. Radiat. Transf. 83 (2004) 243-265. https://doi.org/10.1016/S0022-4073(02)00354-0.

[85] A. V. Nikitin, Y.A. Ivanova, M. Rey, S.A. Tashkun, G.C. Toon, K. Sung, V.G. Tyuterev, Analysis of PH3 spectra in the Octad range 2733-3660 cm-1, J. Quant. Spectrosc. Radiat. Transf. 203 (2017) 472-479. https://doi.org/10.1016/j.jqsrt.2017.04.032.

[86] T.J. Johnson, R.L. Sams, S.W. Sharpe, The PNNL quantitative infrared database for gasphase sensing: a spectral library for environmental, hazmat, and public safety standoff detection, Chem. Biol. Point Sensors Homel. Def. 5269 (2004) 159. https://doi.org/10.1117/12.515604.

[87] A. Perrin, New analysis of the $v 3$ and $v 4$ bands of HNO 3 in the $7.6 \mu \mathrm{m}$ region, J. Phys. Chem. A. 117 (2013) 13236-13248. https://doi.org/10.1021/jp401979v.

[88] A. Perrin, J.M. Flaud, M. Ridolfi, J. Vander Auwera, M. Carlotti, MIPAS database: New HNO3 line parameters at $7.6 \mu \mathrm{m}$ validated with MIPAS satellite measurements, Atmos. Meas. Tech. 9 (2016) 2067-2076. https://doi.org/10.5194/amt-9-2067-2016.

[89] G. Li, I.E. Gordon, R.J. Le Roy, P.G. Hajigeorgiou, J.A. Coxon, P.F. Bernath, L.S. Rothman, Reference spectroscopic data for hydrogen halides. Part I: Construction and validation of the ro-vibrational dipole moment functions, J. Quant. Spectrosc. Radiat. Transf. 121 (2013) 7890. https://doi.org/10.1016/J.JQSRT.2013.02.005.

[90] G. Li, I.E. Gordon, P.G. Hajigeorgiou, J.A. Coxon, L.S. Rothman, Reference spectroscopic data for hydrogen halides, Part II: The line lists, J. Quant. Spectrosc. Radiat. Transf. 130 (2013) 284-295. https://doi.org/10.1016/J.JQSRT.2013.07.019.

[91] G. Li, A. Serdyukov, M. Gisi, O. Werhahn, V. Ebert, FTIR-based measurements of selfbroadening and self-shift coefficients as well as line strength in the first overtone band of $\mathrm{HCl}$ at $1.76 \mu \mathrm{m}$, J. Quant. Spectrosc. Radiat. Transf. 165 (2015) 76-87. https://doi.org/10.1016/J.JQSRT.2015.06.021.

[92] R.E. Asfin, A.V. Domanskaya, C. Maul, Broadening and shifting coefficients of rotationvibrational lines in the fundamental and first overtone bands of $\mathrm{HCl}$ and $\mathrm{HBr}$ induced by oxygen and air, J. Quant. Spectrosc. Radiat. Transf. 130 (2013) 296-303. https://doi.org/10.1016/J.JQSRT.2013.07.014.

[93] B. Lejeune, E. Mahieu, M.K. Vollmer, S. Reimann, P.F. Bernath, C.D. Boone, K.A. Walker, C. Servais, Optimized approach to retrieve information on atmospheric carbonyl sulfide (OCS) above the Jungfraujoch station and change in its abundance since 1995, J. Quant. Spectrosc. Radiat. Transf. 186 (2017) 81-95. https://doi.org/10.1016/j.jqsrt.2016.06.001. 
[94] N.G. Phillips, R. Ackley, E.R. Crosson, A. Down, L.R. Hutyra, M. Brondfield, J.D. Karr, K. Zhao, R.B. Jackson, Mapping urban pipeline leaks: Methane leaks across Boston, Environ. Pollut. 173 (2013) 1-4. https://doi.org/10.1016/j.envpol.2012.11.003.

[95] D. Golebiowski, X. de Ghellinck d'Elseghem Vaernewijck, M. Herman, J. Vander Auwera, A. Fayt, High sensitivity (femto-FT-CEAS) spectra of carbonyl sulphide between 6200 and $8200 \mathrm{~cm}-1$, and new energy pattern in the global rovibrational analysis of $16 \mathrm{O} 12 \mathrm{C} 32 \mathrm{~S}, \mathrm{~J}$. Quant. Spectrosc. Radiat. Transf. 149 (2014) 184-203. https://doi.org/10.1016/j.jqsrt.2014.07.005.

[96] S. Galalou, K. Ben Mabrouk, H. Aroui, F. Kwabia Tchana, F. Willaert, J.M. Flaud, N2 and $\mathrm{O} 2$ pressure broadening and pressure shift in the $4 \mathrm{v} 2$ band of $16 \mathrm{O} 12 \mathrm{C} 32 \mathrm{~S}$, J. Quant. Spectrosc. Radiat. Transf. 112 (2011) 2750-2761. https://doi.org/10.1016/j.jqsrt.2011.08.008.

[97] N. Moazzen-Ahmadi, J. Norooz Oliaee, I. Ozier, E.H. Wishnow, K. Sung, T.J. Crawford, L.R. Brown, V.M. Devi, An intensity study of the torsional bands of ethane at $35 \mu \mathrm{m}, \mathrm{J}$. Quant. Spectrosc. Radiat. Transf. 151 (2015) 123-132. https://doi.org/10.1016/j.jqsrt.2014.09.016.

[98] O.M. Lyulin, V.I. Perevalov, Global modeling of vibration-rotation spectra of the acetylene molecule, J. Quant. Spectrosc. Radiat. Transf. 177 (2016) 59-74. https://doi.org/10.1016/j.jqsrt.2015.12.021.

[99] O.M. Lyulin, V.I. Perevalov, ASD-1000: High-resolution, high-temperature acetylene spectroscopic databank, J. Quant. Spectrosc. Radiat. Transf. 201 (2017) 94-103. https://doi.org/10.1016/j.jqsrt.2017.06.032.

[100] D. Jacquemart, O. Lyulin, V.I. Perevalov, Recommended acetylene line list in the 20-240 $\mathrm{cm}-1$ and 400-630 $\mathrm{cm}-1$ regions: New measurements and global modeling, J. Quant. Spectrosc. Radiat. Transf. 203 (2017) 440-453. https://doi.org/10.1016/j.jqsrt.2017.03.008.

[101] D. Jacquemart, P. Soulard, O.M. Lyulin, Recommended acetylene 12C2H2 line list in 13.6 $\mu \mathrm{m}$ spectral region: New measurements and global modeling, J. Quant. Spectrosc. Radiat. Transf. 256 (2020) 107200. https://doi.org/10.1016/j.jqsrt.2020.107200.

[102] O.M. Lyulin, A. Campargue, An empirical spectroscopic database for acetylene in the regions of 5850-6341 cm-1 and 7000-9415 cm-1, J. Quant. Spectrosc. Radiat. Transf. 203 (2017) 461-471. https://doi.org/10.1016/j.jqsrt.2017.01.036.

[103] O.M. Lyulin, J. Vander Auwera, A. Campargue, The Fourier transform absorption spectrum of acetylene between 8280 and $8700 \mathrm{~cm}-1$, J. Quant. Spectrosc. Radiat. Transf. 177 (2016) 234-240. https://doi.org/10.1016/j.jqsrt.2015.11.026.

[104] O.M. Lyulin, J. Vander Auwera, A. Campargue, The Fourier transform absorption spectrum of acetylene between 7000 and 7500cm-1, J. Quant. Spectrosc. Radiat. Transf. 160 (2015) 85-93. https://doi.org/10.1016/j.jqsrt.2015.03.018.

[105] S. Béguier, O.M. Lyulin, S.M. Hu, A. Campargue, Line intensity measurements for acetylene between 8980 and $9420 \mathrm{~cm}-1$, J. Quant. Spectrosc. Radiat. Transf. 189 (2017) 417-420. https://doi.org/10.1016/j.jqsrt.2016.12.020.

[106] O.M. Lyulin, A. Campargue, D. Mondelain, S. Kassi, The absorption spectrum of acetylene by CRDS between 7244 and 7918cm-1, J. Quant. Spectrosc. Radiat. Transf. 130 (2013) 327334. https://doi.org/10.1016/j.jqsrt.2013.04.028. 
[107] O.M. Lyulin, D. Mondelain, S. Béguier, S. Kassi, J. Vander Auwera, A. Campargue, Highsensitivity CRDS absorption spectroscopy of acetylene between 5851 and $6341 \mathrm{~cm}-1$, Mol. Phys. 112 (2014) 2433-2444. https://doi.org/10.1080/00268976.2014.906677.

[108] S. Kassi, O.M. Lyulin, S. Béguier, A. Campargue, New assignments and a rare peculiarity in the high sensitivity CRDS spectrum of acetylene near $8000 \mathrm{~cm}-1$, J. Mol. Spectrosc. 326 (2016) 106-114. https://doi.org/10.1016/j.jms.2016.02.013.

[109] M. Šimečková, D. Jacquemart, L.S. Rothman, R.R. Gamache, A. Goldman, Einstein Acoefficients and statistical weights for molecular absorption transitions in the HITRAN database, J. Quant. Spectrosc. Radiat. Transf. 98 (2006) 130-155. https://doi.org/10.1016/j.jqsrt.2005.07.003.

[110] R.R. Gamache, C. Roller, E. Lopes, I.E. Gordon, L.S. Rothman, O.L. Polyansky, N.F. Zobov, A.A. Kyuberis, J. Tennyson, S.N. Yurchenko, A.G. Császár, T. Furtenbacher, X. Huang, D.W. Schwenke, T.J. Lee, B.J. Drouin, S.A. Tashkun, V.I. Perevalov, R. V. Kochanov, Total internal partition sums for 166 isotopologues of 51 molecules important in planetary atmospheres: Application to HITRAN2016 and beyond, J. Quant. Spectrosc. Radiat. Transf. 203 (2017) 70-87. https://doi.org/10.1016/j.jqsrt.2017.03.045.

[111] O.M. Lyulin, D. Jacquemart, N. Lacome, V.I. Perevalov, J.Y. Mandin, Line parameters of acetylene in the 1.9 and $1.7 \mu \mathrm{m}$ spectral regions, J. Quant. Spectrosc. Radiat. Transf. 109 (2008) 1856-1874. https://doi.org/10.1016/j.jqsrt.2007.11.016.

[112] A. Alkadrou, M.-T. Bourgeois, M. Rotger, V. Boudon, J. Vander Auwera, Corrigendum to "Global frequency and intensity analysis of the $v 10 / v 7 / v 4 / v 12$ band system of $12 \mathrm{C} 2 \mathrm{H} 4$ at $10 \mu \mathrm{m}$ using the D2h top data system,” J. Quant. Spectrosc. Radiat. Transf. 190 (2017) 88. https://doi.org/10.1016/j.jqsrt.2017.01.007.

[113] A. Alkadrou, M.-T. Bourgeois, M. Rotger, V. Boudon, J. Vander Auwera, Global frequency and intensity analysis of the $v 10 / v 7 / v 4 / v 12$ band system of $12 \mathrm{C} 2 \mathrm{H} 4$ at $10 \mu \mathrm{m}$ using the D2h Top Data System, J. Quant. Spectrosc. Radiat. Transf. 182 (2016) 158-171. https://doi.org/10.1016/j.jqsrt.2016.05.024.

[114] J. Vander Auwera, A. Fayt, M. Tudorie, M. Rotger, V. Boudon, B. Franco, E. Mahieu, Selfbroadening coefficients and improved line intensities for the $v 7$ band of ethylene near $10.5 \mu \mathrm{m}$, and impact on ethylene retrievals from Jungfraujoch solar spectra, J. Quant. Spectrosc. Radiat. Transf. 148 (2014) 177-185. https://doi.org/10.1016/j.jqsrt.2014.07.003.

[115] M. Rotger, V. Boudon, J. Vander Auwera, Line positions and intensities in the $v 12$ band of ethylene near 1450cm-1: An experimental and theoretical study, J. Quant. Spectrosc. Radiat. Transf. 109 (2008) 952-962. https://doi.org/10.1016/j.jqsrt.2007.12.005.

[116] U. Fink, H.P. Larson, R.R. Treffers, Germane in the atmosphere of Jupiter, Icarus. 34 (1978) 344-354. https://doi.org/10.1016/0019-1035(78)90172-0.

[117] K.S. Noll, R.F. Knacke, T.R. Geballe, A.T. Tokunaga, Evidence for Germane in Saturn, Icarus. 75 (1988) 409-422. https://doi.org/10.1016/0019-1035(88)90154-6.

[118] V. Boudon, T. Grigoryan, F. Philipot, C. Richard, F.K. Tchana, L. Manceron, A. Rizopoulos, J. Vander Auwera, T. Encrenaz, Line positions and intensities for the $v 3$ band of 5 isotopologues of germane for planetary applications, J. Quant. Spectrosc. Radiat. Transf. 205 (2018) 174-183. https://doi.org/10.1016/J.JQSRT.2017.10.017.

[119] http://vamdc.icb.cnrs.fr/PHP/gecasda.php, (n.d.). 
[120] C. Richard, V. Boudon, M. Rotger, Calculated spectroscopic databases for the VAMDC portal: New molecules and improvements, J. Quant. Spectrosc. Radiat. Transf. 251 (2020) 107096. https://doi.org/10.1016/j.jqsrt.2020.107096.

[121] M. López-Puertas, J.-M. Flaud, J. Peralta-Calvillo, B. Funke, S. Gil-López, NO+ fundamental and first hot ro-vibrational line frequencies from MIPAS/Envisat atmospheric spectra, J. Mol. Spectrosc. 237 (2006) 218-224. https://doi.org/10.1016/j.jms.2006.03.015.

[122] J. Cernicharo, S. Bailleux, E. Alekseev, A. Fuente, E. Roueff, M. Gerin, B. Tercero, S.P. Treviño-Morales, N. Marcelino, R. Bachiller, B. Lefloch, Tentative detection of the nitrosylium ion in space, Astrophys. J. 795 (2014) 6-11. https://doi.org/10.1088/0004$637 \mathrm{X} / 795 / 1 / 40$.

[123] C.P. Endres, S. Schlemmer, P. Schilke, J. Stutzki, H.S.P. Müller, The Cologne Database for Molecular Spectroscopy, CDMS, in the Virtual Atomic and Molecular Data Centre, VAMDC, J. Mol. Spectrosc. 327 (2016) 95-104. https://doi.org/10.1016/j.jms.2016.03.005.

[124] W.C. Bowman, E. Herbst, F.C. De Lucia, Millimeter and submillimeter spectrum of NO +, J. Chem. Phys. 77 (1982) 4261-4262. https://doi.org/10.1063/1.444307.

[125] W.C. Ho, I. Ozier, D.T. Cramb, M.C.L. Gerry, Diode laser spectroscopy of the vibrational fundamental of NO+, J. Mol. Spectrosc. 149 (1991) 559-561. https://doi.org/10.1016/00222852(91)90311-W.

[126] R. Polák, J. Fišer, A comparative icMRCI study of some NO+, NO and NO- electronic ground state properties, Chem. Phys. 303 (2004) 73-83.

https://doi.org/10.1016/j.chemphys.2004.04.027.

[127] C.P. Rinsland, E. Mahieu, R. Zander, R. Nassar, P. Bernath, C. Boone, L.S. Chiou, Longterm stratospheric carbon tetrafluoride (CF4) increase inferred from 1985-2004 infrared space-based solar occultation measurements, Geophys. Res. Lett. 33 (2006) 2-5. https://doi.org/10.1029/2005GL024709.

[128] E. Mahieu, R. Zander, G.C. Toon, M.K. Vollmer, S. Reimann, J. Mühle, W. Bader, B. Bovy, B. Lejeune, C. Servais, P. Demoulin, G. Roland, P.F. Bernath, C.D. Boone, K.A. Walker, P. Duchatelet, Spectrometric monitoring of atmospheric carbon tetrafluoride (CF4) above the Jungfraujoch station since 1989: Evidence of continued increase but at a slowing rate, Atmos. Meas. Tech. 7 (2014) 333-344. https://doi.org/10.5194/amt-7-333-2014.

[129] M. Carlos, O. Gruson, C. Richard, V. Boudon, M. Rotger, X. Thomas, C. Maul, C. Sydow, A. Domanskaya, R. Georges, P. Soulard, O. Pirali, M. Goubet, P. Asselin, T.R. Huet, Highresolution spectroscopy and global analysis of CF4 rovibrational bands to model its atmospheric absorption, J. Quant. Spectrosc. Radiat. Transf. 201 (2017) 75-93. https://doi.org/10.1016/j.jqsrt.2017.06.039.

[130] V. Boudon, M. Carlos, C. Richard, O. Pirali, Pure rotation spectrum of CF4 in the v3=1 state using THz synchrotron radiation, J. Mol. Spectrosc. 348 (2018) 43-46.

https://doi.org/10.1016/j.jms.2017.07.010.

[131] http://vamdc.icb.cnrs.fr/PHP/tfmecasda.php, (n.d.).

[132] R. Armante, A. Perrin, F. Kwabia-Tchana, L. Manceron, The v4 linelist at $11 \mu \mathrm{m}$ : linelists for the Trans- and Cis- conformer forms of nitrous acid, (HONO), in the 2019 version of the GEISA database, Mol. Phys. (2021) e1951860.

https://doi.org/10.1080/00268976.2021.1951860. 
[133] I. Kleiner, J.M. Guilmot, M. Carleer, M. Herman, The $v 4$ fundamental bands of trans- and cis-HNO2, J. Mol. Spectrosc. 149 (1991) 341-347. https://doi.org/10.1016/00222852(91)90290-Q.

[134] A. Dehayem-Kamadjeu, O. Pirali, J. Orphal, I. Kleiner, P.-M. Flaud, The far-infrared rotational spectrum of nitrous acid (HONO) and its deuterated species (DONO) studied by high-resolution Fourier-transform spectroscopy, J. Mol. Spectrosc. 234 (2005) 182-189. https://doi.org/10.1016/j.jms.2005.09.006.

[135] R.H. Kagann, A.G. Maki, Infrared absorption intensities of nitrous acid (HONO) fundamental bands, J. Quant. Spectrosc. Radiat. Transf. 30 (1983) 37-44. https://doi.org/10.1016/0022-4073(83)90071-7.

[136] A. Perrin, J. Demaison, G. Toon, The $v 1, v 2$, and $v 3$ bands of carbonyl chlorofluoride $(\mathrm{COFCl})$ at $5.3,9.1$, and $13.1 \mu \mathrm{m}$ : position and intensity parameters and their use for atmospheric studies, J. Quant. Spectrosc. Radiat. Transf. 112 (2011) 1266-1279. https://doi.org/10.1016/j.jqsrt.2011.01.003.

[137] A. Perrin, J.-M. Flaud, H. Bürger, G. Pawelke, S. Sander, H. Willner, First High-Resolution Analysis of the Six Fundamental Bands v1, v2, v3, v4, v5, and $v 6$ of COF35Cl in the 340- to 2000-cm-1 Region, J. Mol. Spectrosc. 209 (2001) 122-132. https://doi.org/10.1006/jmsp.2001.8415.

[138] J. Demaison, A. Perrin, H. Bürger, Ab initio anharmonic force field and equilibrium structure of carbonyl chlorofluoride, J. Mol. Spectrosc. 221 (2003) 47-56. https://doi.org/10.1016/S0022-2852(03)00169-3.

[139] A. Perrin, I. Haykal, F. KwabiaTchana, L. Manceron, D. Doizi, G. Ducros, New analysis of the $v 6$ and $2 v 3$ bands of methyl iodide (CH3I), J. Mol. Spectrosc. 324 (2016) 28-35. https://doi.org/10.1016/j.jms.2016.04.014.

[140] F. Kwabia-Tchana, Y. Attafi, L. Manceron, D. Doizi, J. Vander Auwera, A. Perrin, Line intensities for the $v 6$ and $2 v 3$ bands of methyl iodide (12CH3I), J. Quant. Spectrosc. Radiat. Transf. 222-223 (2019) 130-137. https://doi.org/10.1016/j.jqsrt.2018.10.001.

[141] Y. Attafi, A. Ben Hassen, H. Aroui, F.K. Tchana, L. Manceron, D. Doizi, J. Vander Auwera, A. Perrin, Self and N2 collisional broadening of rovibrational lines in the $v 6$ band of methyl iodide (12CH3I) at room temperature: The J and K dependence, J. Quant. Spectrosc. Radiat. Transf. 231 (2019) 1-8. https://doi.org/10.1016/j.jqsrt.2019.04.017.

[142] Y. Attafi, S. Galalou, F. Kwabia Tchana, J. Vander Auwera, A. Ben Hassen, H. Aroui, A. Perrin, L. Manceron, D. Doizi, Oxygen broadening and shift coefficients in the $v 6$ band of methyl iodide (12CH3I) at room temperature, J. Quant. Spectrosc. Radiat. Transf. 239 (2019) 106679. https://doi.org/10.1016/j.jqsrt.2019.106679.

[143] D. Papoušek, P. Pracna, M. Winnewisser, S. Klee, J. Demaison, Simultaneous Rovibrational Analysis of the v2, v3, v5, and v6 Bands of H312CF, J. Mol. Spectrosc. 196 (1999) 319-323. https://doi.org/10.1006/jmsp.1999.7875.

[144] D. Jacquemart, M. Guinet, Line parameters measurements and modeling for the $v 6$ band of CH3F: Generation of a complete line list for atmospheric databases, J. Quant. Spectrosc. Radiat. Transf. 185 (2016) 58-69. https://doi.org/10.1016/j.jqsrt.2016.08.010.

[145] A.B. Ramchani, D. Jacquemart, P. Soulard, M. Guinet, Measurements and modeling of N2broadening coefficients for the $v 6$ band of $\mathrm{CH} 3 \mathrm{~F}$, comparison with $\mathrm{CH} 3 \mathrm{Cl}$ and $\mathrm{CH} 3 \mathrm{Br}$ 
molecules, J. Quant. Spectrosc. Radiat. Transf. 203 (2017) 480-489.

https://doi.org/10.1016/j.jqsrt.2017.06.013.

[146] S. Reymond-Laruinaz, V. Boudon, L. Manceron, L. Lago, D. Doizi, Infrared spectroscopy of ruthenium tetroxide and high-resolution analysis of the $v 3$ band, J. Mol. Spectrosc. 315 (2015) 46-54. https://doi.org/10.1016/J.JMS.2015.02.008.

[147] S. Reymond-Laruinaz, M. Faye, V. Boudon, D. Doizi, L. Manceron, High-resolution infrared spectroscopy and analysis of the $v 2 / v 4$ bending dyad of ruthenium tetroxide, J. Mol. Spectrosc. 336 (2017) 29-35. https://doi.org/10.1016/J.JMS.2017.04.010.

[148] J. Vander Auwera, S. Reymond-Laruinaz, V. Boudon, D. Doizi, L. Manceron, Line intensity measurements and analysis in the $v 3$ band of ruthenium tetroxide, J. Quant. Spectrosc. Radiat. Transf. 204 (2018) 103-111. https://doi.org/10.1016/J.JQSRT.2017.09.016.

[149] http://vamdc.icb.cnrs.fr/PHP/rucasda.php, (n.d.).

[150] N.A. Lombardo, C.A. Nixon, R.K. Achterberg, A. Jolly, K. Sung, P.G.J. Irwin, F.M. Flasar, Spatial and seasonal variations in $\mathrm{C} 3 \mathrm{Hx}$ hydrocarbon abundance in Titan's stratosphere from Cassini CIRS observations, Icarus. 317 (2019) 454-469. https://doi.org/10.1016/j.icarus.2018.08.027.

[151] N.A. Lombardo, C.A. Nixon, T.K. Greathouse, B. Bézard, A. Jolly, S. Vinatier, N.A. Teanby, M.J. Richter, P.J. G Irwin, A. Coustenis, F.M. Flasar, Detection of Propadiene on Titan, Astrophys. J. 881 (2019) L33. https://doi.org/10.3847/2041-8213/ab3860.

[152] A. Coustenis, T. Encrenaz, B. Bézard, G. Bjoraker, G. Graner, M. Dang-Nhu, E. Arié, Modeling Titan's Thermal Infrared Spectrum for High-Resolution Space Observations, Icarus. 102 (1993) 240-260. https://doi.org/10.1006/icar.1993.1047.

[153] J. Chazelas, J. Plíva, A. Valentin, L. Henry, Analysis of the v9 v10 band system of allene, J. Mol. Spectrosc. 110 (1985) 326-338. https://doi.org/10.1016/0022-2852(85)90298-X.

[154] J. Plíva, J. Kauppinen, High-resolution Fourier transform study of the perpendicular band $v 11$ of allene at $353 \mathrm{~cm}-1$, J. Mol. Spectrosc. 111 (1985) 93-101. https://doi.org/10.1016/0022-2852(85)90072-4.

[155] Y. Koga, S. Kondo, T. Nakanaga, S. Saëki, Infrared absorption intensities of allene, J. Chem. Phys. 71 (1979) 2404-2411. https://doi.org/10.1063/1.438645.

[156] A. Jolly, Y. Benilan, L. Manceron, Search for evidence of Butane on Titan with new spectroscopic data, EPSC Abstr. 11 (2017) 10-11.

[157] S. Nissen, F. Hegelund, M.S. Johnson, B. Nelander, High-Resolution infrared study of the $v 11$ band of Allene, J. Mol. Spectrosc. 216 (2002) 197-202. https://doi.org/10.1006/jmsp.2002.8596.

[158] F. Hegelund, N. Andresen, M. Koivusaari, A High-Resolution Infrared Study of the $v 9+v 11$ $-v 11, v 10+v 11-v 11$ Hot Band System in Allene, J. Mol. Spectrosc. 159 (1993) 230-248. https://doi.org/10.1006/jmsp.1993.1120.

[159] E. Es-sebbar, A. Jolly, Y. Benilan, A. Farooq, Quantitative mid-infrared spectra of allene and propyne from room to high temperatures, J. Mol. Spectrosc. 305 (2014) 10-16. https://doi.org/10.1016/j.jms.2014.09.004.

[160] F. Cheruy, N.A. Scott, R. Armante, B. Tournier, A. Chedin, Contribution to the development 
of radiative transfer models for high spectral resolution observations in the infrared, J. Quant. Spectrosc. Radiat. Transf. 53 (1995). https://doi.org/10.1016/0022-4073(95)00026-H.

[161] L. Regalia, C. Oudot, S. Mikhailenko, L. Wang, X. Thomas, A. Jenouvrier, P. Von der Heyden, Water vapor line parameters from 6450 to $9400 \mathrm{~cm}-1$, J. Quant. Spectrosc. Radiat. Transf. 136 (2014) 119-136. https://doi.org/10.1016/j.jqsrt.2013.11.019.

[162] P. Macko, D. Romanini, S.N. Mikhailenko, O. V. Naumenko, S. Kassi, A. Jenouvrier, V.G. Tyuterev, A. Campargue, High sensitivity $\mathrm{CW}$-cavity ring down spectroscopy of water in the region of the $1.5 \mu \mathrm{m}$ atmospheric window, J. Mol. Spectrosc. 227 (2004) 90-108. https://doi.org/10.1016/j.jms.2004.05.020.

[163] R. a Toth, Line lists of water vapor parameters from 500 to $8000 \mathrm{~cm}-1$, JPL Nasa. (2013).

[164] R.R. Gamache, A.L. Laraia, N2-, O2-, and air-broadened half-widths, their temperature dependence, and line shifts for the rotation band of H216O, J. Mol. Spectrosc. 257 (2009) 116-127. https://doi.org/10.1016/j.jms.2009.07.004.

[165] R.R. Gamache, Lineshape parameters for water vapor in the 3.2-17.76 $\mu \mathrm{m}$ region for atmospheric applications, J. Mol. Spectrosc. 229 (2005) 9-18. https://doi.org/10.1016/j.jms.2004.08.004.

[166] D.P. Dee, S.M. Uppala, A.J. Simmons, P. Berrisford, P. Poli, S. Kobayashi, U. Andrae, M.A. Balmaseda, G. Balsamo, P. Bauer, P. Bechtold, A.C.M. Beljaars, L. van de Berg, J. Bidlot, N. Bormann, C. Delsol, R. Dragani, M. Fuentes, A.J. Geer, L. Haimberger, S.B. Healy, H. Hersbach, E. V Hólm, L. Isaksen, P. Kållberg, M. Köhler, M. Matricardi, A.P. McNally, B.M. Monge-Sanz, J.-J. Morcrette, B.-K. Park, C. Peubey, P. de Rosnay, C. Tavolato, J.-N. Thépaut, F. Vitart, The ERA-Interim reanalysis: configuration and performance of the data assimilation system, Q. J. R. Meteorol. Soc. 137 (2011) 553-597. https://doi.org/10.1002/qj.828.

[167] H. Hersbach, B. Bell, P. Berrisford, S. Hirahara, A. Horányi, J. Muñoz-Sabater, J. Nicolas, C. Peubey, R. Radu, D. Schepers, A. Simmons, C. Soci, S. Abdalla, X. Abellan, G. Balsamo, P. Bechtold, G. Biavati, J. Bidlot, M. Bonavita, G. De Chiara, P. Dahlgren, D. Dee, M. Diamantakis, R. Dragani, J. Flemming, R. Forbes, M. Fuentes, A. Geer, L. Haimberger, S. Healy, R.J. Hogan, E. Hólm, M. Janisková, S. Keeley, P. Laloyaux, P. Lopez, C. Lupu, G. Radnoti, P. de Rosnay, I. Rozum, F. Vamborg, S. Villaume, J.-N. Thépaut, The ERA5 global reanalysis, Q. J. R. Meteorol. Soc. 146 (2020) 1999-2049. https://doi.org/10.1002/qj.3803.

[168] H. Ke, V. Boudon, C. Richard, V. Madhur, M. Faye, L. Manceron, Analysis and modeling of combination bands of sulfur hexafluoride 32SF6 based on global fits. Update of the SHeCaSDa database, J. Mol. Spectrosc. 368 (2020) 1-14. https://doi.org/10.1016/j.jms.2020.111251.

[169] A. V. Nikitin, M. Rey, I.S. Chizhmakova, V.G. Tyuterev, First Full-Dimensional Potential Energy and Dipole Moment Surfaces of SF6, J. Phys. Chem. A. 124 (2020) 7014-7023. https://doi.org/10.1021/acs.jpca.0c02733.

[170] M. Rey, A. V. Nikitin, Y.L. Babikov, V.G. Tyuterev, TheoReTS - An information system for theoretical spectra based on variational predictions from molecular potential energy and dipole moment surfaces, J. Mol. Spectrosc. 327 (2016) 138-158. https://doi.org/10.1016/j.jms.2016.04.006.

[171] P. Varanasi, Z. Li, V. Nemtchinov, A. Cherukuri, Spectral absorption-coefficient data on HCFC-22 and SF6 for remote-sensing applications, J. Quant. Spectrosc. Radiat. Transf. 52 
(1994) 323-332. https://doi.org/10.1016/0022-4073(94)90162-7.

[172] N.H. Ngo, D. Lisak, H. Tran, J.M. Hartmann, An isolated line-shape model to go beyond the Voigt profile in spectroscopic databases and radiative transfer codes, J. Quant. Spectrosc. Radiat. Transf. 129 (2013) 89-100. https://doi.org/10.1016/j.jqsrt.2013.05.034. 


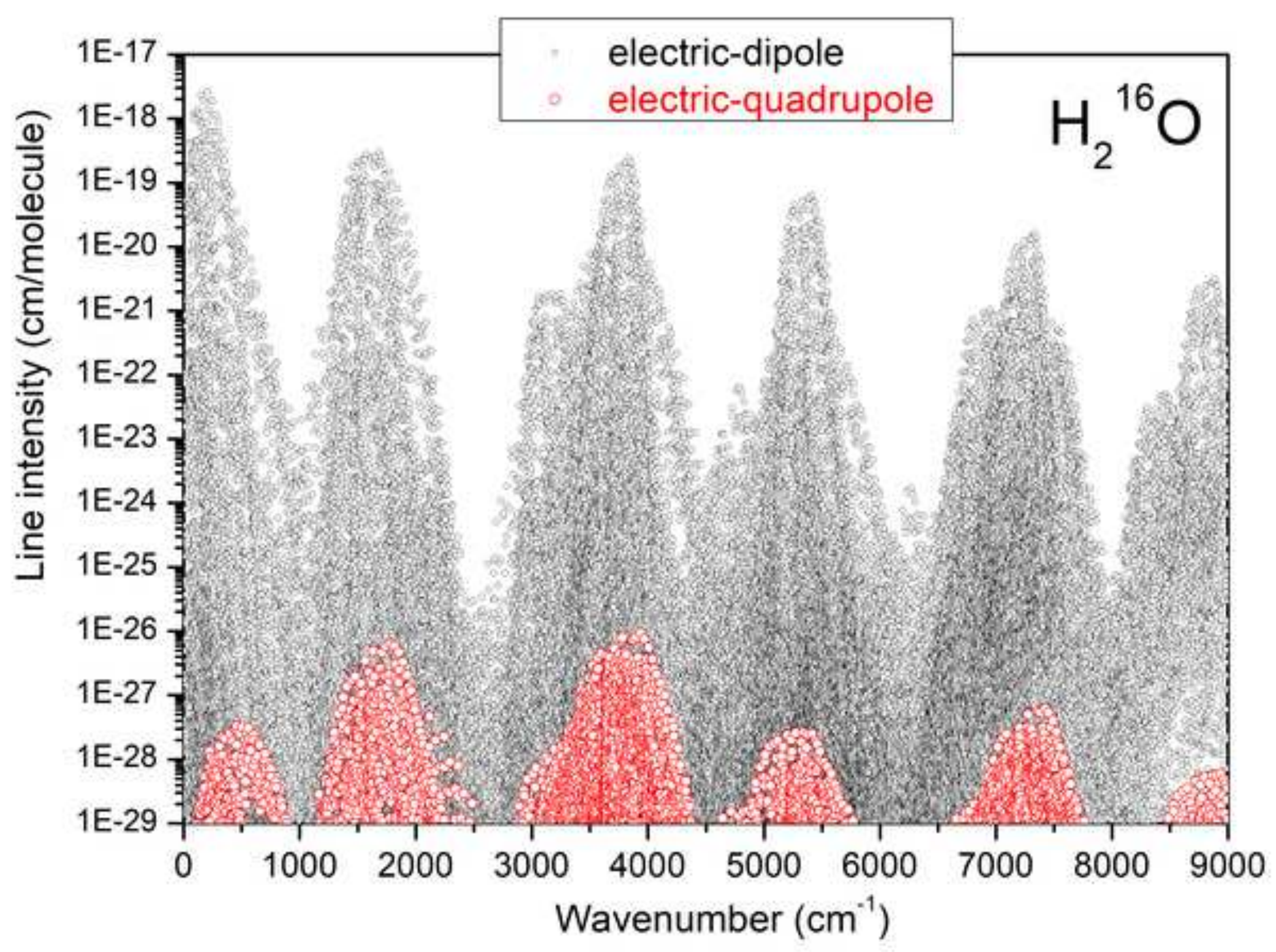




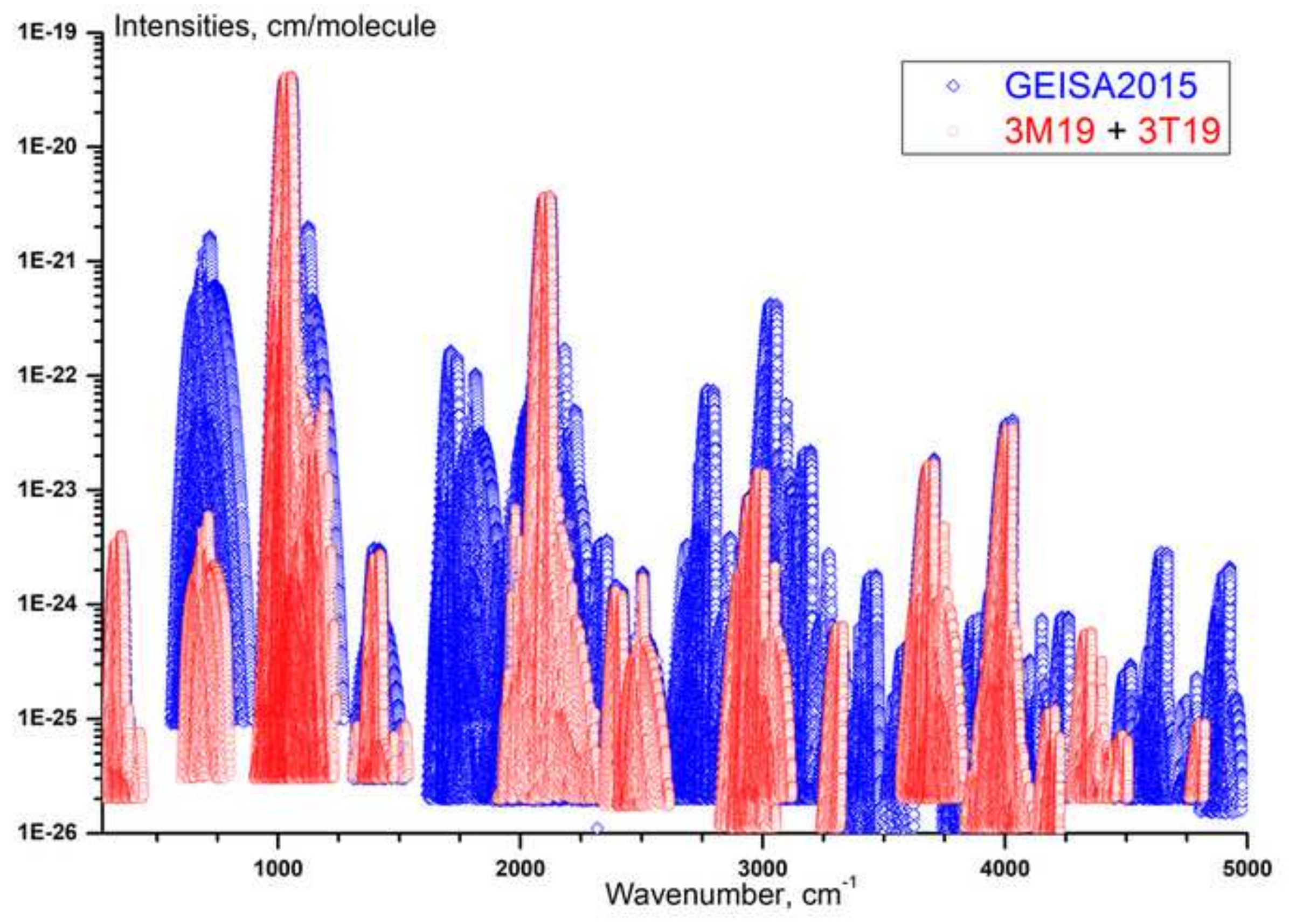




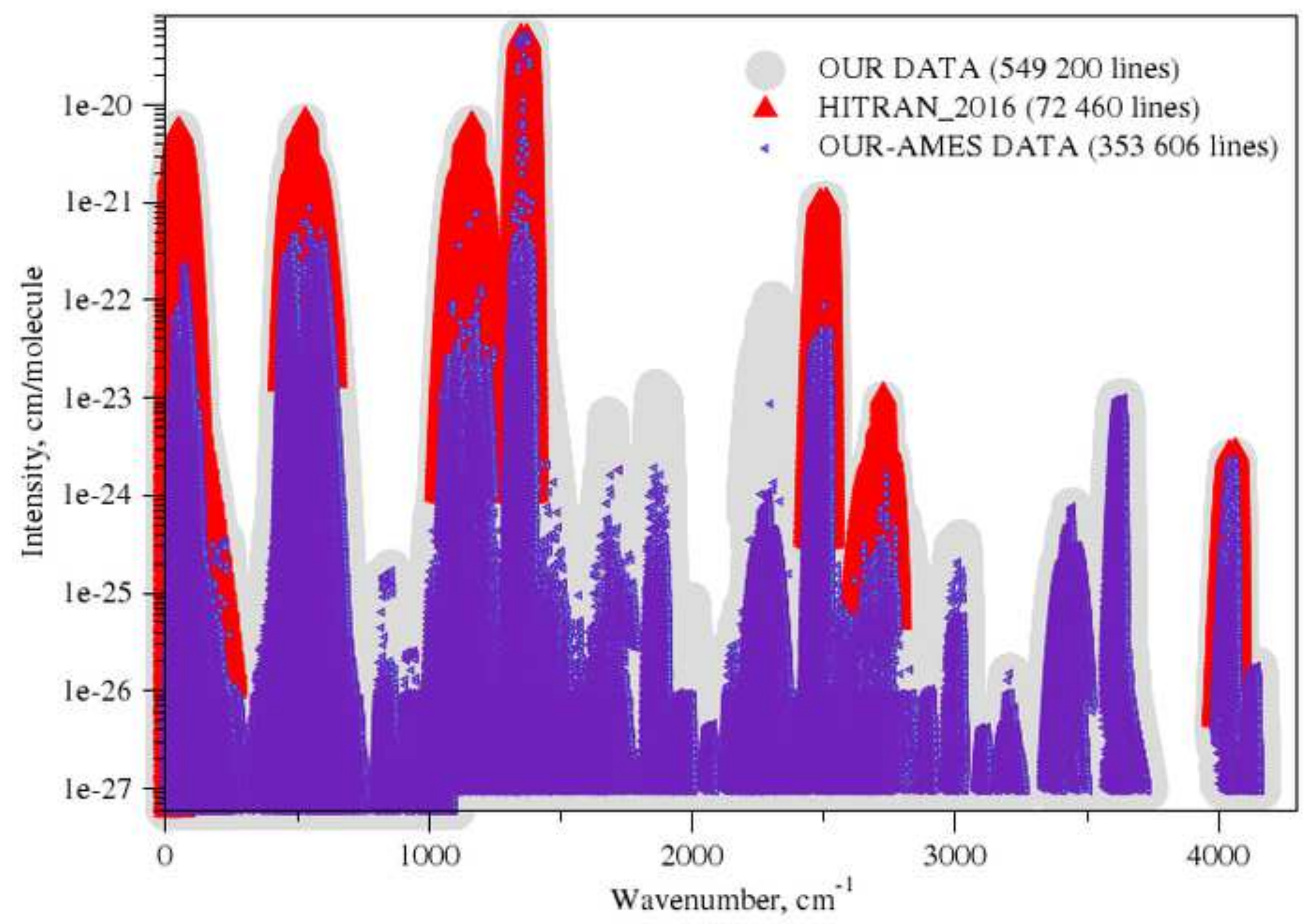




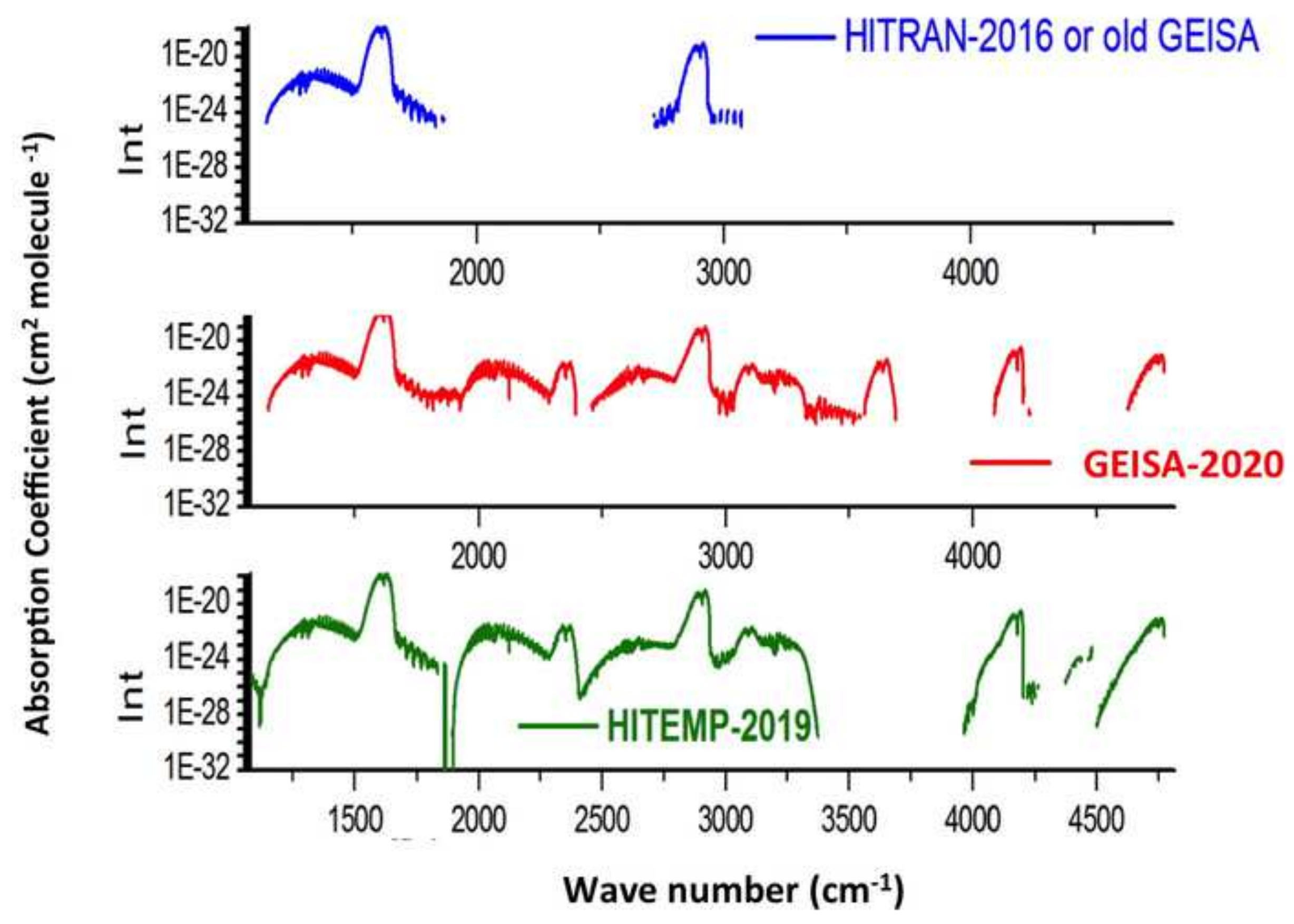



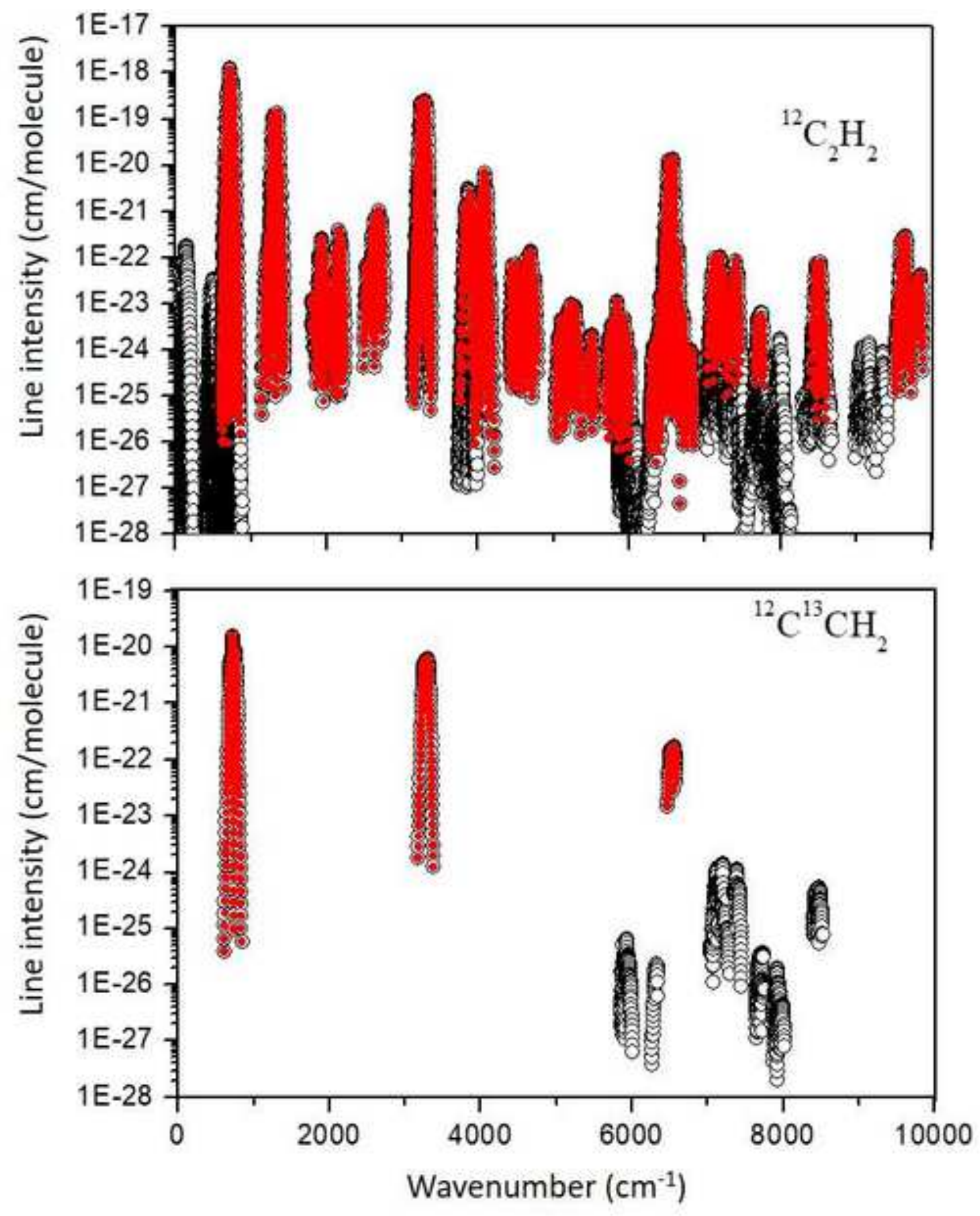


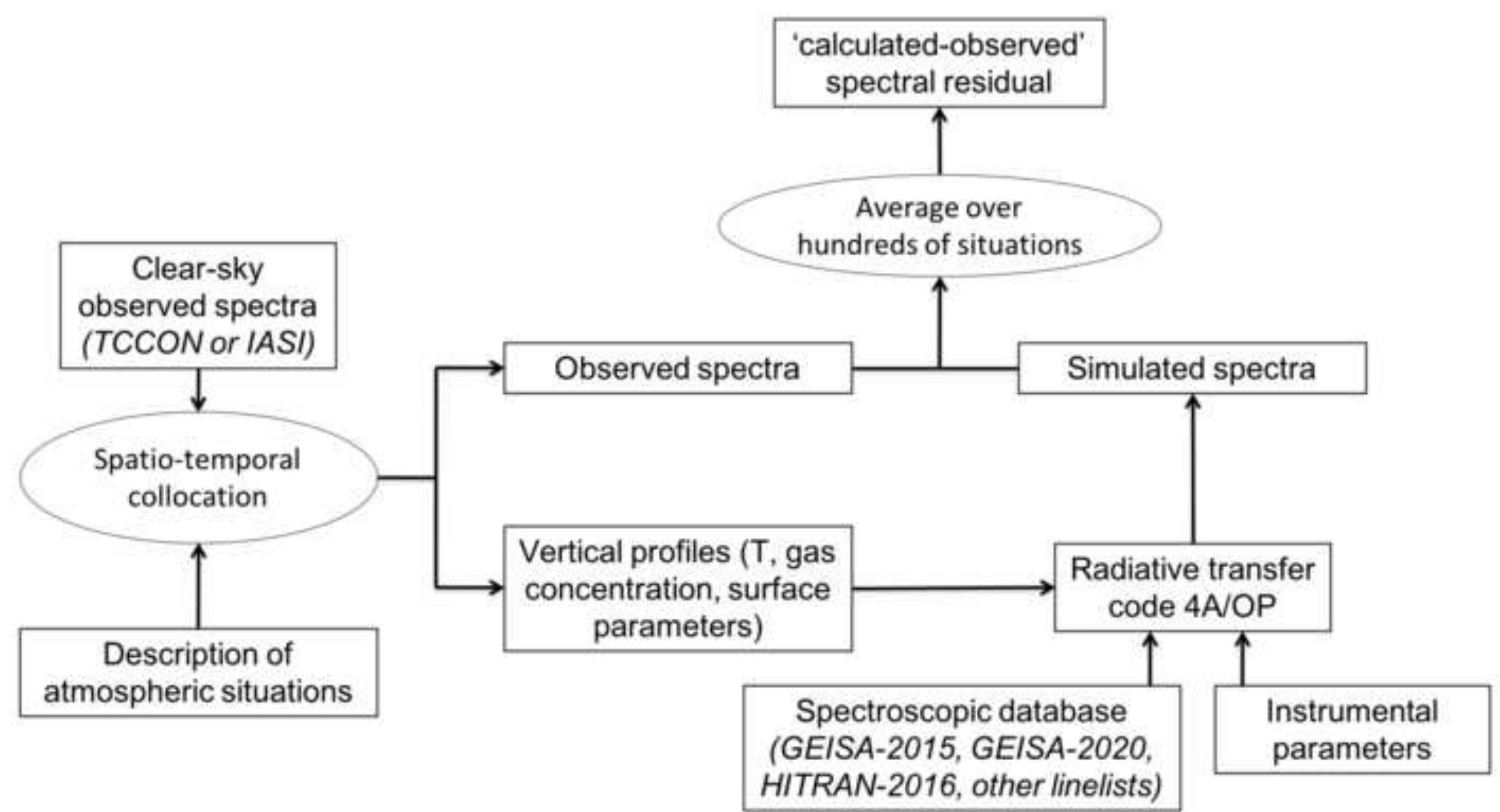

Spatio-temporal HITRAN-2016, other linelists) 
TCCON Observations
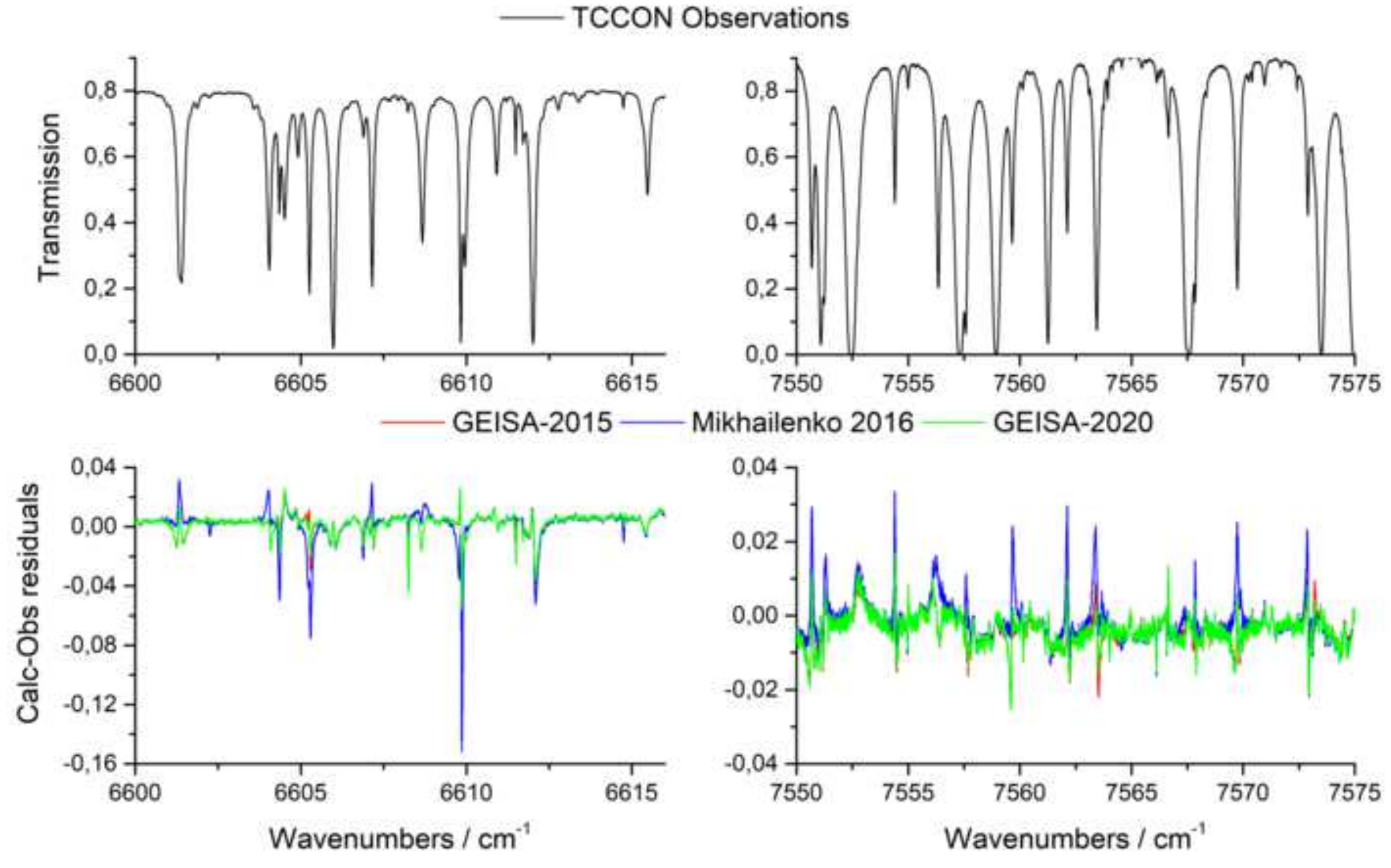


\section{TCCON Observations}
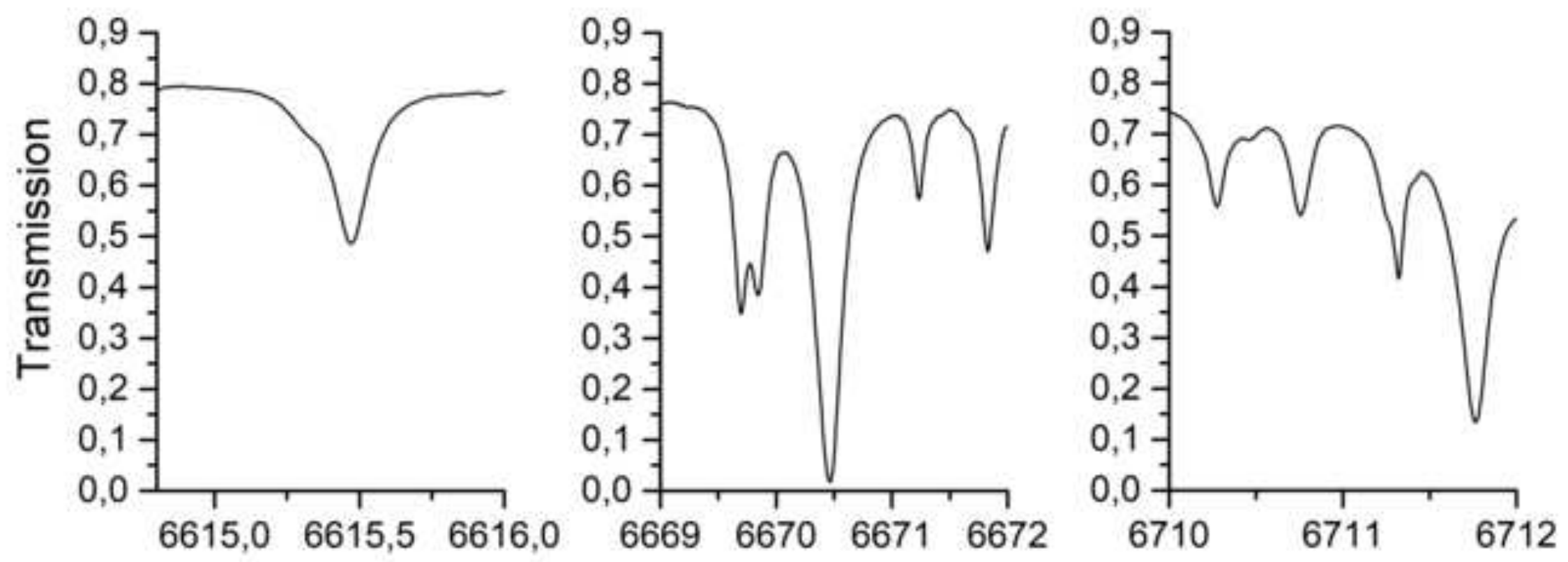

GEISA-2015 — Mikhailenko 2016

GEISA-2020
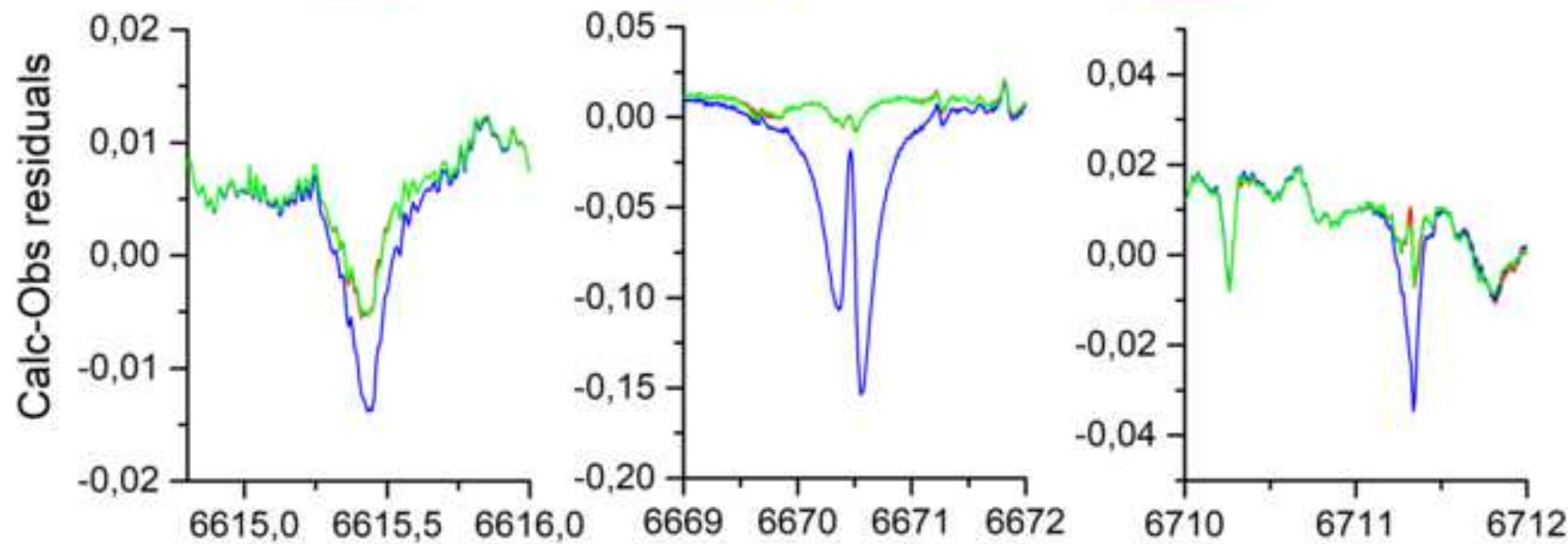

Wavenumbers $/ \mathrm{cm}^{-1}$

Wavenumbers $/ \mathrm{cm}^{-1}$

Wavenumbers $/ \mathrm{cm}^{-1}$ 


\section{TCCON Observations}

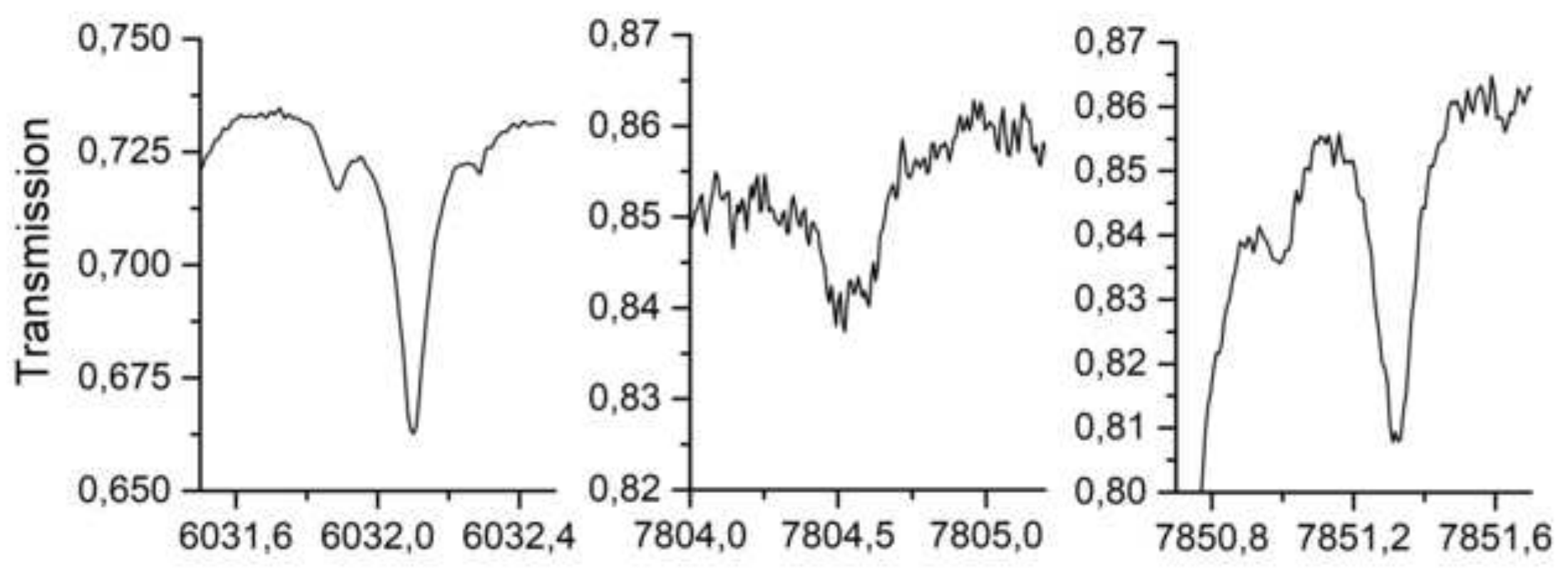

GEISA-2015 — Mikhailenko 2016 GEISA-2020
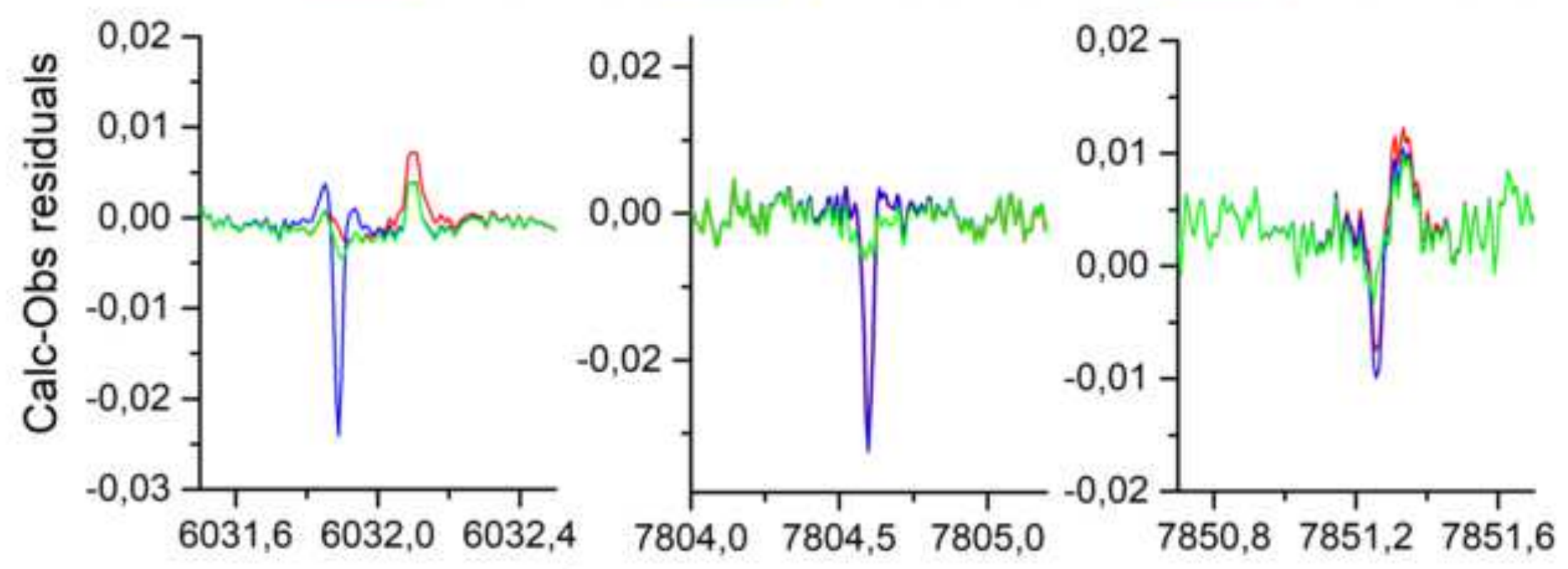
Wavenumbers $/ \mathrm{cm}^{-1}$ Wavenumbers $/ \mathrm{cm}^{-1}$ Wavenumbers $/ \mathrm{cm}^{-1}$ 


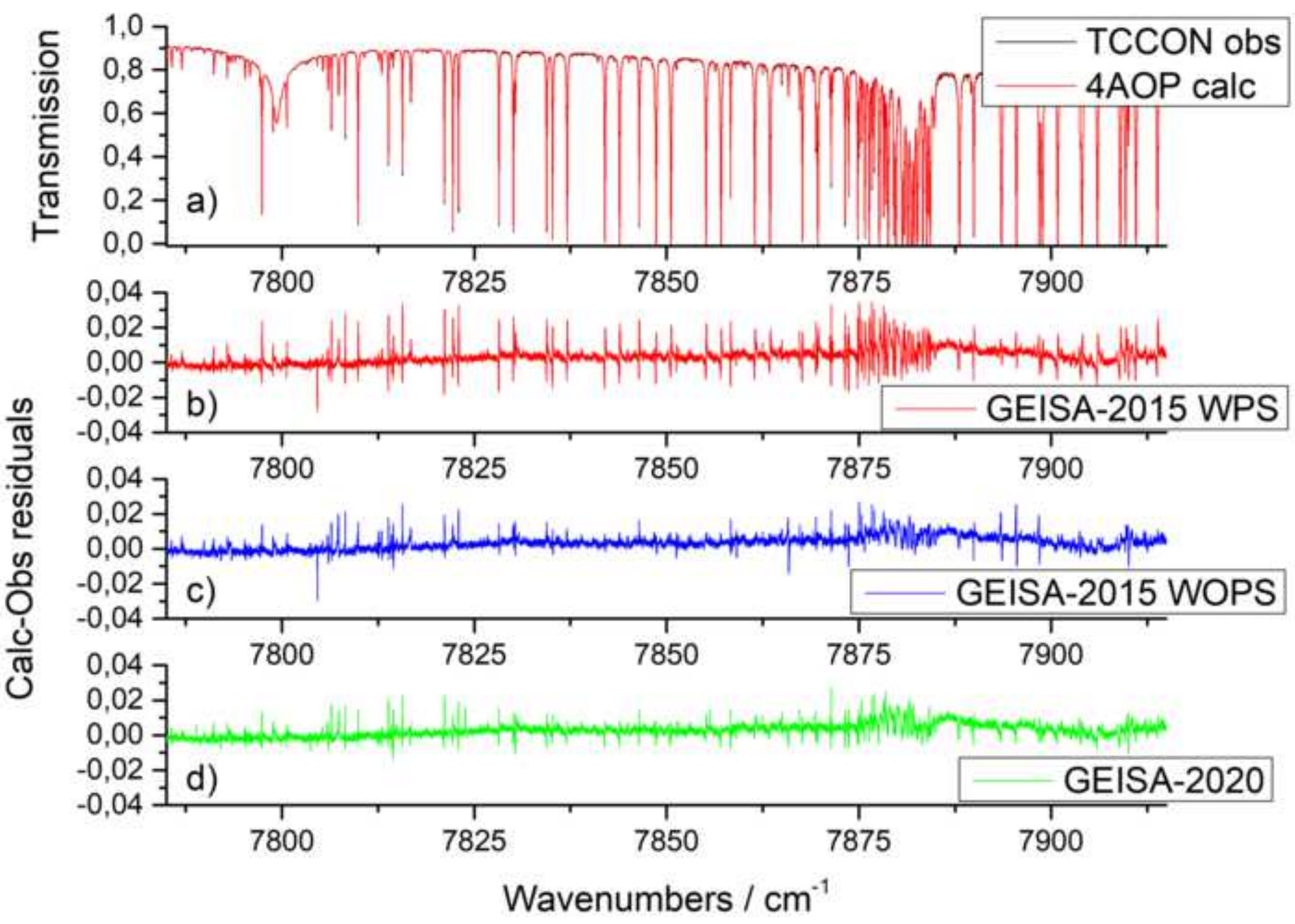




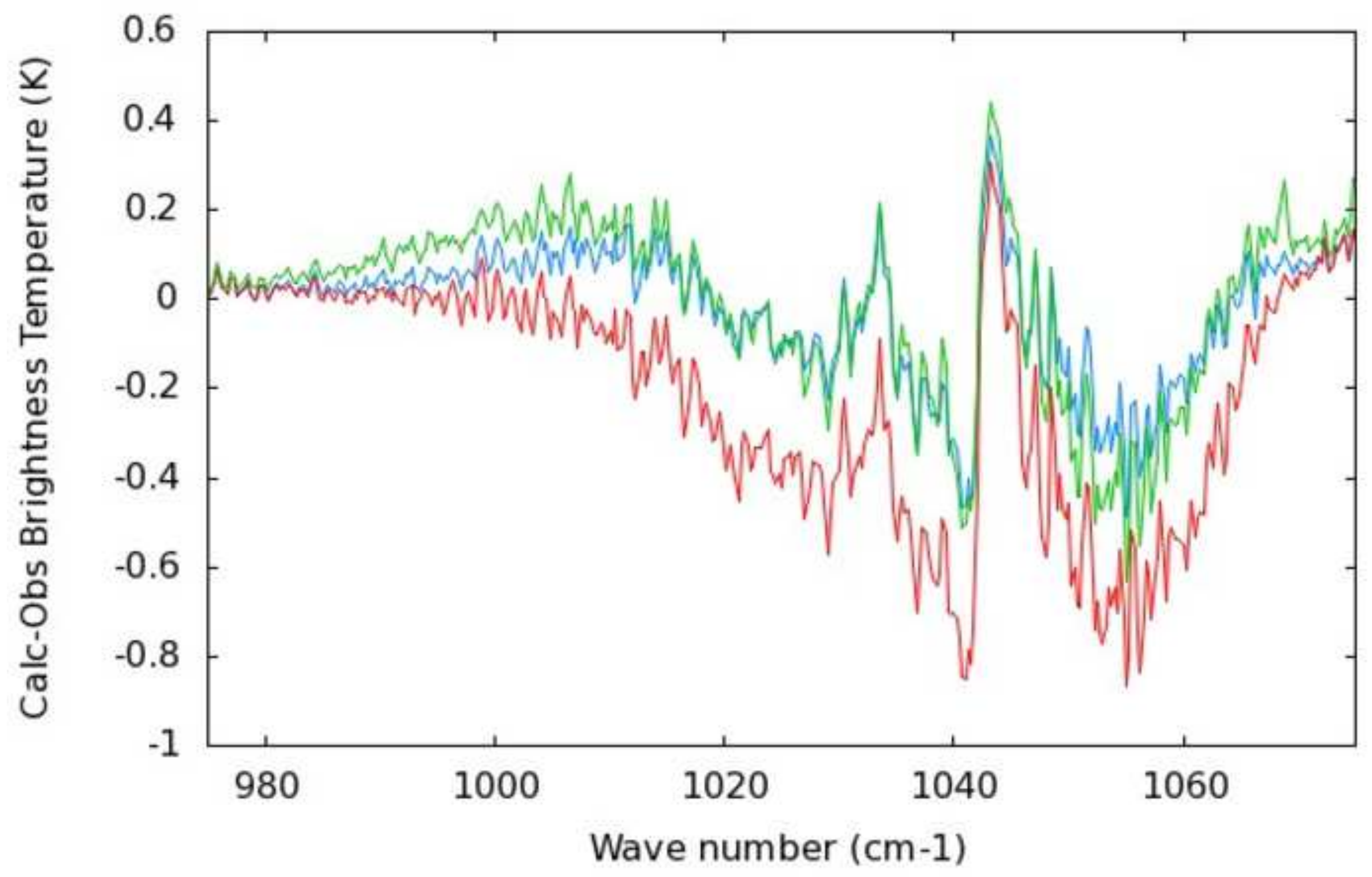

O3 GEISA-2015, ERA-Interim O3 GEISA-2020, ERA-Interim O3 GEISA-2020, ERA-5 


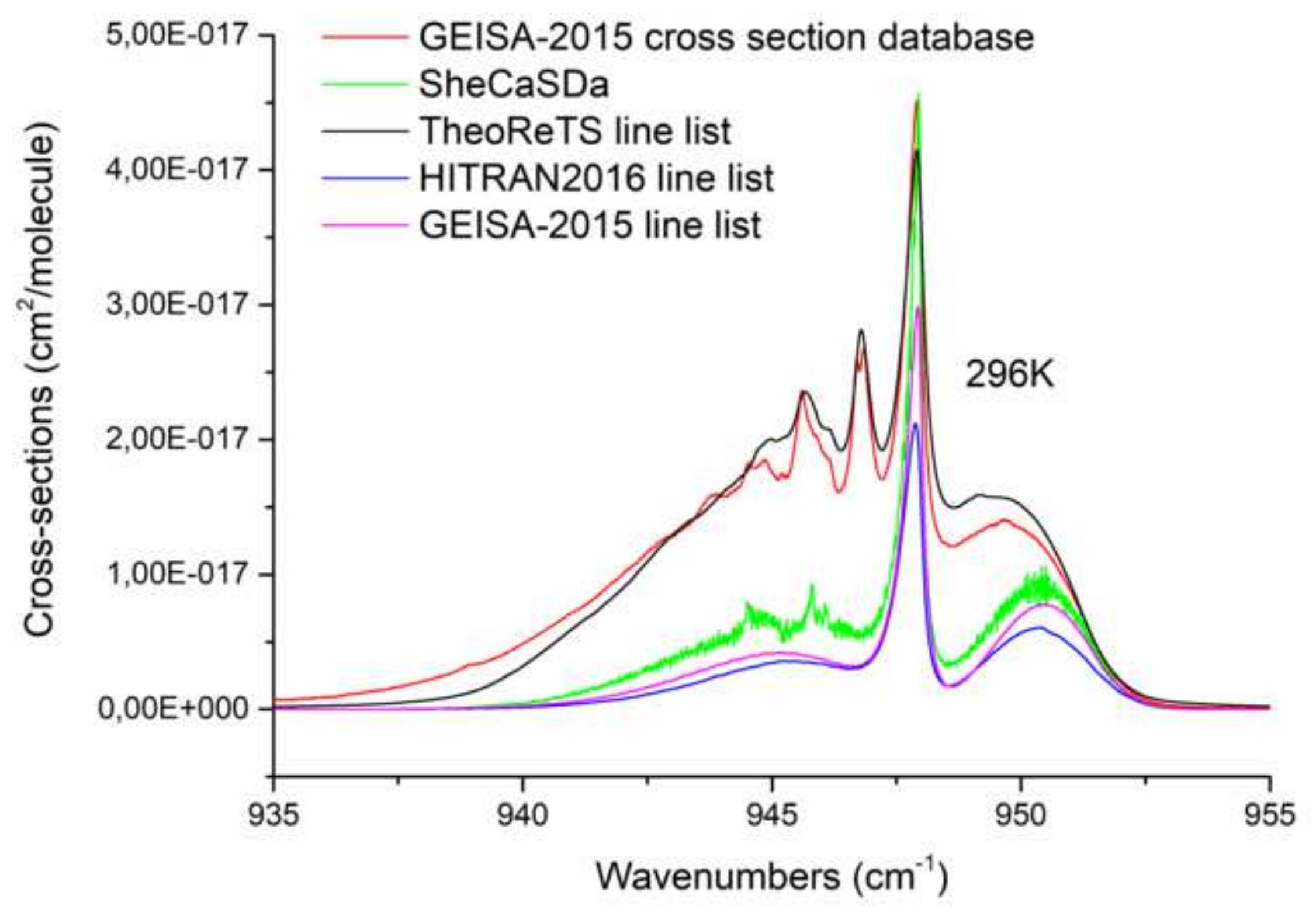




\section{Declaration of interests}

$\bigotimes$ The authors declare that they have no known competing financial interests or personal relationships that could have appeared to influence the work reported in this paper.

$\square$ The authors declare the following financial interests/personal relationships which may be considered as potential competing interests:

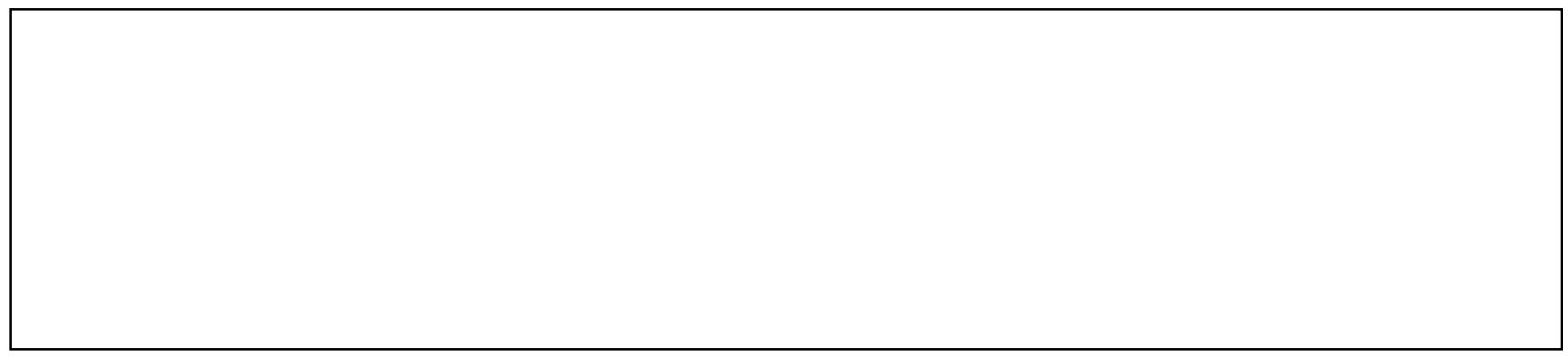




\section{CRediT author statement}

Manuscript: The 2020 edition of the GEISA spectroscopic database

Conceptualization: R. Armante, A. Chédin, C. Crevoisier, T. Delahaye, N.A. Scott, N. Jacquinet-Husson,

Methodology: R. Armante, T. Delahaye, N. Jacquinet-Husson, N.A. Scott

Software: R. Armante, L. Crépeau, T. Delahaye, V. Douet

Validation: R. Armante, T. Delahaye

Investigation: R. Armante, T. Delahaye

Formal analysis: $R$. Armante, T. Delahaye

Writing - Original Draft: R. Armante, A. Chédin, C. Crevoisier T. Delahaye, N.A. Scott

Writing - Review \& Editing: R. Armante, T. Delahaye

Resources: A. Perrin, A. Barbe, V. Boudon, A. Campargue, L.H. Coudert,V. Ebert, J.-M. Flaud, R.R. Gamache, D. Jacquemart, A. Jolly, F. Kwabia Tchana, A. Kyuberis, G. Li, O.M. Lyulin, L. Manceron, S. Mikhailenko, N. Moazzen-Ahmadi, H.S.P. Müller, O.V. Naumenko, A. Nikitin, V.I Perevalov, C. Richard, E. Starikova, S.A. Tashkun, Vl.G. Tyuterev, J. Vander Auwera, B.Vispoel, A. Yachmenev, S. Yurchenko 